\title{
Environmental Cost/Benefit Analysis for Fusion Power Plants
}

\section{J. R. Young}

November 1976

Prepared for the Energy Research and Development Administration under Contract E(45-1)-1830

\section{Battelle}




\section{NOTICE}

This report was prepared as an account of work sponsored by the United States Covernment. Neither the United States nor the Energy Research and Development Administration, nor any of their employees, nor any of their contractors, subcontractors, or their employees, makes any warranty, express or implied, or assumes any legal liability or responsibility for the accuracy, completeness or usefulness of any iniormation, apparatus, product or process disclosed, or represents that its use would not infringe privately owned rights.

\section{PACIFIC NORTHWEST LABORATORY}

operated by

BATTELLE

for the

ENERGY RESEARCH AND DEVELOPMENT ADMINISTRATION

Under Contract EY-76-C-05-1830

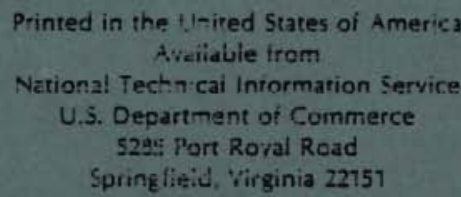

Price: Printad Coay $\because$ Nicrofiche $\$ 3.00$

$\begin{array}{cc}\text { PPages } & \text { NTIS } \\ 001-025 & \text { Selling Price } \\ 021-025 & \$ 4.50 \\ 026-050 & \$ 5.00 \\ 051-075 & \$ 5.50 \\ 075-100 & \$ 6.00 \\ 101.125 & \$ 6.50 \\ 126-150 & \$ 7.00 \\ 151-175 & \$ 7.75 \\ 176-209 & \$ 3.50 \\ 201-225 & \$ 8.75 \\ 225-250 & 59.00 \\ 251-275 & \$ 10.00 \\ 276-300 & 510.25\end{array}$


BNWL -2028

UC-20

\section{2}

ENVIRONMENTAL COST/BENEFIT ANALYSIS FOR

FUSION POWER PLANTS

by

J. R. Young

November 1976

BATTELLE

Pacific Northwest Laboratories

Richland, Washington 99352 


\section{PREFACE}

Fusion reactor technology has developed far enough to expect laboratory demonstration of practical levels of fusion employing the D-T reaction to occur in the early 1980s. Following that demonstration, and depending upon the national priorities for energy from $D-T$ fusion, construction and operation of experimental reactors and demonstration power reactors could occur before the end of this century. Operation of the first commercial power plants could then follow, starting about 2010 .

Development and adoption of a new power system eventually will require a description of the environmental effects in an environmental statement providing a comparison to the effects of competitive systems. In anticipation of that statement, an environmental analysis (BNWL-2010) has been prepared for the ERDA Division of Magnetic Fusion Energy. That analysis estimates the environmental effects of constructing and operating D-T fusion reactors as an economically competitive source of electricity in the 21 st century.

The analysis has four primary purposes:

1. To describe the general nature of the environmental effects,

2. To determine current ability to estimate the effects,

3. To determine methods for reducing the effects, and

4. To determine research necessary for increasing capability to define and reduce the effects.

Timely identification of needed research and methods for reducing effects will permit the performance of that research and the revision of conceptual fusion power plant designs before preparation of the program environmental statement. This would improve the quality of the environmental statements and could reduce the estimated adverse environmental effects due to fusion power plants.

The environmental analysis (BNWL-2010) concludes that the following assumed characteristics are the best set for the first operating fusion power plants:

- The D-T fusion reaction

- Large quantities of activation products

- Kilogram quantities of tritium in the plant systems

- Massive reactor structures

- Large lithium inventories

- Large inventories of liquid metals and salts
- Standard electricity generation - Standard radioactive waste systems - Large magnetic fields

- A self-contained fuel cycle

- Rural siting

Using these characteristics a reference reactor was analyzed to determine the environmental effects by using available concepts of plant subsystems designs that control interactions with the environment or by assumption that best current technology would be used in subsystems design. Because this analysis does not take into account advances in both fusion and waste control technology during the next thirty years, the estimated effects probably are significantly higher than the actual effects will be for the first fusion power plants. The estimated environmental effects should be interpreted only as being the probable upper limit for the actual effects. 
Preparation of the fusion power plant environmental analysis required development and use of specially developed data and analysis methods not used in the preparation of current environmental statements for fossil and fission power plants. These data and analysis requirements are documented in a series of reference topical reports to make this information publicly available and to assure understanding of the basis for the conclusions made in the environmental analysis. These reference topical reports sumarize the state-of-the-art as applicable to preparation of environmental statements for fusion power plants. They present the data and analytical techniques used in the environmental analysis to estimate the interactions with the environment and the resultant environmental effects. This information then was analyzed for adequacy and the need was determined for additional research to assure satisfactory ability to prepare environmental statements for the fusion development program and experimental facilities in the early 1980s. Estimated environmental effects are presented in these reference documents only as necessary to illustrate use of the data and analytical techniques.

This report is one of those reference documents for the environmental analysis. The other documents in this series contain more details of the power plant concepts and the probable environmental effects of fusion power plants with the assumed characteristics listed above. These documents are available through the National Technical Information Service:

An Environmental Analysis of Fusion Power to Determine Related R\&D Needs, BNWL-2010 Review of Fusion Research Program: Historical Sumary and Program Projections, BNWL-2011

Fuel Procurement for First Generation Fusion Power Plants, BNWL-2012

Current Fusion Power Plant Design Concepts, BNWL-2013

Reference Comerical Fusion Power Plants, BNWL-2014

Siting Commercial Fusion Power Plants, BNWL-2015

Materials Availability for Fusion Power Plant Construction, BNWL-2016

Projected Themodynamic Efficiencies of Fusion Power Plants, BNWL-2017

Tritium Source Terms for Fusion Power Plants, BNWL-2018

Management of Nontritium Radioactive Wastes from Fusion Power Plants, BNWL-2019

Methodology for Estimating Radiation Doses Due to Tritium and Radiocarbon Releases, BNWL-2020

Magnetic Field Considerations in Fusion Power Plant Environs, BNWL-2027

Biological Effects of Tritium Releases from Fusion Power Plants, BNWL-2022

Biological Effects of Activation Products and Other Chemicals Released from Fusion Power Plants, BNWL -2023

Safety Review of Conceptual Fusion Power Plants, BNWL-2024

An investigation of the Transportation Requirements of Fusion Power Plants, BNWL-2025

Considerations of the Social Impact of Fusion Power, BNWL-2026

Environmental Impacts of Nonfusion Power Systems, BNWL-2027

Environmental Cost/Benefit Analys is for Fusion Power Plants, BNWL-2028

Biomagnetic Effects: A Consideration in Fusion Reactor Development, BNWL-1973

An Analysis of Tritium Releases to the Atmosphere by a CTR, BNWL-1938 
CONTENTS

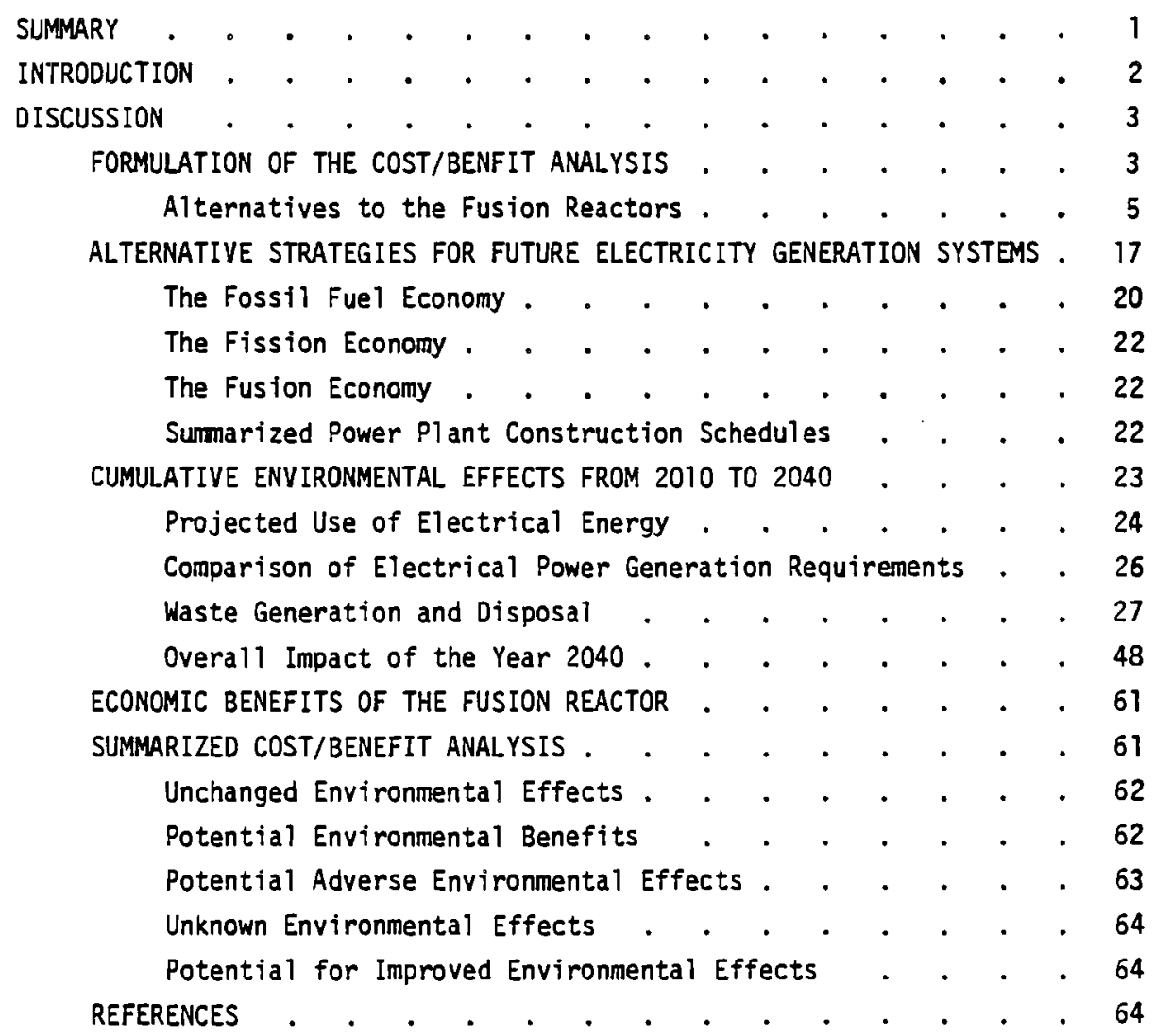




\section{COST/BENEFIT ANALYSIS FOR FUSION POWER PLANTS}

\section{SUMMARY}

A cost/benefit analysis has been made for the environmental effects of the first commercial fusion power plants. The environmental effects of the entire U.S. electricity generation industry have been compared for three alternative cases. These cases represent the probable range of use of fossil, fission, and fusion power plants during 2010 to 2040.

Comparison of the potentiai environmental impacts of these three types of power plants indicates that introducing the fusion reactor may significantiy benefit the environment. In particular, it could reduce land use; concerms about nuclear safety and safeguards; high- and low-level radioactive waste disposal; and radiation doses. Moreover, improved tritium control technology could essentially eliminate the radiation doses to the general population that are due to routine radionuclide releases.

However, the fusion reactor may increase the use of construction materials. But this increase cannot be large if the fusion reactor is to be economically competitive with fission reactors.

An unknown environmental effect may result from the presence of large magnetic fields needed in some fusion concepts. Much research must be completed before it can be concluded that exposure to those magnetic fields has either a beneficial or detrimental effect.

Economic benefits of the fusion reactor are included in this analysis only by an example reduction in the U.S. electric energy costs from 2010 to 2040 due to introduction of the fusion reactor. If the fusion reactor produces electricity at a $10 \%$ lower cost than does the LMFBR, the total reduction in electricity cost during 2010 to 2040 is estimated to be about $\$ 120$ billion dollars. Available design and economic information for both fusion and the alternatives is insufficient to permit economic comparisons.

The environmental benefits of the fusion reactor appear to far outweigh its development costs, and these direct and indirect benefits will not be limited by finite fuel resource availability. Fusion reactor power costs are essentially independent of the cost of fuel resources such as uranium, whereas foss $i l$ and fission converter systems have considerable cost sensitivity to fuel costs. Thus power systems using the fusion reactor are freed of the economic and strategic implications of dwindling low-cost fuel resources and are assured of deriving power from the entire U.S. reserve of lithium and deuterium.

This analysis recognizes that development of other energy sources and conversion techniques, plus efficient and thrifty use of energy resources, is needed to provide a balanced, flexible power system assuring sufficient low-cost, environmentally safe energy in the future. The role of the various possible components of a balanced future energy strategy is acknowledged. Continued development and timely deployment of the fusion reactor does not foreclose any other potential energy systems. 


\section{INTRODUCTION}

Development of commercial fusion power plants is expected to require many years of effort. The benefits from use of those plants must repay those development costs. A cost/benefit comparison of the entire U.S. electricity generation industry with and without the fusion reactor is necessary to determine the magnitude of the benefits from use of fusion reactors.

This document presents a cost/benefit analysis of use of fusion power plants early in the 21 st century. The first section describes the general formulation of the analysis. Included are the selection of the alternatives to the fusion reactor, selection of the power system cases to be compared, and a general comparison of the environmental effects of the selected alternatives. The second section compares the cumulative environmental effects from 2010 to 2040 for the primary cases of the power system with and without fusion reactors. The third section briefly illustrates the potential economic benefits if fusion reactors produce electricity at a lower unit cost than LMFBRs can. The fourth section sumarizes the cost/benefit analysis.

A cost/benefit analysis summarizes and analyzes the information developed in an environmental analysis. The purpose is to determine the general nature of the changes in economic costs and environmental effects if the proposed system is adopted. This cost/benefit analysis is based on information given in the other documents in this series. For more knowledge about sources of that information readers are referred to those documents. In particular, certain summary statements in this document came directly from those other documents and are not repeated in the discussion section of this report. The specific information so obtained are the conclusions on fuel supply, noise, odors, nuclear safety, nuclear safeguards, aesthetics, construction material use, and magnetic field effects. The sumary statements for these effects thus require no development of additional explanation and numerical values such as seemed appropriate for the effects detailed in this document.

Numerical values are used in this cost/benefit analysis only to indicate the potential general change in environmental effects. They should not be interpreted as representing the actual numerical values for the environmentai effects for comercial power plants nor should they be used in other numerical comparisons to the effects of alternative power systems. These values are based on numerous assumptions concerning the possible characteristics of fusion power plants and were designed to represent a worse case or upper 1 imit on effects. Many years of research should result in significantly lower environmental effects than shown herein for fusion power plants. 


\section{DISCUSSION}

\section{FORMUILATION OF THE COST/BENEFIT ANALYSIS}

This cost/benefit analysis examines the cost and benefits of developing and implementing fusion reactors as an energy source for central electricity generating plants. The anaiysis considers mainily the external human and environmental impacts of the fusion reactors and of alternative energy systems.

As an option for electric power generation, fusion reactors may be used as an integral component of the national power economy. The costs and benefits of fusion reactors can be compared with other aiternatives in the framework of projected altemative electric generating strategies. Comparison of strategies is important because the ultimate use of any option is affected by its relative cost and benefits. Furthermore, no option alone is expected to provide a practical solution to the U.S. needs for electrical energy.

First described are the energy conversion and production alternatives to the fusion reactor which will be available during the period of 2010 to 2040 . Neither the fusion reactor nor any of these alternatives should necessarily be considered as mutually exclusive. Unless allocation of research and development monies favors one technology to the exclusion of others, all can develop simultaneously. The present funding of the fusion program does not reflect a decision by the Energy Research and Development Administration (ERDA) as to which alternative should be implemented.

Alternative systems are discussed qualitatively to give an indication of their impacts, and estimates are made of their potential for meeting a portion of future power demand. This is followed by a discussion of alternative energy strategies that may be used to meet future total power demand. The three main alternative strategies considered are:

- The fusion reactor is assumed to be developed and widely deployed in the 2010 to 2040 period.

- The fusion reactor is not developed, but nuclear power plants continue to be deployed in the form of HTGRs, LWRs, and LMFBRs.

- No additional nuclear plants are built beyond those committed, thus leading to a system without any fission or fusion reactors.

Since the economic costs of these possible future alternative power systems and the fusion reactor are not well developed at this time, they have not been evaluated in a highly quantitative economic cost/benefit study. 
If it were possible to assign dollar values to all of the costs and benefits to society associated with energy production, these values could be internalized and the competitiveness of alternatives could be estimated entirely in terms of economics. However, current knowledge regarding long-term changes in the environment, as they affect human health, safety, and the viability of ecological systems, is both incomplete and nonuniform. Progress is being made in acquiring the requisite knowledge, and the major development decisions must reflect, insofar as possible, considerations of the added dimensions of social and environmental impacts. An appropriate evaluation can be made by examining separately the types of impacts which can now be perceived and by comparing them to alternative systems.

The second section discusses the cumulative external impacts during the period 2010 to 2040 and compares them for the different strategies considered. The variocis.strategies are examined in more detail, and the external costs associated with each component of the proposed strategies are defined and discussed. In the treatment of external costs, conventional fossil-fueled systems were evaluated on the basis of current technology.

Longer-term fossil-fueled systems are likely to be based on advanced technology such as coal gasification or liquefaction. Detailed external costs for potential alternative advanced systems such as solar or fusion are not available because these are currently in the conceptual stage of development. As development of the fusion reactor and al ternative systems proceeds, additional knowledge will be accumulated on the potential environmental impacts of each system. Comparative impact evaluation will be possible prior to a final decision for deployment of any type of alternative system.

The economic analysis in the third section briefly describes the potential economic benefits of using the fusion reactor to generate electrical power. The potential economic benefits are defined as the net savings in electrical power cost that would result from including fusion power plants in the national electric power system. No attempt is made to develop a cost-benefit-ratio for the fusion development program because the total program costs and economic benefits will not be available for many years.

The number of each type of power plant operated during 2010 to 2040 was determined by modeling the national electric-power generating system with a linear program on a computer. For a fixed set of input variables (a case) the program selected a unique plant building program (a power plant mix) that would minimize the discounted cash flow to produce power (the present valued power cost) for the period 1975 to 2040 . For each case, the model had the option of selecting any combination of available plants and fuel that would enable the system to meet the total electrical energy demand of consumers. The heart of the study was based on two cases: one in which the total power demand would be met with a system that allows the fusion power industry to develop and expand freely and one in which no fusion power plants would be built.

Each calculation started with a projected electrical energy demand which is essentially an extrapolation of current trends with energy input to electric power projected to grow from $25 \%$ (1970) to about 60\% (2040) of total energy demand. 
Within the framework of an assumed electrical power demand, the cost/benefit model selected a schedule of generating plants. Calculations covered the period from the present through December 31, 2039; and the linear program selected the building schedules for each biennium from 1974 to 1999 and each 5-year period from 2000 to 2039. The costs for reactors built prior to 2040 were calculated through to the end of their 30-year lives. Thus the minimum total power cost for plants required to meet the electrical power demand to the year 2040, including the operating cost through the year 2069, was computed in terms of the mid-1975 present worth. This procedure is consistent with standard utility practices for evaluating alternatives.

The linear program model successively alters the variables in the equation which determines the present-worth cash flow until a system is found that will produce the minimum present-worth power cost for the study period. Plant selection is based strictly on the need to supply new demands and to replace retired plants. Introduction constraints were included in the model to prevent the program from introducing new reactor types at a rate faster than practical limitations allow.

The cash flow items contributing to the computed "busbar" power costs include all costs directly dependent on the choice of generating plant type. Cost of transmission and distribution, relatively independent of the generating plant type, was not included in the calculations. The busbar cost items represent a large input for each plant. The input parameters used were based on extensive study and on data from government agencies, electric utilities, reactor manufacturers, architect-engineers, and firms engaged in fuel-cycle operations. To include the fusion reactor in these calculations, the cost for producing electricity in a fusion power plant was arbitrarily assumed to be only 90 or $97 \%$ of the cost for producing electricity in the LMFBR. A lower cost than for the LMFBR has to be assumed because selection of the plants that will be built is solely on a basis of economics. If the fusion power plant has a higher cost than the LMFBR, it probably would not be forecast to be built.

The final section sumarizes the results of the cost/benefit study. Any analysis of the U.S. power system requires consideration of a large number of variables. Prediction of the impact of factors involved in power generation for a 65-year period introduces uncertainty. The forecasts of this analysis must be considered as only indicative of future events.

The information presented herein, particularly for the fusion reactor, must be considered a worst case. Only current technology was used. Many years of development effort should result in substantial reductions in environmental interactions and impacts.

Alternatives to the Fusion Reactors

The United States economy is based on the large-scale use of energy to multiply the productivity of human labor. At current growth rates, the U.S. total consumption of energy will double about every 2 decades. Electric energy demand nearly doubles every decade. In 1975, the conversion of fossil fuels to thermal, mechanical, and electrical energy satisfied $94 \%$ of the U.S. energy demand. Another $4 \%$ was supplied by hydroelectric power and $2 \%$ by nuclear power. However, fossil fuels, natural nuclear fuels, and available hydropower sites all represent finite resources. Domestic fossil fuels, particularly oil and gas, appear inadequate to meet 
the U.S. growth needs. Coal resources are becoming more expensive to use due in part to environmental costs of mining and combustion. Conversion of natural uranium to thermal energy in present nuclear reactors will encounter rising costs as low-cost uranium ores are depleted. New and improved technology is needed to maintain the U.S. energy consumption growth rate without the severe economic penalties that are related to finite fuel resources. Also, energy must be conserved.

Each alternative energy source technology described herein has the technical potential to convert natural resources to thermal, mechanical, and electric energy. The relative economics and comparative environmental impacts depend in large measure on their particular application. The fusion reactor is being developed as an optional electric generating technology. Many conventional and some anticipated technclogies may be used to generate electricity, or they may be more valuable in other phases of the U.S. total energy supply strategy.

\section{Selection of Candidate Power Systems}

The numerous types of power plants and energy conversion and storage systems shown in Table 1 may be available in the 21 st century. To create a manageable cost/benefit analysis, the number of candidate power systems is reduced to eight that can be readily compared in a table. The basic criteria used for eliminating candidate systems are as follows:

- The system is not expected to provide a significant portion (>10\%) of the U.S. energy requirements if fusion reactors were not adopted.

- The environmental effects would be essentially the same as for another system, which can be considered as representative.

- The system or improvement would generally have universal application to most other energy systems and consequently could not be considered to create a unique advantage or disadvantage for fusion reactors in comparison to other systems.

Systems with Low Utilization. The systems that can be eliminated because they are not expected to provide a significant portion of the U.S. energy requirements are as follows:

a. Tidal Energy. Only two sites in the United States, with a potential power production of only 40,000 MWe, have been identified as worthy of consideration. These sites could not provide a significant fraction of the total electricity requirements.

b. Ocean Thermal. Ocean thermal power generation is restricted to tropical and subtropical seacoast regions with favorable themal conditions. Otherwise, the electricity transmission costs become excessive, or conversion of the energy to other forms, such as hydrogen, 
TABLE 1. 21st Century Power Plant Alternatives

- Light Water Reactors (LWRs)

- High Temperature Gas Reactors (HTGRs)

- Light Water Breeder Reactors (LWBRs)

- Liquid Metal Fast Breeder Reactors (LMFBRs)

- Molten Salt Breeder Reactors (MSBRs)

- Gas-Cooled Fast Breeder Reactors (GCFRs)

- Fusion Power Plants

- Fossil-Fueled Power Plants (Coal, oil shales and tar sands are the sources of fuel)

- Geothermal Energy

- Solar Energy
- Wind Power

- Ocean Thermal Energy

- Tidal Energy

- Synthetic Fuels

- Organic Wastes as Fuel

- Improvement of Energy Conversion and Storage

- Steam Turbines

- Internal Combustion Engines

- Gas Turbines

- Binary Cycles

- Fuel Cells

- Thermoelectric Converters

- Thermionic Converters

- Magnetohydrodynamic (MHO) Converters

- Batteries

is necessary. Because of the unsolved technical and economic problems and the long transmission distances to current electric load centers, generation of a significant fraction of the U.S. electricity demand by use of ocean themal gradients appears to have a low probability.

c. Organic Waste. Combustion of all organic waste would produce about $13 \%$ of current electricity demand. Since combustion of all such waste probably is not economically competitive, organic waste is not expected to provide a significant fraction of the total electricity generated.

d. Internal Combustion Engines. No method is apparent for making internal combustion engines economically competitive for large-scale electricity production. Such engines are expected to generate only a small fraction of the total electricity produced.

e. Gas Turbines. Depletion of oil and gas reserves will eliminate the main source of fuel for oil and gas fueled power plants so that they probably will have to use synthetic fuels created from coal or organic waste. As a result, coal-fired power plants probably will produce electricity at a lower cost, resulting in use of gas turbines chiefly for peak load generation.

f. Fuel Cells. Electricity produced in fuel cells is expected to be more costly than electricity produced in coal-fired plants because of the higher fuel cost. A synthetic fuel 
such as hydrogen or an organic compound probably will have to be used. Because these fuels probably will cost more than coal per unit of electricity produced, fuel cells are expected to have only a specialty role in power generation and not be used for large-scale base load generation.

g. Thermoelectric Devices. Thermoelectric devices are expected to have special-purpose usage since no methods are apparent for making these devices economically competitive to base load generating plants.

Systems Representated by 0ther Systems. The systems that have environmental effects similar to those of other systems and in general can be represented by those other systems are:

a. The Light Water Breeder Reactor. This light water (therma1) reactor has a Thorium-232 Uranium-233 fuel cycle. The environmental impacts of the reactor and the fuel cycle are close enough to those of the high temperature gas reactor that the effects of the HTGR can be considered representative. The main differences are in the higher thermal efficiency for the HTGR and in the small amount of radionuclide releases at the reactor plants.

b. The Gas-Cooled Fast Breeder. The Gas-Cooled Fast Breeder reactor differs from the LMFBR chiefly in the coolant, which is helium instead of sodium. The fuel cycles are essentially identical. The environmental impacts for these two types of breeders are expected to be much the same.

c. The Molten Salt Breeder Reactor. The Molten Salt Breeder Reactor is a thermal reactor with a graphite moderator and thorium fuel cycle. The main difference between it and the HTGR is the use of a combination molten salt fuel and coolant stream in comparison to the fixed fuel and a helium coolant in the HTGR. In general the environmental effects of the HTGR probably will be the same as for the MSBR. The chief exceptions might be a somewhat higher thermal efficiency for the MSBR and elimination of impacts from shipment of irradiated fuel to reprocessing facilities.

Systems with Universal Application. The systems that appear to have universal application to most base-load power systems are as follows:

a. Snythetic Fuels. Creation of synthetic fuels requires use of energy from another base-load source during the synthesis process. As a result, synthetic fuels are not a prime source of energy and cannot be considered a competitor for fusion reactors. The competitiveness of synthetic fuels depends on the availability of a low-cost primary source of energy.

b. Steam Turbines. Steam turbines are needed for nearly all electricity generation alternatives. Generally, any improvement in steam turbines will apply equally to most alternatives. (The exceptions are wind generators, thermoelectric solar plants, and possibly LMFBRs.)

c. Topping Cycles (Turbines, Thermionic Devices, and MHD). Each topping cycle is intended to increase the thermal efficiency of the power generating equipment by converting high temperature energy into electricity. The temperatures of concern are those higher than can be utilized economically by steam turbines. In general, such devices would have universal 
benefit for the alternatives that can generate the higher temperatures (fossil, fusion, solar, and HTGRs). They probably would not benefit the alternatives that do not have a steam cycle (wind generators) or which cannot create those higher temperatures (geothermal and LMFBRs).

d. Batteries. Batteries are an energy storage device and cannot compete as a primary source of electricity.

Systems Selected for Comparison. As a result of the above elimination of power systems, the remaining power systems that are compared to the fusion reactor in the cost/benefit analysis are:

- Fosstl-fueled plants

- Hydroelectric plants

- LWRs

- HTGRs
- LMFBRS

- Solar plants

- Geothermal plants

- Wind-powered plants

Al1 these alternatives appear to have potential for providing a significant fraction of the U.S. electricity generation. However, the only ones developed far enough for commercial use in generating large amounts of electricity are coal-fired, hydroelectric, LWRs and geothermal plants. The HTGR is close to large-scale commercial use, and the LMFBRs, solar, and wind are expected to be fully developed by the year 2000. In all cases, continued research and development efforts are needed to assure full utilization. Although the technology of hydroelectric plants is fully developed, such plants are not expected to be a major future source of electricity. By 2010 the hydroelectric resource probably will be essentially fully developed and will represent a constant generation capability thereafter. As a result, this resource is included in the forecasts but not treated as a potential future source of a significant additional amount of electricity generation capacity.

\section{Alternative Energy Sources (a)}

Fossil-Fueled Conventional Power Plants. The fossil fuel resources of the United States are expected to continue to supply the largest portion of total energy demand for, at least, several decades.

Since over $80 \%$ of these resources are coal and because of the current and projected scarcities of petroleum and natural gas, expansion of electricity production using fossil fuels will most likely be based on coal. A greater proportion of the remaining oil and gas resources will probably be used for direct energy applications (rather than electrical energy production) for which they are uniquely suited. Table 2 shows the projected contribution of oil and natural gas to total and electrical energy consumption through the end of this century as forecast by the Department of the Interior.

As Table 2 depicts, the percentage contribution of ofl to electricity generation is expected to drop from $15.9 \%$ in 1975 to $6.3 \%$ in the year 2000. The percentage contribution of natural gas

(a) Those desiring more information concerning these energy sources should consult BNWL-2027. 
TABLE 2. Projected Contributions of $0 i 1$ and Natural Gas to Total and Electrical Energy Consumption

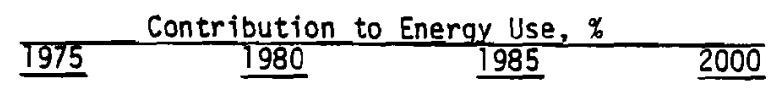

$\begin{array}{ccccc}\begin{array}{c}\text { Total Use } \\ \text { Oif (a) }\end{array} & 43.8 & 43.9 & 43.5 & 37.2 \\ \text { Natural Gas } & 31.4 & 28.1 & 24.3 & 17.7 \\ & & & \\ \text { Electrical Use } & & 16.9 & 16.8 & 6.3 \\ \text { Oif(a) } & 15.9 & 12.2 & 8.7 & 3.3 \\ \text { Natural Gas } & 16.8 & & & \end{array}$

(a) Including natural-gas liquids.

is expected to drop from $16.8 \%$ in 1975 to only $3.3 \%$ in the year 2000 . As natural gas reserves are depleted, priority allocation will probably be given to residential and commercial consumers. Natural gas and, to a lesser extent, petroleum are not expected to be available for expanded utility and industrial use in the future. In this analysis all electricity generation by fossil plants after 2010 is assumed to be by burning coal.

A large number of coal gasification and liquefaction processes are currentiy under development, and at least two utilities have announced plans to build gasification plants.

A 1000-Mwe coal-fired power plant requires approximately 3 million tons of coal per year of operation, or about 90 million tons during its operating lifetime. If the estimated electrical system capacity additions were all fueled from coal resources, about 340 billion tons of coal would be used up to the year 2020 or committed for future use by plants built up to the year 2020. This approaches the total of about 400 billion tons of coal resources estimated to be economically recoverable by current tecnhology.

If the United States were to develop a complete reliance on coal for most of its energy demands, domestic resources would be rapidly depleted. Economically recoverable coal resources are estimated to be adequate to meet 1972 consumption rates for 300 to 700 years. In 1972, coal provided only about $20 \%$ of the total U.S. energy usage; most of the remaining energy was provided by $0 i l$ and gas. If coal also substitutes for oil and gas, as seems probable, then the resources would be adequate for only the next 60 to 150 years at the 1972 total energy consumption level. Allowing for continued growth of total energy consumption at about $4 \%$ per year, the energy consumption in year 2000 would be about three times that in 1972. Thus the duration of coal resources at the year 2000 projected total energy consumption rate would be reduced to about 
20 to $\mathbf{5 0}$ years. Even if all the coal resources thought to be technically recoverable (regardless of cost) were included, the maximum duration of the coal resource would be increased to only about 100 years.

The economics of fuel for electrical energy production have changed considerably in the past 2 years. In March, 1973, the average price of coal delivered to electric utilities was about $0.39 \$ / M B t u$, but by March 1974 the average price had risen to about $0.61 \$ / M$ Btu. By 1976, the average price was $0.80 \$ / M B t u$. The price of 011 has risen even more dramatically. In March 1973, utilities paid an average of $68.5 \$ / M ~ B t u$ for residual fuel ofl, but a year later the average price was $\$ 1.89 / \mathrm{M} \mathrm{Btu}$, an increase of $176 \%$. In 1976 , the average price was $\$ 1.94 / \mathrm{M} \mathrm{Btu}$. The costs of fossil fuels for utilities continue to rise with no prediction possible of when and at what level they will stabilize.

A $\$ 1 / M$ Btu increase in the cost of fuel currently increases the average cost of delivered electricity by $9 \mathrm{mills} / \mathrm{kWh}$. (In 1975, residential customers paid anywhere from 10 to 50 mills/ $\mathrm{kWh}$ for delivered electricity.) By way of comparison, a $\$ 1 / \mathrm{M}$ Btu increase in fossil fuel price is equivalent to a $\$ 150 / 1 b$ increase in the cost of $U_{3} 0_{8}$ to an LWR. The current price for the purchase of $U_{3} O_{8}$ for future delivery is about $\$ 30$ to $\$ 40 / 1 \mathrm{~b}$.

Although problems still exist, emissions problems due to the burning of coal are expected to be satisfactorily solved at reasonable costs. The major remaining environmental and social impacts of coal use in the future will likely be associated with the mining. Considerable land disturbance will probably occur, particularly if much of the coal is strip-mined. Adequate restoration of this land would be difficult, particularly in areas of low rainfall, such as in the Western United States where most of the low-sulfur coal reserves are located, and in the mountainous Appalachian regions. The deep mining of coal would cause less land disturbance than strip-mining but would be more expensive and more hazardous. The mining of coal has historically been a hazardous occupation. The implementing of the 1969 Mine Safety Act reduced fatality rates, and further improvements in mine safety may be implemented in the future. These safety regulations may increase the internalized cost of $\operatorname{coa} 1$ through both increased mine capital requirements and lower mine productivity, but hopefully will decrease the external impacts.

Hydroelectric Power Plants. The 66,000 MNe of currently installed conventional hydroelectric capacity is about $13 \%$ of the total U.S. electrical generation capacity. The Federal Power Commission estimates that 128,000 MWe of undeveloped hydroelectric capacity are in the contiguous 48 states, but economic feasibility, environmental constraints, and legislative prohibitions make it unlikely that this potential capacity will ever be fully developed. The Federal Power Comission estimates that an additional 30,000 Me will be added by 1990, but by that time hydroelectric power will be only about $7 \%$ of the total installed generating capacity because of the rapid growth in the total capacity. If it were practical to fully develop the hydroelectric potential of the U.S., about $12 \%$ of the projected year 2000 power demand and less than $5 \%$ of the year 2020 demand would be produced. Since hydroelectric power is ideally suited to provide fast response peaking power, the numerous units operating in this mode would have significantly lower 
capacity factors. Only the largest facilities would operate almost continuously to provide baseload power. A leveling off of conventional hydroelectric capactity will probably occur toward the end of this century. However, because of gradual conversion of those facilities to peaking operation, additional capacity additions to yield a total capacity of about 165,000 MWe is expected.

Hydroelectric plants have both positive and negative environmental effects. They are essentially pollution-free in their effects on air quality and have no fuel cycle waste. The reservoirs also are valuable for flood control and recreation. However, the presence of large dams has a major impact on site ecology, both upstream and downstream. Interference with normal river flow often alters water quality and temperature. Persons concerned about the shrinking wilderness area in the United States argue against the complete development of our hydroelectric potential. The large land area flooded by the reservoir makes a major dam economically possible only in unsettled regions. The question becomes one of whether or not a significant fraction of the remaining wilderness, which is irreplaceable, should be given up for a small increase in capacity to generate electrical energy.

In any event, the total capacity of potential hydroelectric power plant sites does not appear adequate for hydroelectricity to be a principal contributor in a future energy supply sys tem.

Nuclear Fission Converter Reactors. Nuclear fission converter reactors (LWRs and HTGRs) are the only alternatives to fossil-fuel and hydroelectricity generating plants that are currently comercially available for major utility system expansion. Converter reactors use the fissile ${ }^{(a)}$ isotope $235 U$ as their naturally occurring source of energy. However, only about $0.7 \%$ of the uranium found in nature is the ${ }^{235} \mathrm{U}$ isotope. The remaining $99.3 \%$ is the fertile ${ }^{(b)}$ isotope. ${ }^{238} \mathrm{U}$, which does not readily fission in the current types of converter reactors. In an operating reactor some of the ${ }^{238} \mathrm{U}$ is converted (hence the name converter reactor) to a fissile isotope of plutonium (239 $\mathrm{Pu}$ ) which can be recovered and used as fuel for converter reactors, or thorium is converted to $233 \mathrm{U}$. However, even with this conversion and the recycle of ${ }^{239} \mathrm{pu}$ or ${ }^{233} \mathrm{U}$ fuel, the fission converter reactors can use only 1 to $2 \%$ of the uranium extracted from ore deposits. The remainder becomes waste uranium, which is so depleted in the ${ }^{235} \mathrm{~J}$ isotope that it cannot be used to fuel converter reactors.

Thus fission converter reactors require a continuing supply of ${ }^{235} U$, which must be obtained by mining natural uranium.

By the end of 1975, about 38,000 Me of installed nuclear generating capacity were providing about $6 \%$ of the U.S. total electric energy. These plants have demonstrated that fission converter reactors are a safe and economical method of generating electric energy. Utilities have demonstrated their confidence in converter reactors by building, ordering, or announcing a total of 236 comercial reactors, with a combined capacity of 235,000 Me. This is equivalent to about $40 \%$ of the currently installed generating capacity in the United States.

(a) Easily caused to fission by neutrons of any energy.

(b) Isotopes that become fissile by absorbing a neutron are known as fertile isotopes. 
Probably enough uranium and thorium exist in the United States to supply a growing fission converter reactor industry for some time to come--at some cost. However, uranium and thorium ore is distributed in the earth's crust in either small scattered deposits or in dilute (10w) concentrations, and the cost of uranium will rise as the U.S. is forced to use less accessible deposits and the more dilute resources. The currently known domestic resources of uranium and thorium that can be developed economically and in an environmentally acceptable manner may be inadequate to support continued growth of converter reactor capacity beyond the turn of the century. Once these high-grade ore resources are expended, lower grade ores, such as the Chattanooga shales, will have to be mined to supply the converter reactor needs for uranium. Uranium concentrations in these ores are so low that, when the uranium from a ton of shale is used in a converter, the amount of energy generated is roughly equal to the energy generated by burning a ton of coal in a coal-fired power plant. Hence an expanding power system using dilute ores would face large-scale mining and material processing problems and risks, similar to the problems and risks in a coal-based power economy. The resulting social costs would include substantial disruption of land by mining, effects of the mine waste, and deaths and injuries in mining accidents. While these effects have not been extensively examined, an expanding converter reactor industry based on uranium from the Chattanooga shales is expected to have accident statistics comparable to those in a coal-based energy industry.

The cost of mining and producing $U_{3} \mathrm{O}_{8}$ from low-concentration ores is estimated to be at least $\$ 100 / 1 b$ of $\mathrm{U}_{3} \mathrm{O}_{8}$ in the future, and it may be even higher in actual practice. As discussed below, this would have a substantial impact on the fuel-cycle costs of fission converter reactors.

The two major portions of the fuel cycle cost for a converter reactor are for $U_{3} \mathrm{O}_{8}$ purchase and for the enrichment of that uranium to a higher concentration of the fissile ${ }^{235} U$ isotope. For the current converters, each $\$ 10 / \mathrm{lb}$ of $\mathrm{U}_{3} \mathrm{O}_{8}$ leads to a fuel cycle cost contribution of about $0.6 \mathrm{mi11} / \mathrm{kWh}(\mathrm{e})$. Therefore, if low-concentration ores could be mined and processed for about $\$ 100 / 1 \mathrm{~b}$ of extracted $\mathrm{U}_{3} \mathrm{O}_{8}$, the uranium cost alone would contribute about $6 \mathrm{mi} 1 \mathrm{ls} / \mathrm{kWh}(\mathrm{e})$ to the busbar cost of electricity. The current cost of uranium enrichment is about $\$ 60$ per separative work unit (SWU); this adds about $1.5 \mathrm{mills} / \mathrm{kWh}(\mathrm{e})$ to the busbar cost of electricity. Enrichment is a power-intensive operation, and its cost will increase as the cost of power increases. The enrichment cost, in turn, will lead to higher power costs. Each $\$ 10 /$ SWu increase in

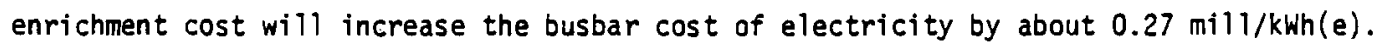

To provide a basis for comparison with the above numbers, converters currently are estimated to have a busbar power cost of about $15 \mathrm{mills} / \mathrm{kWh}(\mathrm{e})$. Ten mills/kWh(e) is due to the plant capital investment, about $1 \mathrm{mill} / \mathrm{kWh}(\mathrm{e})$ for nonfuel operating and maintenance costs, and

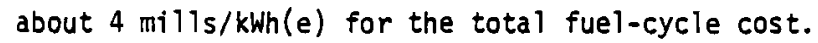

Forecasts of future nuclear plant construction predict that the high temperature gas reactor (HTGR) will gradually replace the light water reactor (LWR) as the primary type of converter built after the breeder reactor is introduced. After 2010, LWRs are forecast to be built chiefly as burners that consume the excess plutonium produced by breeders. In this analysis 
the HTGR is assumed representative of the converters, but data is included for the LWR because numerous LWRs are expected to still be operating in 2040.

The HTGR is a helium-cooled graphite-moderated reactor which uses a uranium-thorium fuel cycle. The fuel elements are large graphite blocks containing holes filled with small spheres of uranium and thorium oxide coated with graphite. Helium passing through holes in the graphite blocks provides cooling. Irradiation of the thorium creates ${ }^{233} \mathrm{U}$, which is recycled back to the reactor as fissile fuel. Because the reactor has a breeding ratio less than one, $235_{U}$ also is added to the fuel elements to provide the necessary reactivity. Operation of HTGRs creates fission products and the accompanying high-level waste disposal problems. The plutonium production is much lower than for LWRs or LMFBRs, un less a ${ }^{235} \mathrm{U}-{ }^{238} \mathrm{U}$ fuel cycle is used.

The HTGR has the advantages of use of thorium as a fuel and of a higher thermal efficiency than the LWR. Use of thorium extends the supply of nuclear fuel. The higher thermal efficiency resuits from the higher permissible helium operating temperatures without excessive pressures. Although the first generation HTGRs are not expected to have a thermal efficiency as high as the LMFBR, the subsequent generations are expected to have higher thermal efficiencies comparable to the LMFBR and modern fossil plants.

HTGRs currently are just being introduced as comercial power plants. Several years of operation are necessary before the technology and the costs will be well known.

Fission Breeder Systems. Several alternative breeder systems are being developed. These systems are the Light Water Breeder Reactor (LWBR), the Gas-Cooled Fast Breeder Reactor (GCFR), the Molten-Sait 8reeder Reactor (MSBR), and the Liquid Metal Fast Breeder Reactor (LMFBR). AII breeder reactor systems have much the same environmental impacts as the LMFBR and offer no significant improvement in that respect. The LMFBR is described here as the representative breeder reactor.

The LMFBR is the main line breeder reactor currently being developed by the ERDA. Current planning anticipates construction and operation of a prototype reactor in the 1980s and introduction of commercial reactors about 1990. Sufficient development work has been completed in the last 20 years to indicate that the LMFBR can be successfully developed to produce electricity at a lower cost than for thermal reactors.

The LMFBR is visualized as having a uranium-plutonium oxide fuel cycle and a liquid sodium coolant. The favorable nuclear physics is expected to result in a breeding ratio greater than 1.0 so that more plutonium is produced than is consumed as fuel. Irradiation of depleted uranium (tails from the gaseous diffusion plants) with the excess neutrons would create the plutonium.

The two prime advantages of the LMFBR in comparison to the light water reactor would be utilization of most of the uranium--not just about $2 \%$--and a higher thermal efficiency. Theoretically, the LMFBR could convert all the ${ }^{238} U$ in uranium to plutonium. But in reality, losses are expected to occur during irradiation and processing of the fuel elements. Part of the uranium would be converted to other elements such as neptunium, and part would be lost in waste 
streams. The higher thermal efficiency would result from use of sodium as a coolant. Higher operating temperatures than in LWRs would be permissible without uneconomical coolant pressures.

Operation of LMFBRs would create large quantities of plutonium and fission products, causing the same safeguards, waste disposal, and radiation dose problems as for LWRs.

Because large LMFBRs have not been built and operated, the forecast electricity production costs still must be considered tentative. Several years' operating experience is needed before accurate estimates can be made.

Solar. A number of methods have been proposed for using solar energy. These include direct utilization, such as thermal conversion, photovoltaic conversion, and thermal energy collection for space conditioning, as well as indirect solar energy systems such as those based on wind and ocean thermal gradients. The solar energy reaching the surface of the United States exceeds the energy produced from conventional fuels by a factor of nearly 700 . However, the portion of this energy that can be effectively utilized is 1 imited by technical, economic, environmental, and social considerations.

The major drawback in the use of solar energy is the diffuse and periodic nature of sunlight. Considering nights, weather, seasons, atmospheric attenuation, and variations in latitude, the average rate at which solar energy reaches the surface of the U.S. is $17 \mathrm{~W} / \mathrm{ft}^{2}$. Although certain areas of the Untted States are better suited for solar conversion, large amounts of land would be required to meet present and future electrical demands through solar-to-electric conversion. For example, a 1000-MNe thermal conversion solar plant capable of operating at a $70 \%$ capacity factor would require about $10 \mathrm{miles}{ }^{2}$ of land. Large amounts of land, especially in the Southwest, could probably be made available for this purpose, but a greater problem would be the manufacture and construction of the collection and conversion systems. The manufacture of the collectors, converters, and energy distribution equipment to cover large areas of land would require vast amounts of resources as well as the development of an industry to supply the equipment. The efficiency of solar systems must be high if land use is to be minimized. Estimates of the efficiency of solar-to-electric conversion systems vary from a 10 w of 1 or $2 \%$ for the combustion of photosynthetic material to a high of $30 \%$ for a thermal conversion system.

Cost estimates for solar conversion systems vary widely. For example, estimates for a solar-to-thermal conversion system vary from $\$ 450 / \mathrm{kWe}$ to $\$ 2000 / \mathrm{kWe}$ installed capacity for a system providing peaking capacity. Solar conversion systems large enough to meet total base and variable demand are estimated to have costs that could be five times as much as those previously given. With such a wide variation in predicted costs, an accurate analysis of the economic competitiveness of solar power is not possible.

All proposed solar energy systems, with the exception of thermal collection for buildings, appear to have poor prospects for economically competing with either coal or nuclear systems for at least several decades. The NSF/NASA Solar Energy Panel concluded that the most significant contribution of solar energy will be for the heating and cooling of buildings. The NSF/NASA 
Panel also estimated that $1 \%$ and $20 \%$ of electric demand could be met with solar-to-electric conversion in the years 2000 to 2020 respectively. The Panel's estimates have been adopted as the potential contribution of solar-to-electric conversion.

Geothermal Energy Sources. Geothermal energy may play an important role in meeting future electrical demand, especially in the western third of the U.S. The conversion of geothermal heat to electrical energy is less efficient than using the higher temperature and pressure steam produced in nuclear and fossil-fueled bollers. But the absence of fuel costs makes geothermal power attractive if geothermal reservoirs can be developed economically. Geothermal energy also has other uses such as the production of industrial heat and the desalinization of water.

There are several types of geothermal systems. Vapor-dominated systems, such as the geysers which produce live steam, are rare and are not entirely prototypic of future geothermal developments. Liquid-dominated reservoirs are more common, and some of these are already under comercial development. Liquid-dominated reservoirs produce a hot, corrosive, liquid brine which is used to produce steam or vapor to drive a turbine. Ory, hot rock systems are the most comon, but developmental work to utilize these resources is just beginning.

The quantity of geothermal energy below the earth's surface in the United States is vast, but there is wide disagreement as to what extent this energy may be utilized in the coming decades. The Hickel panel has estimated that 75,000 Mie could be developed by the year 2000 with a moderate research and development program and that 395,000 we could be developed with an accelerated research and development program. The Department of the Interior estimates in the "Final Environmental Statement for the Geothermal Leasing Program" that 75,000 MWe will be produced geothermally by the year 2000 .

The Bureau of Mines has made an even lower estimate of 40,000 me for the year 2000 . The projected geothermal capacities adopted are those proposed in "The Nation's Energy Future." The projected capacities were 80,000 and 200,000 Me for the years 2000 and 2020 , respectively, which is $6 \%$ of the projected demand for both of these years. A large number of potential geothermal sites have been identified in the western United States. However, the technology to economically extract energy from many of the sites has not been developed. Until this is done, how much geothermal energy can be counted as a recoverable resource cannot be detenmined.

The major potential environmental impacts of the use of geothermal energy are in the general areas of surface and groundwater quality impaiment as a result of fluid disposal; air emissions such as hydrogen sulfide; noise from drilling and from steam venting during operation; uncontrolled blowouts; aesthetic impact; land subsidence from fluid withdrawal or reinjection; land use; and damage to vegetation and wildlife. The environmental impact of geothermal generation is largely restricted to the generating site and its immediate surroundings--a contrast with fossil--or the nuclear-fueled generation, for which impacts occur at several locations (mines, processing plants, disposal sites). The different types of geothermal systems present different environmental impacts. Because of the relatively pure fluid in the vapor-dominated reservoirs, the fluid-disposal problem is relatively small compared with that of the hot-brine systems, 
whose high salinity represents a potentially serious environmental impact. The environmental impact of hot-rock utilization has not yet been thoroughly evaluated and cannot now be fully defined.

Wind Power. Large quantities of electricity could be generated by harnessing the wind. The principle of the wind generators is relatively simple, consisting of a fan or windmill and a generator. The quantity of electricity that would be produced cannot be predicted, and the cost of the electricity in the 21 st century cannot be predicted. Much development work is necessary before the cost can be reduced to competitive levels.

Summary Comparison of Alternatives. The seven primary alternatives are compared in Tables 3 and 4 . In addition to the six alternatives identified above, two fusion alternatives are included--the reference and advanced fusion power plants.

Table 3 presents the significant absolute or total environmental impacts for each of the eight alternatives. Table 4 presents a differential comparison of the six alternatives to the reference fusion power plant. In Table 4 the information for the reference fusion power plant is the same absolute data presented in Table 3 for the first generation fusion power plant. For the other alternatives, the data in Table 4 are the difference between the data in Table 3 for that alternative and for the reference fusion plant. As a result, the alternatives can be rapidly compared to the reference fusion plant simply by reading the information in Table 4.

These basic assumptions were used in preparation of Tables 3 and 4:

- A11 plants generate $6.13 \times 10^{9} \mathrm{kWh} /$ year. This corresponds to $1000 \mathrm{MWe}$ capacity at $70 \%$ plant factor.

- Coal plants have precipitators and stack gas scrubbers.

- No topping cycles (MHD, tubrines, thermionics) are used.

- Solar plants will use the thermal conversion process.

- Thirty-year power plant life.

\section{ALTERNATIVE STRATEGIES FOR FUTURE ELECTRICITY GENERATION SYSTEMS}

Future electrical energy needs will probably be fulfilled by generating systems composed of various energy sources and conversion systems. The choice of any particular strategy for the use of the available generating options depends on the energy demand and the relative costs of the options. As used here, the costs inciude both internal expenses reflected in the power cost and external, uncompensated expenses incurred as a result of environmental or human impacts. Another important element of any strategy is the possibility of altering energy needs through conservation. Reductions in electrical energy demands are considered in the strategy alternatives which follow.

Numerous strategies for future electricity generation are possible because of the many types of power plants that could be built and the many uncertainties concerning the costs and environmental effects of most of them. To simplify the evaluation of fusion power plants, only three strategies are analyzed: 
IABLE 3. Alternative Power Plant Environmental Effects ${ }^{(a)}$

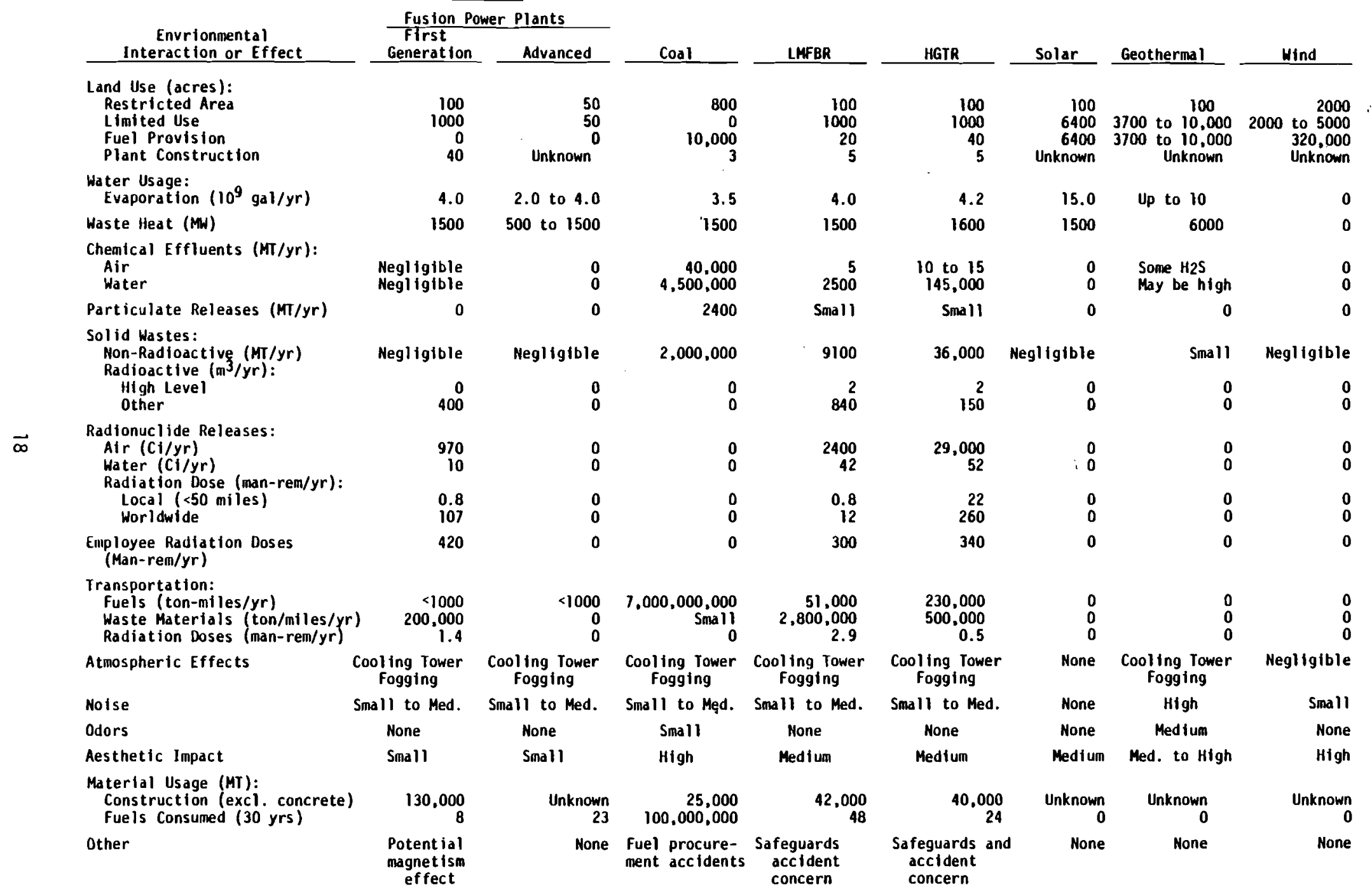

(a) All plants produce 1000 me at $70 \%$ plant factor (or $0.7 \mathrm{GWe} / \mathrm{yr}$ ). 


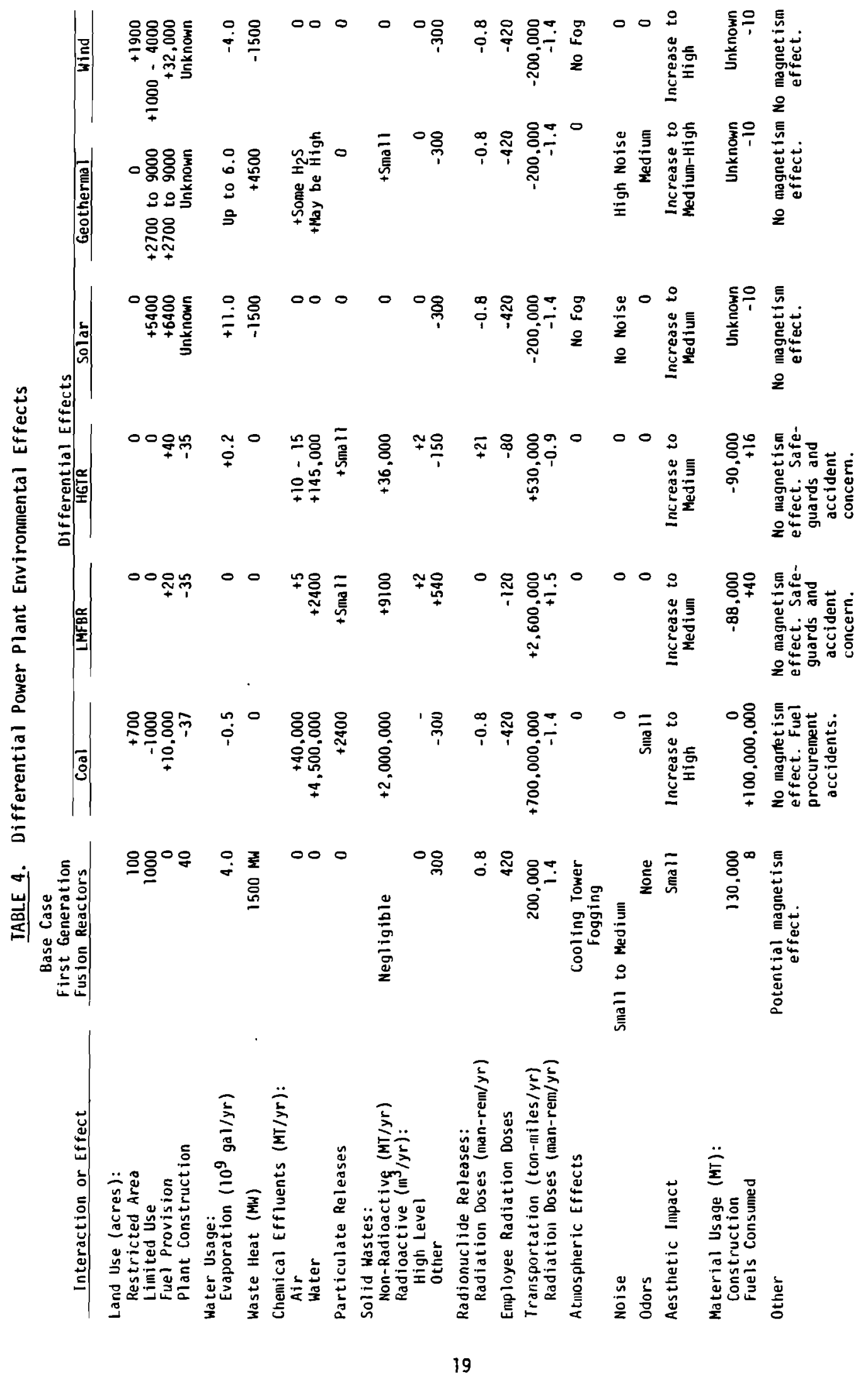


- A base case of primarily fossil plants supplemented by hydroelectric and the advanced technologies of solar, geothermal and wind.

- The base case with the addition of fission reactors.

- The base case with the addition of fission and fuston reactors.

\section{The Fossil Fuel Economy}

Current opposition to fission plants because of concern about reactor safety and releases of long-half-life radioisotopes such as plutonium could result in abandonment of the fission reactor as a source of electricity. In that case, the primary source of electricity would be fossil power plants until new technologies such as solar and geothermal could be developed and adopted.

Because the economic competitiveness of these new technologies is not known, accurate predictions cannot be made of this portion of the total electricity production of the future. A recent evaluation by the U.S. Atomic Energy Commission is used to show the potential electricity generation by sources other than fossil or nuclear (WASH-1535). The data of that analysis were modified only by assuming that coal-fired plants would be substituted for the nuclear plants.

Potential energy sources, such as solar, geothermal, and organic waste are included in the energy mix at levels estimated to be attainable under optimistic conditions; the estimated distribution of energy sources is shown in Table 5 for the year 2000, and in Table 6 for 2020.

As illustrated in Table 5, the advanced technology sources might be capable of supplying up to 13\% of the year 2000 base-case electricity demand. However, no assurance can be given that such sources will be technically available and economically viable at that time. If conservation is assumed effective in reducing the demand by $20 \%$, the potential sources could account for about $16 \%$ of the reduced demand. The arbitrary (but conservative) assumption here is that energy conservation is applied only to conventional sources and that the absolute contributions of other sources remain constant. Thus conventional sources would be needed to produce 7.1 to 9.2 trillion $\mathrm{kWh}$, and the required fossil and hydroelectric capacity would be equivalent to about 1700 plants of 1000 Mwe each.

By 2020 (Table 6) advanced technology energy sources might be producing $13 \%$ of the electricity demand or, if conservation reduces total demand by $20 \%$, these sources might provide $16 \%$ of energy generation. This would leave 18 to 24 trillion $\mathrm{kWh}$ to be supplied from coal and hydroelectric power; the required conventional generating capacity would be equivalent to 3300 to 4600 plants of 1000 MNe each. If the total energy demand in 2020 were reduced $50 \%$ below the base-case projection, this same energy contribution by the potential systems would provide 26\% of the lower demand. This would leave about 10 trillion kwh of electrical energy to be generated by conventional sources. 
TABLE 5. Energy Sources for Electricity

Production in the Year 2000

\begin{tabular}{|c|c|}
\hline & $\begin{array}{l}\text { e Case } \\
\text { nd }\end{array}$ \\
\hline $\begin{array}{c}\text { Trillition } \\
\text { kWh }\end{array}$ & $\begin{array}{c}\text { Percent of } \\
\text { Demand }\end{array}$ \\
\hline
\end{tabular}

With 20\%

Reduction By

Energy Demand

Conservation

$10.60 \quad 100$

\begin{tabular}{l} 
Trillion \\
kWh \\
\hline
\end{tabular}

8.48

Percent of Demand

Advanced Technology Energy Sources

Solar

Geothermal

Organic Waste

Subtota1

Conventiona 1

TOTAL

\begin{tabular}{crrr}
0.21 & 2 & 0.21 & 2.5 \\
0.63 & 6 & 0.63 & 7.4 \\
0.54 & 5 & 0.54 & 6.4 \\
\hline 1.38 & $\frac{5}{13}$ & $\overline{1.38}$ & 16.3 \\
9.22 & 87 & 7.10 & 83.7 \\
\hline 10.60 & 100 & $\overline{8.48}$ & 100
\end{tabular}

TABLE 6. Energy Sources for Electricity Production in the Year 2020

\begin{tabular}{|c|c|c|c|c|c|c|}
\hline & \multicolumn{2}{|c|}{$\begin{array}{c}\text { With Base Case } \\
\text { Demand }\end{array}$} & \multicolumn{2}{|c|}{$\begin{array}{l}20 \% \\
\text { Reduction }\end{array}$} & \multicolumn{2}{|c|}{$\begin{array}{c}50 \% \\
\text { Reduction } \\
\end{array}$} \\
\hline & $\begin{array}{c}\text { Trillion } \\
\text { kWh }\end{array}$ & $\begin{array}{c}\text { Percent of } \\
\text { Demand } \\
\end{array}$ & $\begin{array}{c}\text { Trillion } \\
\text { kWh } \\
\end{array}$ & $\begin{array}{l}\text { Percent of } \\
\text { Demand } \\
\end{array}$ & $\begin{array}{l}\text { Trillion } \\
\text { kWh } \\
\end{array}$ & $\begin{array}{c}\text { Percent of } \\
\text { Demand }\end{array}$ \\
\hline Energy Demand & 27.6 & 100 & 22.1 & 100 & 13.8 & 100. \\
\hline \multicolumn{7}{|l|}{ Energy Sources } \\
\hline \multicolumn{7}{|l|}{ Potential } \\
\hline Solar & 1.40 & 5 & 1.40 & 6.3 & 1.40 & 10 \\
\hline Geotherma 1 & 1.60 & 6 & 1.60 & 7.3 & 1.60 & 12 \\
\hline Organic Waste & 0.54 & 2 & 0.54 & 2.4 & 0.54 & 4 \\
\hline Subtotal & 3.54 & $\sqrt{3}$ & 3.54 & T6 & 3.54 & $\overline{26}$ \\
\hline Conventional & 24.06 & 87 & 18.56 & 84 & 10.26 & 74 \\
\hline TOTAL & $\overline{27.6}$ & $\overline{100}$ & $\overline{22.1}$ & $\overline{100}$ & $\overline{13.8}$ & $\overline{100}$ \\
\hline
\end{tabular}

The data of Table 6 make the very conservative assumption that the energy generated by potential systems is not reduced by the conservation measures, thereby causing the conventional sources to absorb all of the reductions. The more reasonable event to be expected is that all the energy sources would generate less energy in the energy-conservation cases and that the reductions would be distributed more or less proportionately to all energy sources. This was the assumption used in deriving the energy consumption projections for the conventional. 
cost/benefit analysis, leading to a base case with $80 \%$ of the electricity generation by coalfired plants in 2010 to 2040 . The remaining capacity is assumed to include 165,000 Me hydroelectric, with the rest of the generation capacity split equally between solar and geothermal. As a simplification, burning of organic waste was assumed to be represented by burning of coal. Gas turbine plants will be included in the total generation capacity but are expected to generate a very small fraction of electricity.

\section{The Fission Economy}

Current forecasts show continued construction of fission reactors with a conversion from themal to fast breeder reactors late in the current century. This probably will result in a mixture of nuclear, fossil, hydroelectric and new sources such as solar and geothermal in the 21 st century.

Again the penetration of the new sources is not known and must be assumed. In this case, it is assumed from year 2010 to year 2040 that nuclear plants will generate most of the electricity and that the remainder (as for the base case) will be about $80 \%$ coal and $20 \%$ hydroelectric, solar, and geothermal.

The forecasts of the numbers of each type of power plants built include only fossit, fission, and fusion power plants because adequate economic data are not available for the new technologies, and generation by hydraelectric plants can be treated as a constant. The forecast number of power plants built was adjusted to include the new technologies by assuming that they would displace coal-fired power plants and would produce electricity at the same cost as for coal.

\section{The Fusion Economy}

In this case, the fission economy was modified by assuming that the fusion reactor would be introduced in 2010 and that it would have an electricity production unit cost equal to about $97 \%$ of the unit cost for the LMFBR. This slightly lower electricity cost is necessary because the forecast of the number of plants built is based solely on economics. If fusion costs more than the LMFBR, it probably would not be built in significant numbers. The electricity production by new technology sources was assumed to continue at $18 \%$ of the total non-nuclear as for the fossil and fission economies. (Power plant construction was also forecast with the assumption that the cost of electricity produced by fusion reactors will be only $90 \%$ of the cost for LMFBRs. The number of fusion reactors built before 2040 was essentialiy the same as when the fusion reactor electricity cost was $97 \%$ of the cost for LMFBRs.)

Summarized Power Plant Construction Schedules

The number of 1000-MWe power plants built for each of the three strategies is summarized for the period of 2010 to 2039 in Table 7. The assumptions and methods used for making these forecasts are presented in BNWL-2016. These forecasts show that the fusion reactor probably will dominate the electricity production industry if it is commercially competitive.

As soon as the fusion power plant has become established following the 10-year introduction period (2010 to 2019), it would be built at a rate equal to the expansion of the generation rate. The number of other power plants operating remains essentially constant or starts to decline as in the case of the fast reactor, reflecting the gradual shutdown of obsolete plants. 
TABLE 7. Power Plant Construction Schedules

\begin{tabular}{|c|c|c|c|c|c|c|c|}
\hline Economy & Type Plant & $\begin{array}{c}\text { Aver } \\
2010 \\
\text { to } \\
2014 \\
\end{array}$ & $\begin{array}{c}\text { Numb } \\
2015 \\
\text { to } \\
2019 \\
\end{array}$ & $\begin{array}{c}1000 \\
2020 \\
\text { to } \\
2024 \\
\end{array}$ & $\begin{array}{c}\text { de Pla } \\
2025 \\
\text { to } \\
2029 \\
\end{array}$ & $\begin{array}{c}\text { s Oper } \\
2030 \\
\text { to } \\
2034 \\
\end{array}$ & $\begin{array}{c}\text { Ing } \\
2035 \\
\text { to } \\
2039 \\
\end{array}$ \\
\hline \multirow[t]{2}{*}{ Fossil } & $\begin{array}{l}\text { Gas Turbine } \\
\text { Hydroelectric } \\
\text { Solar and Wind } \\
\text { Geothermal } \\
\text { Foss } 11\end{array}$ & $\begin{array}{r}97 \\
148 \\
167 \\
168 \\
1838\end{array}$ & $\begin{array}{r}112 \\
165 \\
248 \\
249 \\
2136\end{array}$ & $\begin{array}{r}130 \\
165 \\
261 \\
262 \\
2622\end{array}$ & $\begin{array}{r}150 \\
165 \\
323 \\
324 \\
3098\end{array}$ & $\begin{array}{r}174 \\
165 \\
393 \\
393 \\
3630\end{array}$ & $\begin{array}{r}205 \\
165 \\
471 \\
472 \\
4230\end{array}$ \\
\hline & TOTAL & 2418 & 2910 & 3440 & 4060 & 4755 & 5543 \\
\hline \multirow[t]{2}{*}{ Fission } & $\begin{array}{l}\text { Gas Turbine } \\
\text { Hydroelectric } \\
\text { Solar and Wind } \\
\text { Geothermal } \\
\text { Fossil } \\
\text { Thermal Reactor } \\
\text { Fast Reactor }\end{array}$ & $\begin{array}{r}97 \\
148 \\
35 \\
36 \\
391 \\
1067 \\
644\end{array}$ & $\begin{array}{r}112 \\
165 \\
44 \\
44 \\
477 \\
1018 \\
1050\end{array}$ & $\begin{array}{r}130 \\
165 \\
55 \\
56 \\
557 \\
980 \\
1497\end{array}$ & $\begin{array}{r}150 \\
165 \\
67 \\
67 \\
638 \\
1033 \\
1940\end{array}$ & $\begin{array}{r}174 \\
165 \\
77 \\
73 \\
676 \\
1151 \\
2443\end{array}$ & $\begin{array}{r}205 \\
165 \\
80 \\
80 \\
715 \\
1227 \\
3071\end{array}$ \\
\hline & TOTAL & 2418 & 2910 & 3440 & 4060 & 4759 & 5543 \\
\hline \multirow[t]{2}{*}{ Fusion } & $\begin{array}{l}\text { Gas Turbine } \\
\text { Hydroelectric } \\
\text { Solar and Wind } \\
\text { Geothermal } \\
\text { Fossil } \\
\text { Thermal Reactor } \\
\text { Fast Reactor } \\
\text { Fusion }\end{array}$ & $\begin{array}{r}97 \\
148 \\
30 \\
31 \\
335 \\
1100 \\
672 \\
5\end{array}$ & $\begin{array}{r}112 \\
165 \\
40 \\
41 \\
439 \\
1166 \\
930 \\
17\end{array}$ & $\begin{array}{r}130 \\
165 \\
53 \\
53 \\
530 \\
1224 \\
1124 \\
161\end{array}$ & $\begin{array}{r}150 \\
165 \\
60 \\
60 \\
580 \\
1293 \\
1200 \\
552\end{array}$ & $\begin{array}{r}174 \\
165 \\
65 \\
65 \\
601 \\
1339 \\
1139 \\
1207\end{array}$ & $\begin{array}{r}205 \\
165 \\
68 \\
69 \\
609 \\
1309 \\
1015 \\
2103\end{array}$ \\
\hline & TOTAL & 2418 & 2910 & 3440 & 4060 & 4755 & 5543 \\
\hline
\end{tabular}

CUMULATIVE ENVIRONMENTAL EFFECTS FROM 2010 TO 2040

This section discusses the environmental effects from 2010 until 2040 of the total U.S. electrical generation industry. Three cases are considered. In the base case, only coal-fired, hydroelectric, and advanced systems such as solar are assumed to be operating. In the second case, fission plants are added to the base case. In the third case, fission plants are added to the base case and fusion is introduced commercially in 2010. The difference between these cases represents the environmental impact of the technology being developed in the Fusion Program (whether or not fission power plants are viable). A brief discussion of the expected roles that each energy conversion technique is expected to play and of the environmental effects associated with a unit of generation from each is followed by the sumation of these effects to the year 2040 and a discussion of the projected impact of the Fusion Program. (In this section, environmental effects are based on a unit of electrical energy, the gigawatt year. A gigawatt is one billion watts or one million kilowatts. A gigawatt year is the energy produced in one year's continuous operation of a plant whose capacity is one gigawatt.) 
This section draws partly on results from two studies undertaken by the AEC and ERDA as part of a continuing program to determine the environmental impact of various (mainly nuclear) energy conversion techniques. One study, known as "The Year 2000 Study," involves estimation of population dose in a large region resulting from extensive use of nuclear facilities (such as might be expected to the year 2000) in that region (WASH-1209). The other study, known as the "Risk-Cost-Benefit S.tudy," estimates some of the external societal costs for alternative energy conversion systems (WASH-1224).

\section{Projected Use of Electrical Energy}

A forecast of the use of electrical energy to the year 2040 is shown in Figure 1. This forecast, like many others, is based on projections of energy use per capita and of U.S. population. A more detailed description of its derivation is found in BNWL-2016. As illustrated in Figure 1, not all of the electrical energy requirements would be met by large, central power plant units. Hydroelectric power and energy produced in fossil-fuel peaking units (including gas turbines and internal combustion units) would supplement the central station generation

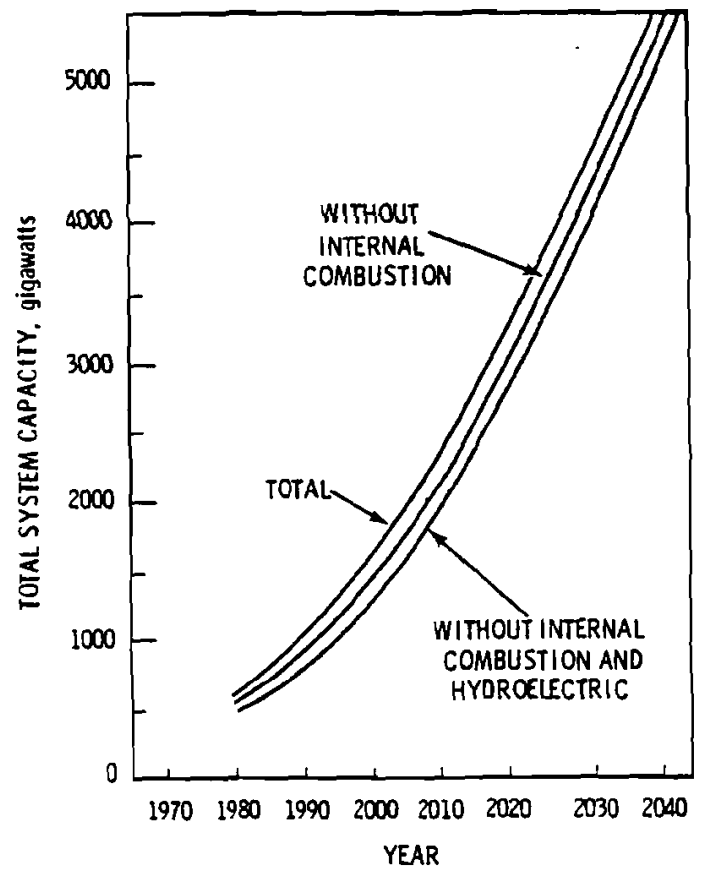

FIGURE 1. Projected Demand for Electrical Generating Capacity 1980-2040 
of electrical power during periods of peak demand or when otherwise appropriate. Figure 1 shows the relative contributions of these various generation techniques to meeting the aggregate demand.

Most of the electricity generation in the U.S. is expected to be in base-load plants-the most probable use of fusion power plants because of the capital-intensive nature. Less than $10 \%$ of all generating facilities are expected to be peaking units in the 21 st Century, as shown in Table 8.

That portion of the energy expected to be supplied by central station electrical generation will be generated in units fueled by fossil fuels (coal, oil, gas) or by nuclear power such as that obtained from an LWR, HTGR, LMFBR, or fusion. Projections of the "mix" of these types of plants have been made, taking into account the anticipated economic parameters of each (capital cost and fuel cost), the expected abailability of fuel, and the growth capability of supporting industries. Of particular interest is the situation where fusion plays its expected role, in contrast to the situation in which fusion does not compete and the currently available other energy conversion techniques are used instead. Figures 2 and 3 show the expected contributions of the various energy sources for these two cases. The fossil component is essentially the same for both cases so that the primary competition is between fusion and the nuclear options.

The other component of Figures 2 and 3 represents the estimated contributions from all fossil sources, including coal, oil, and gas, plus the contributions from solar, geothermal, or other advanced sources. The specific contributions of residual fuel oil and natural gas are assumed to have decreased to essentially zero by 2010 . After 2010 all electricity generation by fossil plants is assumed to result from burning coal because depletion of other fuels would result in excessive costs.

TABLE 8. Projected Capacity Contributions of Electrical Generation Peaking Facilities (Percentage of Central Station Capacity)

\begin{tabular}{cccc} 
Year & $\begin{array}{c}\text { Internal Combustion } \\
\text { Gas Turbine, \% }\end{array}$ & $\begin{array}{c}\text { Pumped } \\
\text { Storage, \% }\end{array}$ & Total, \% \\
\cline { 2 - 3 } 1970 & 5.5 & $\frac{1.1}{6.6}$ \\
1980 & 8.0 & 3.5 & 11.5 \\
1990 & 7.7 & 4.5 & 12.2 \\
2000 & 6.8 & 4.0 & 10.8 \\
2010 & 5.5 & 3.3 & 8.8 \\
2020 & 4.3 & 2.6 & 6.9
\end{tabular}




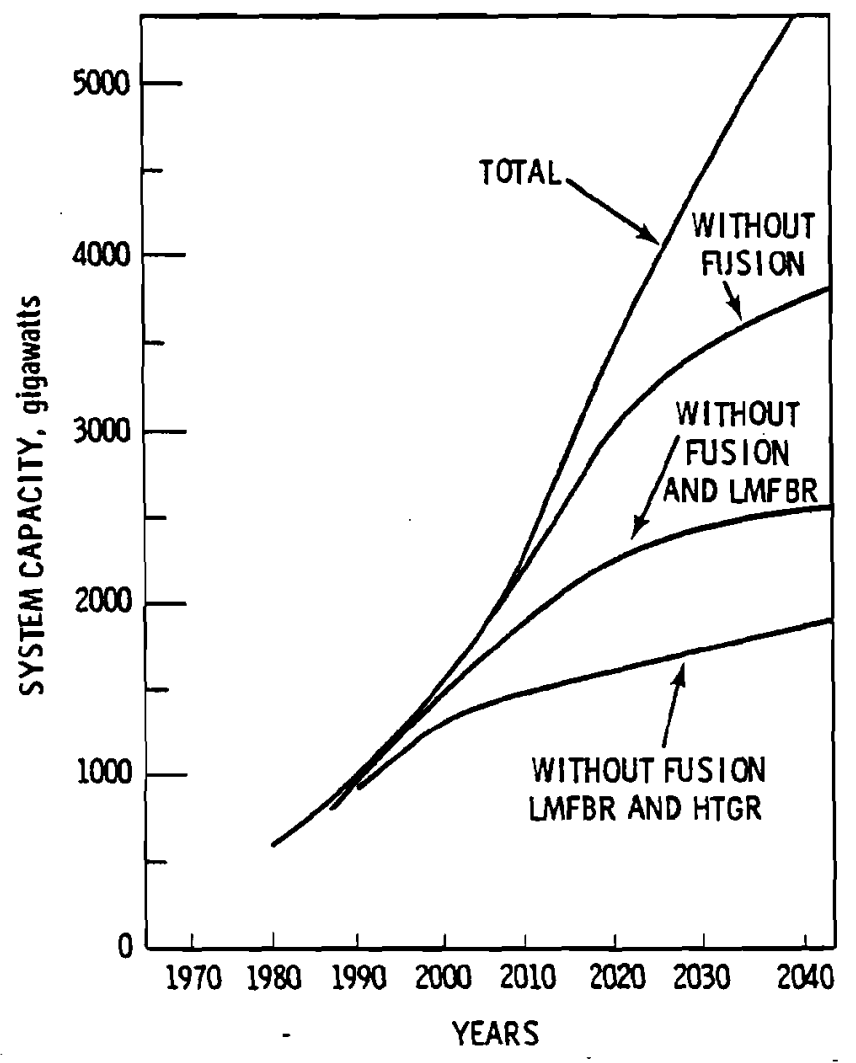

FIGURE 2. Projected Central Station Capacity by Energy Source with Fusion: 1970 - 2040

This assessment has not addressed specifically the introduction of moderately advanced fossil-fuel burners (using liquified or gasified coal). The overall pollutant burden (chiefly the contained ash and sulfur) that must be handled in processing coal to produce electricity remains roughly the same regardless of the processing scheme involved; only the locale and the cost of pollution abatement measures would change.

Very generally, the overall impact lessens as the pollutant removal point is moved from the post-combustion handiing step to the mining step. In this regard, in-situ gasification or liquefaction (which may have limited applicability at strip mines) shows great promise, because the offending materials are not removed from the ground. In any event, the heal th effects of these pollutants are not considered in the cumulative impacts developed in this section. Thus fossil fuels are generally assumed to have advanced pollution control technology available. Comparison of Electrical Power Generation Requirements

The various techniques for producing electrical energy consume this energy as required by their respective fuel cycles. Since the same total power demand is to be supplied in every 


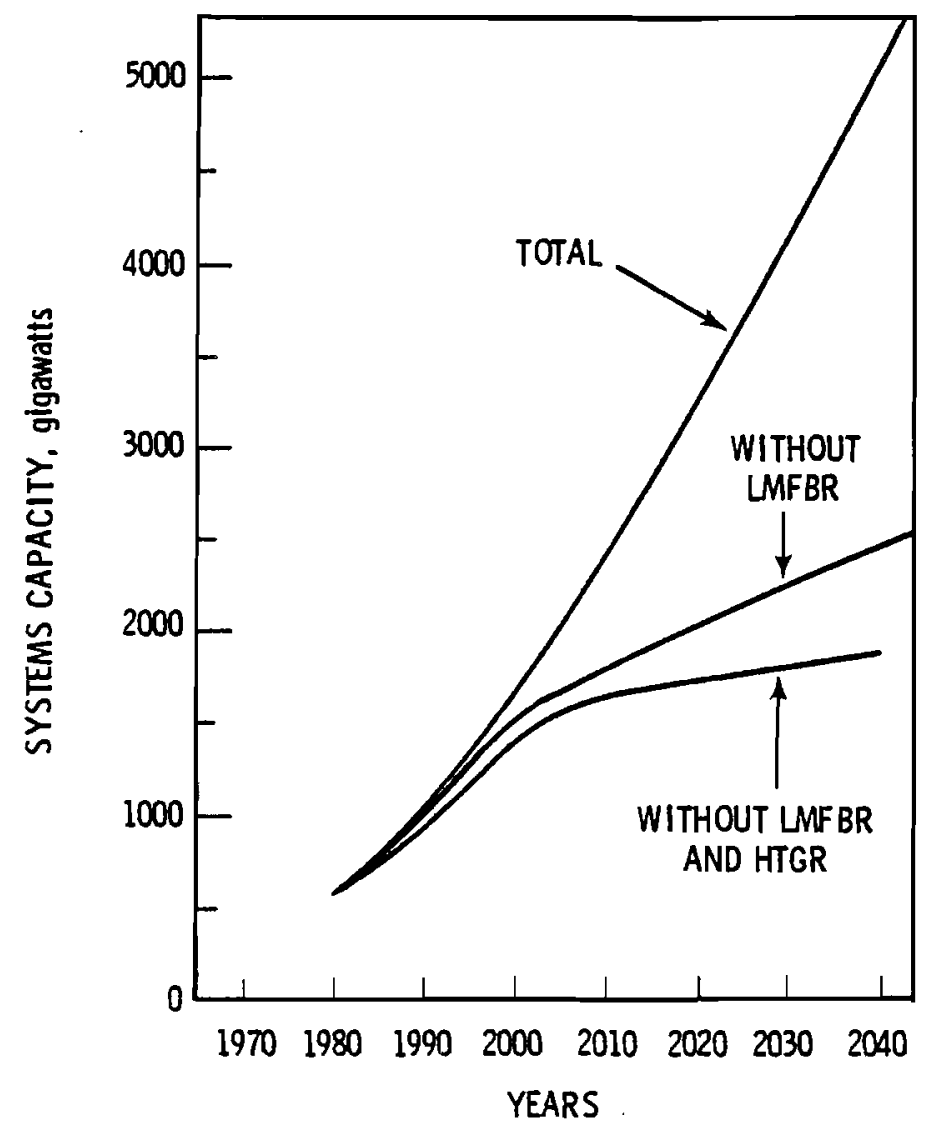

FIGURE 3. Projected Central Station Capacity by Energy Source without Fusion: $1970-2040$

case, the difference in use of electrical energy is factored into the analysis by requiring each energy conversion technique to produce enough additional electrical power to compensate for its associated fuel cycle use. Table 9 lists the electrical energy required for various conversion schemes, detailed according to use. In the nuclear generation methods, enrichment of the fuel in $235 \downarrow$ is the major use of electrical energy. Those techniques that minimize or bypass that step require less total generation. Thus 1.0003 units of generation are required for a fusion power plant to produce a single unit of "deliverable" energy.

Waste Generation and Disposal

\section{Heat}

Heat dissipated to the environment is not considered to accumulate but is, instead, ultimately radiated to outer space soon after release. Thus the heat dissipation impact is proportional to the heat rejection at the time of consideration and not the total discharged over the period involved. 
TABLE 9. Electrical Energy Usage of Various Conversion Techniques (kWh Required/kWh Produced)

\begin{tabular}{|c|c|c|c|c|c|}
\hline & $\underline{\mathrm{Coa} I}(\mathrm{a})$ & $\operatorname{LWR}^{(b)}$ & $\operatorname{LMFBR}^{(c)}$ & Fusion (d) & $\mathrm{HTGR}(\mathrm{c})$ \\
\hline Mining and Milling & 0.00119 & 0.00039 & & & 0.00020 \\
\hline Conversion and Enrichment & & 0.04548 & & 0.00028 & 0.03073 \\
\hline Fuel Fabrication & & 0.00022 & 0.00012 & & 0.00007 \\
\hline Reprocessing & & 0.00006 & 0.00003 & & 0.00004 \\
\hline Desulfurization & $\underline{0.01431}$ & & & & \\
\hline TOTAL $^{(e)}$ & 0.01550 & 0.04615 & 0.00015 & 0.00028 & 0.03704 \\
\hline
\end{tabular}

(a) USAEC Report WASH-1224.

(b) Requirements from USAEC Report WASH-1237, modified to account for updated mass balances as used in the cost/benefit studies reported in Section 11.2 of that document.

(c) Requirements from USAEC Report WASH-1237, adjusted to LMFBR and HTGR mass balances (Section 11.2).

(d) Deuterium production for the D-T fuel cycle. Lithium energy costs are not included because it probably will be a coolant provided at the outset, and the amount used during production of tritium will be small enough that makeup will not be necessary.

(e) In plant (at the power generation station) electrical energy uses are assumed to be the same for all conversion techniques.

The heat rejection to the environment is mainly at the generating station, with relatively minor contributions from the fuel cycle. In fossil-fuel powered generating stations, a portion (about 10\%) of the heat of combustion is lost to the system through the stack. The rest of the energy that is not converted into electricity is generally dissipated in the condenser. The subsequent release to the environment may be to the air from dry (nonevaporative) or wet (evaporative) cooling towers, to artificial or natural lakes and ponds, or to rivers. of course, even when the heat is assimilated by a water body, it normally is transferred to the atmosphere by energy exchange at the water surface, largely through the mechanism of evaporation.

The amount of heat released to the environment is a direct function of the efficiency of the energy conversion process. In the electrical generation industry, efficiency is commonly measured by the heat rate, the amount of energy required to produce $1 \mathrm{kWh}$ of electrical energy. Because the thermal equivalent of a $\mathrm{kWh}$ is $3413 \mathrm{Btu}$, a heat rate of $3413 \mathrm{Btu} / \mathrm{kWh}$ would indicate $100 \%$ efficiency, $6826 \mathrm{Btu} / \mathrm{kWh}$ would correspond to $50 \%$ efficiency and so forth. Technological improvements have dramatically reduced the heat rate (improvement in efficiency) over the decades, and this trend is expected to continue, although at a slower rate. 
Figure 4 shows representative historical and projected future heat rate data through the year 2000. The data for the year 2000 were considered representative of the period 1970 to 2040. The projection for bituminous coal follows roughly the Federal Power Commission (FPC) data (1971). The projections for $0 i 1$ and gas reflect the results of analysis of National Coal Association data (1972), as shown also in Figure 4. The lignite and subbituminous coal data were developed from a multiple regression analysis of FPC (1972) data from operating plants. During the 1960's, the average heat rate of a coal-fired plant was determined to increase by about $33 \mathrm{Btu} / \mathrm{kWh}$ (about 0.3\%) for each $100 \mathrm{Btu} / \mathrm{lb}$ decrease in the heat value of coal. Application of these results to lignite and subbituminous coals $(6700 \mathrm{Btu} / 1 \mathrm{~b}$ and $9500 \mathrm{Btu} / 1 \mathrm{~b}$, respectively, compared with 13,000 Btu/lb for bituminous coal) indicated a heat rate for subbituminous coal plants some $12.6 \%$ higher than for bituminous coal plants and some $22.4 \%$ higher in the case of 1 ignite. These ratios continued through the rest of the century in the projection shown in Figure 4 . Nuclear efficiencies came from WASH-1139. The resulting process heat requirements for the various energy conversion techniques are shown in Table 10. The likely path of their dissipation, to air or water, is also shown. Generally, the dissipation to water includes the potential for dissipation in cooling towers, including dry towers which do not evaporate water.

As noted earlier, the discharge of heated effluents to the environment is not really an environmental impact but is instead an index of such impact. Actual impacts are better described by determining the effects of the heated discharge. The effects of this discharge in terms of evaporation of water and its consequent removal from downstream uses is discussed elsewhere in this section. Biological impacts have not been included in this section for two reasons. First, the variety of potential impacts is strongly dependent upon the specific plant site. Second, individual discharges are presumed to be within applicable state and Federal regulations designed to protect the environment. Also, decisions regarding site selection and plant cooling water supply selection for a particular installation will be made with due regard for all pertinent factors, including environmental impact at candidate sites.

All fusion power plants will presumably meet the same site suitability criteria as LWRs, HTGRs, LMFBRs, and fossil-fuel plants. The actual impacts of waste heat discharges cannot be predicted because the majority of the sites for fusion power plants (and other plants) are not now selected. In general, though, future use of current best technology for the LMFBR, fusion, HTGR, and fossil plants is expected to result in about the same heat rate and waste heat release rates for all of these types of plants.

\section{Radioactive Waste}

Radioactive waste from nuclear reactors and their associated fuel cycle processing steps can be conveniently categorized in major groups. High-level waste is essentially the fission product waste from chemical reprocessing plants. Current NRC regulations require solidification of this waste. The major tradeoff between short-term uses and long-term commitments is that 


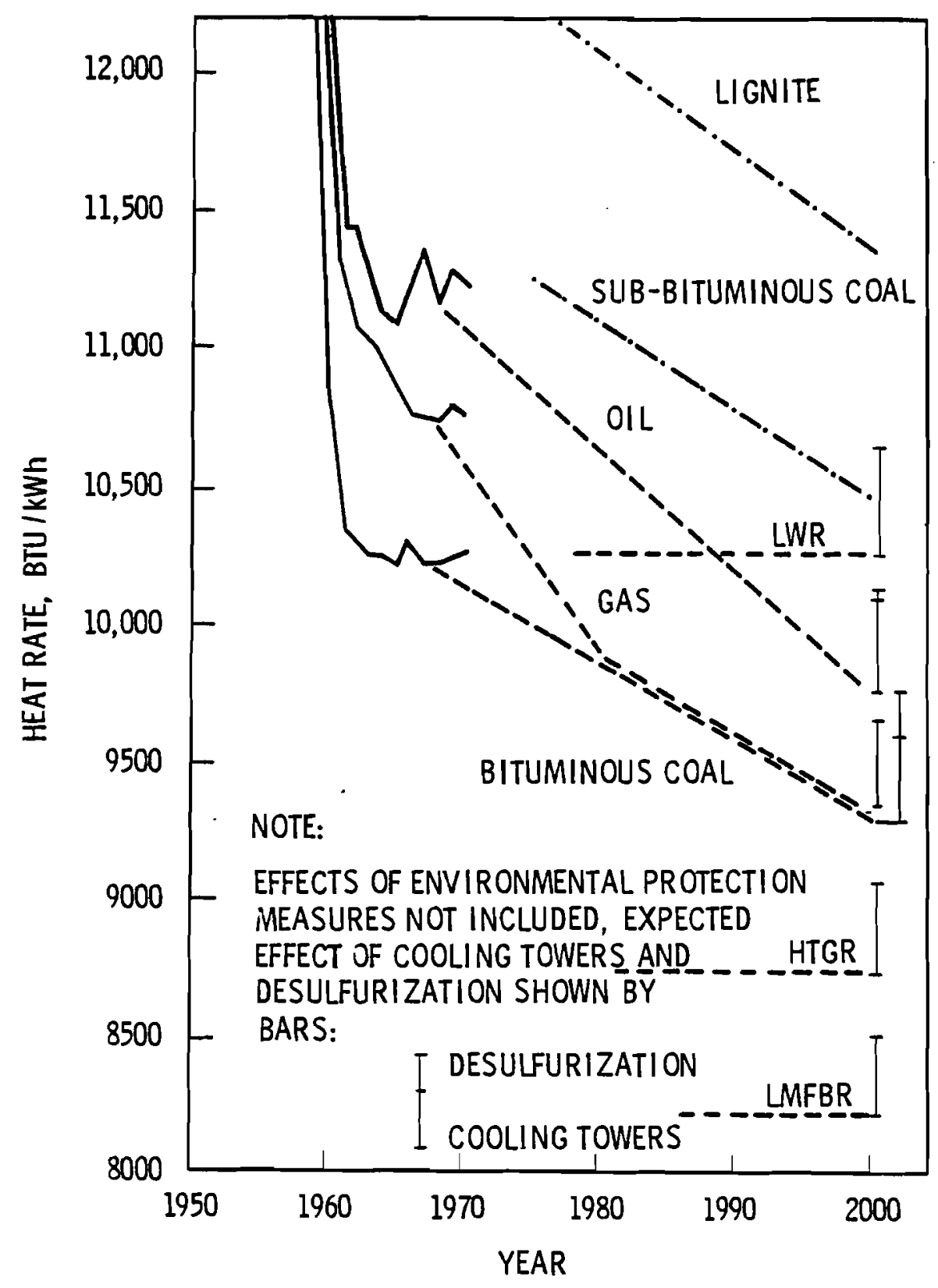

FIGURE 4. Projected Heat Rates of Various Energy Conversion Techniques 


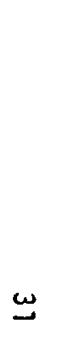

Energy Usage (Btu/kWh)

Mining and Milling (a)

Fabrication and Processing (a)

Transportation (a)

Base Heat Rate ${ }^{(b)}$

Cooling Tower Penalty (c)

Desulfurization Penalty (a)

TOTAL.

Energy Dissipated $\left(10^{12}\right.$ Btu/GW-year $)$

$\begin{array}{lllllllll}\text { To Air } & 43.7 & 50.6 & 52.1 & 50.1 & 33.0 & 38.4 & 122.1 & 33.0 \\ \text { To Hater } & 14.3 & 16.9 & 17.4 & 16.7 & 11.0 & 12.8 & 40.7 & 11.0\end{array}$

(a) From USAEC Report WASH-1224 adjusted as needed for updated mass balances.

(b) From projections, Figure 4.

TABLE 10. Equivalent Process Heat Usage

\begin{tabular}{|c|c|c|c|c|c|c|c|}
\hline Bitum. & $\frac{\text { Coal }}{\text { Subbitum. }}$ & Lignite & LWR & LMFBR & HTGR & Geothermal & $\begin{array}{c}\text { Solar and } \\
\text { Fusion }\end{array}$ \\
\hline 73 & 11 & 172 & 14 & 0 & 0 & 0 & $<1$ \\
\hline 0 & 0 & 0 & $<1$ & $<1$ & $<1$ & 0 & 0 \\
\hline 35 & 52 & 80 & $<1$ & $<1$ & $<1$ & 0 & $<1$ \\
\hline 9,300 & 10,470 & 11,380 & 10,250 & 8,230 & 8,750 & 22,000 & 8,230 \\
\hline 306 & 371 & 422 & 417 & 294 & 325 & 0 & 294 \\
\hline 162 & 60 & 107 & $\underline{0}$ & $\underline{0}$ & $\underline{0}$ & $\underline{0}$ & 0 \\
\hline 9,576 & 11,684 & 12,161 & 10,681 & 8,524 & 9,075 & 22,000 & 8,524 \\
\hline
\end{tabular}

(c) Evaporative cooling towers, consistent with USAEC Report WASH-1224, modified to account for different heat rates. 
the generation of electricity by fission plants is accompanied by the generation of high-level waste that will be hazardous essentially forever whereas fusion power plants create no high-level waste.

Low-level waste includes gaseous, liquid, and solid waste products from the reactor and the fabrication and reprocessing plants. All of these wastes for fusion power plants are discussed in BNWL-2018 and 2019, and a brief review of pertinent data is presented in Table 11. In addition to these wastes, some routine releases of radioactive material from nuclear plants are expected to take place. The accumulation of these releases is only an index of the environmental impact. Since the low-level solid waste generated is buried, the primary impacts are the land use required for disposal and the guardianship that may be required. The impact of routine releases is not the actual release but the resultant dose to the populace and any health effects from that dose. These measures of impact are discussed later.

The amount of radioactive material in high- and low-level wastes measured in total curies differs by only a few percent for nuclear power systems with and without the fusion reactor. The primary difference in quantities of radioactive waste material is in the categories of highlevel waste, cladding hulls, and plutonium-contaminated waste, as shown in Table 12 . In general, the volume of the waste is the critical index for environmental impact and determines the land requirements for disposal.

Routine Releases. Routine releases of radionuclides from fission facilities introduce into the biosphere not only fission products but also transuranium nuclides and various activation products. These releases are dispersed by air and water transport and, over a period of time, build up in the air and water, on the soil, and at the bottoms of lakes, rivers, and oceans. The buildup is not strictly cumulative because the radionuclide decay results in removal from the

TABLE 11. Generation of Radioactive Waste Per Gigawatt/Year

\begin{tabular}{|c|c|c|c|c|}
\hline & LWR & LMFBR & HTGR & Fusion \\
\hline High-Level Solids, $\mathrm{ft}^{3(\mathrm{a})}$ & 69 & 69 & 63 & 0 \\
\hline Low-Level Solids, $\mathrm{ft}^{3(\mathrm{a})}$ & 39,000 & 32,500 & 7,500 & 20,000 \\
\hline Plutonium-Contaminated Solids, $\mathrm{ft}^{3(\mathrm{a})}$ & 3,000 & 9,700 & $0^{(c)}$ & 0 \\
\hline Cladding Hulls, $\mathrm{ft}^{3(\mathrm{a})}$ & 72 & 206 & 0 & 0 \\
\hline Mine Tailings, metric ton ${ }^{(b)}$ & 105,200 & 0 & 55,000 & 0 \\
\hline
\end{tabular}

(a) HTGR assumed on a par with LMFBR, except no fuel cladding. Includes $5000 \mathrm{ft}^{3}$ of fusion reactor inner walls.

(b) From USAEC Report WASH-1237, adjusted to update mass balances.

(c) Plutonium and higher transuranics produced in the HTGR fuel cycle are included in the high-level solid waste. 
TABLE 12. Accumulation of Long-Half-Life Waste, Millions of Curies(a)

\begin{tabular}{ccc} 
Year & $\begin{array}{c}\text { Without } \\
\text { Fusion }\end{array}$ & $\begin{array}{c}\text { With } \\
\text { Fusion }\end{array}$ \\
\cline { 2 - 3 } 2010 & 140 & 140 \\
2020 & 270 & 260 \\
2030 & 440 & 400 \\
2040 & 680 & 520
\end{tabular}

(a) Assumes all radioactivity due to longlived radionuclides (half-life $>20$ years) .

(b) Assumes that fusion does not create a significant quantity of long-lived radionuclides.

environment. A few representative values of elemental release rates from the entire fuel cycle are found in Table 13. Cumulated concentrations, in the air and on the ground, are found in a later portion of this section. Most of the emitted plutonium (in terms of curies) is $238 \mathrm{Pu}_{\text {, }}$ formed by transmutation of ${ }^{241} \mathrm{Pu}$ to ${ }^{242} \mathrm{Cm}$ and subsequent decay by alpha particle emission. Recycled plutonium in the equilibrium LWR fuel cycle assumed for "The Year 2000 Study". and previous cost/benefit studies has a much higher ${ }^{241}$ y content than that in the LMFBR cycle. In terms of whole-body dose, or dose to the lungs, ${ }^{241} \mathrm{Pu}$ is not a large contributor, despite the fact that about 30 times as much ${ }^{24} l_{\mathrm{Pu}}$ is released as ${ }^{238} \mathrm{Pu}$ in the LMFBR fuel cycle. However, ${ }^{241} \mathrm{Am}$, the decay product of $241_{\mathrm{Pu}}$, contributes substantially to the bone dose.

In contrast, the only routine releases from a fusion reactor are expected to be tritium and a very small amount of gaseous ${ }^{14} \mathrm{C}$. Neither of these is expected to concentrate at a specific location in the environment.

Activity Retained in Radioactive Waste Systems. Virtually all effluents from nuclear facilities are treated to remove contained radionuclides. The portion removed from the effiuent streams then remains in the radioactive waste treatment system until the material (such as resins) is removed for burial or other handing. Of particular interest to fission plants are the noble gases and to fusion is tritium, which may be delayed in charcoal beds, or dessicants, or bottled. Modern LWR plants using charcoal beds with "holdup times" of about 1 day for krypton and 15 days for xenon would release only a very small amount of radioactive noble gases, the rest having decayed to nonradioactive species. By the end of 50 days--typicai of a PWR--the inventory in the radioactive waste system would be down to about one ten-thousandth of the original amount, and about $80 \%$ is krypton. 
TABLE 13. Representative Release Rates of Radioactive Elements

(Release Rates in Curies per Gigawatt-Year)

\begin{tabular}{|c|c|c|c|c|c|}
\hline Gaseous Effluents & $\operatorname{LWR}-U^{(a)}$ & $L W R-P u^{(a)}$ & LMFBR & HTGR & Fusion \\
\hline Tritium & $28.1 \times 10^{3}$ & $37.0 \times 10^{3}$ & $1.35 \times 10^{3}$ & $36.8 \times 10^{3}$ & 1400 \\
\hline Krypton & $4.28 \times 10^{3}$ & $2.67 \times 10^{3}$ & $2.08 \times 10^{3}$ & $4.37 \times 10^{3}$ & 0 \\
\hline Xenon & 48.5 & 48.5 & negligible & negligible & 0 \\
\hline Strontium & $0.97 \times 10^{-3}$ & $0.61 \times 10^{-3}$ & $0.61 \times 10^{-3}$ & $0.98 \times 10^{-3}$ & 0 \\
\hline Iodine & $72.7 \times 10^{-3}$ & $72.7 \times 10^{-3}$ & $1.01 \times 10^{-3}$ & $4.51 \times 10^{-3}$ & 0 \\
\hline Cesium & $5.30 \times 10^{-3}$ & $5.06 \times 10^{-3}$ & $2.30 \times 10^{-3}$ & $6.00 \times 10^{-3}$ & 0 \\
\hline Plutonium (b) & $44.1 \times 10^{-6}$ & $266 \times 10^{-6}$ & $122 \times 10^{-6}$ & $64.7 \times 10^{-6}$ & 0 \\
\hline Transuranics $(c)$ & $89.6 \times 10^{-6}$ & $1965 \times 10^{-6}$ & $121 \times 10^{-6}$ & $6.7 \times 10^{-6}$ & 0 \\
\hline \multicolumn{6}{|l|}{ Liquid Effluents. } \\
\hline Tritium & 142 & 142 & 60 & 74 & 10 \\
\hline Strontium & $1.13 \times 10^{-3}$ & $1.13 \times 10^{-3}$ & 0 & $0.45 \times 10^{-3}$ & 0 \\
\hline lodine & $88.0 \times 10^{-3}$ & $88.0 \times 10^{-3}$ & 0 & 0 & 0 \\
\hline Cesium & $0.86 \times 10^{-3}$ & $0.85 \times 10^{-3}$ & 0 & $8.4 \times 10^{-3}$ & 0 \\
\hline Plutonium (b) & $14.5 \times 10^{-6}$ & $86.3 \times 10^{-6}$ & $39.7 \times 10^{-6}$ & $16.8 \times 10^{-6}$ & 0 \\
\hline \multirow[t]{2}{*}{ Transuranics (c) } & $9.5 \times 10^{-6}$ & $38.8 \times 10^{-6}$ & $42.5 \times 10^{-6}$ & $0.14 \times 10^{-6}$ & 0 \\
\hline & $33,000 \mathrm{Ci} / \mathrm{yr}$ & $40,000 \mathrm{Ci} / \mathrm{yr}$ & $3,490 \mathrm{Ci} / \mathrm{yr}$ & $41,000 \mathrm{Ci} / \mathrm{yr}$ & $1,410 \mathrm{Ci} / \mathrm{yr}$ \\
\hline
\end{tabular}

(a) LWR-U refers to an LWR that is refueled with uranium fuel re-enriched in 235U. LWR-PU refers to an LWR refueled with recycled plutonium. This latter type of fuel is expected to dominate the industry around the turn of the century. The "representative" LWR is taken from a population in which one-third of the reactors are BWRs and the remainder are PWRs.

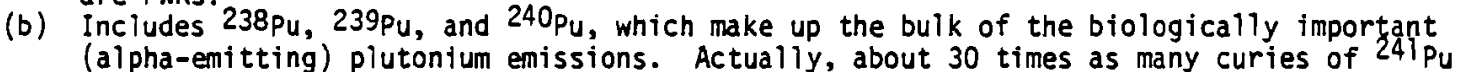
are emitted, but the biological effect of this emission in terms of whole-body or lung dose is less than a few percent of that of the plutonium listed. However, 241 Am, the decay product of $241 \mathrm{Pu}$, makes a substantial contribution to the bone dose (see WASH-1535. Appendix II.G).

(c) Includes $24 i_{\mathrm{Am}}, 242 \mathrm{~cm}$, and $244 \mathrm{~cm}$, the other major alpha-emitting radionuclides. 
Fission Products Delivered to Waste Storage. By far the greatest amount of fission products is separated from the fuel at the reprocessing plant, solidified, and delivered to a retrievable surface storage facility for interim storage prior to transfer to some ultimate waste repository. Most of the activity decays in the "cooling time" before the spent fuel is shipped to the reprocessing plant. For example, only about $2.4 \%$ of the original fission product radioactivity is still present when the fuel from an LWR is shipped to the reprocessor. After the first year, the radionuclide activity of the waste products decreases by some $25 \%$ each year. Considering the anticipated growth of the industry (about 11 to 12\%/year to 2000, and about 5\% thereafter) together with the decay, at any one time the total activity in accumulated high-level solid waste is about three times the amount produced that year. It is somewhat greater prior to 2000 and somewhat less thereafter. Thus, in the year 2000 , some $8.5 \times 10^{10}$ of high-level waste, occupying about $60,000 \mathrm{ft}^{3}$, is expected to be produced, and the total inventory from the entire nuclear power industry, including the LMFBR, is expected to be roughly $22 \times 10^{10} \mathrm{Ci}$. In the year 2020, some $21.4 \times 10^{10} \mathrm{Ci}\left(171,000 \mathrm{ft}^{3}\right)$ will be produced, and the inventory will amount to about $62 \times 10^{10} \mathrm{Ci}$ in $3 \mathrm{M} \mathrm{ft}^{3}$ of waste. The actual releases of radionuclides would be only about one ten-thousandth of the amount retained in the fuel after 1 year's decay or about onemillionth of that produced in the reactor. Since fusion reactors do not create fission products, they do not have this storage problem.

Other Radioactive Waste. Other types of radioactive waste are generated in the nuclear industry, including cladding hulls (metallic tubes from which the previously contained $\mathrm{UO}_{2}$ fuel has been removed) from the reprocessing plants and various types of low-level waste such as contaminated supplies and equipment. This low-level waste will be buried in large 55-gal drums in approved burial grounds. Recently, the EPA inventoried the contents of a solid waste repository in Kentucky (Clark, 1973). The specific activity of solid waste buried there in 1970 to 1972 (representative of power reactor operations) ranged from an average of less than $0.1 \mathrm{Ci} / \mathrm{ft}^{3}$ (for $2600,000 \mathrm{ft}^{3}$ ) to about $20 \mathrm{Ci} / \mathrm{ft}^{3}$ (for $1700 \mathrm{ft}^{3}$ ). Overal1, the specific activity of the buried material is $20.15 \mathrm{Ci} / \mathrm{ft}^{3}$. The cladding hulls (and other transuranic wastes) will be stored retrievably at a Federal repository.

Also, the uranium mine tailings produced at the mill are somewhat radioactive due to the residual uranium content and the uranium decay products, some of which have very long half-lives and one of which (radon) is gaseous. These materials are confined to the mill site. It is currently anticipated that tailings ponds from uranium milling activities will be restored to resemble the surrounding terrain when the $m i 11$ is decomissioned. Despite this reclamation, the land will most likely not be available for unrestricted use, except possibly for grazing. Present regulations prohibit release of tailings material to the surrounding area and restrict access to the taflings storage area. These regulations are binding on all owners of the land for 50 years from licensing of the mill site. 
In addition to the normal low-level waste, fusion reqctors may also have a storage problem for spent inner walls. Preliminary designd indicate that up to $140 \mathrm{~m}^{3}\left(5000 \mathrm{ft}^{3}\right)$ of this material may be generated per year. Because of the value of this material and the short half-lives for most of the radioisotopes, it probably will be placed in an onsite retrievable storage and be reused after an appropriate decay period.

Radiological Implications. Operation of nuclear plants results in radiation doses to the general population, the plant workers, and other nearby life forms. Substitution of fusion reactors for other nuclear facilities would change the release rates and types of radionuclides released and consequently the radiological effects on life forms. Because the final design of the fusion reactors is not known, the actual change cannot be predicted. However, general conclusions can be made on the basis of the current fusion reactor design concepts.

a. General Population Radiation Doses. Representative release rates of radioisotopes from power plants were presented in Table 13. Comparison of the types of radioisotopes shows that operation of fusion reactors probably would eliminate releases of essentially all radioisotopes other than tritium. This results from the fact that neither fission products or transuranics are used or created in fusion reactors. Hence, operation of fusion reactors eliminates concern about releases of these radioisotopes which generally do not occur naturaliy and probably will result in releases of mainly naturally occurring radioisotopes.

The radiation doses resulting from the releases of tritium and possibly ${ }^{14} \mathrm{C}$ at fusion reactors currently are estimated to above equal those estimated to result from operation of the LMFBR (Table 3). The release estimates in this analysis were based on current tritium control technology. Forty years of additional research and development could identify many methods for reducing the release rates.

A significant benefit from the change in the types of radioisotope releases is the elimination of the noble gas releases. This creates the possibility that general population doses can be essentially eliminated by siting fusion reactors on offshore islands or on seacoasts. Development of methods for releasing all of the tritium into seawater could essentialiy eliminate the radiation doses because of the large dilution effects and long trave 1 paths before the tritium would return to human activities. This advantage is not available for fission reactors because of the krypton and xenon releases.

b. Power Plont Worker Radiation Doses. In addition to the dose rate to the general population, the dose rate to people working in the nuclear industry must be considered. Typical exposures and annual doses for the various fuel cycle steps are given in Table 14. These data are similar to those in WASH-1224 but have been modified to account for updated mass balances. 
TABLE 14. Occupational Exposure to Radiation

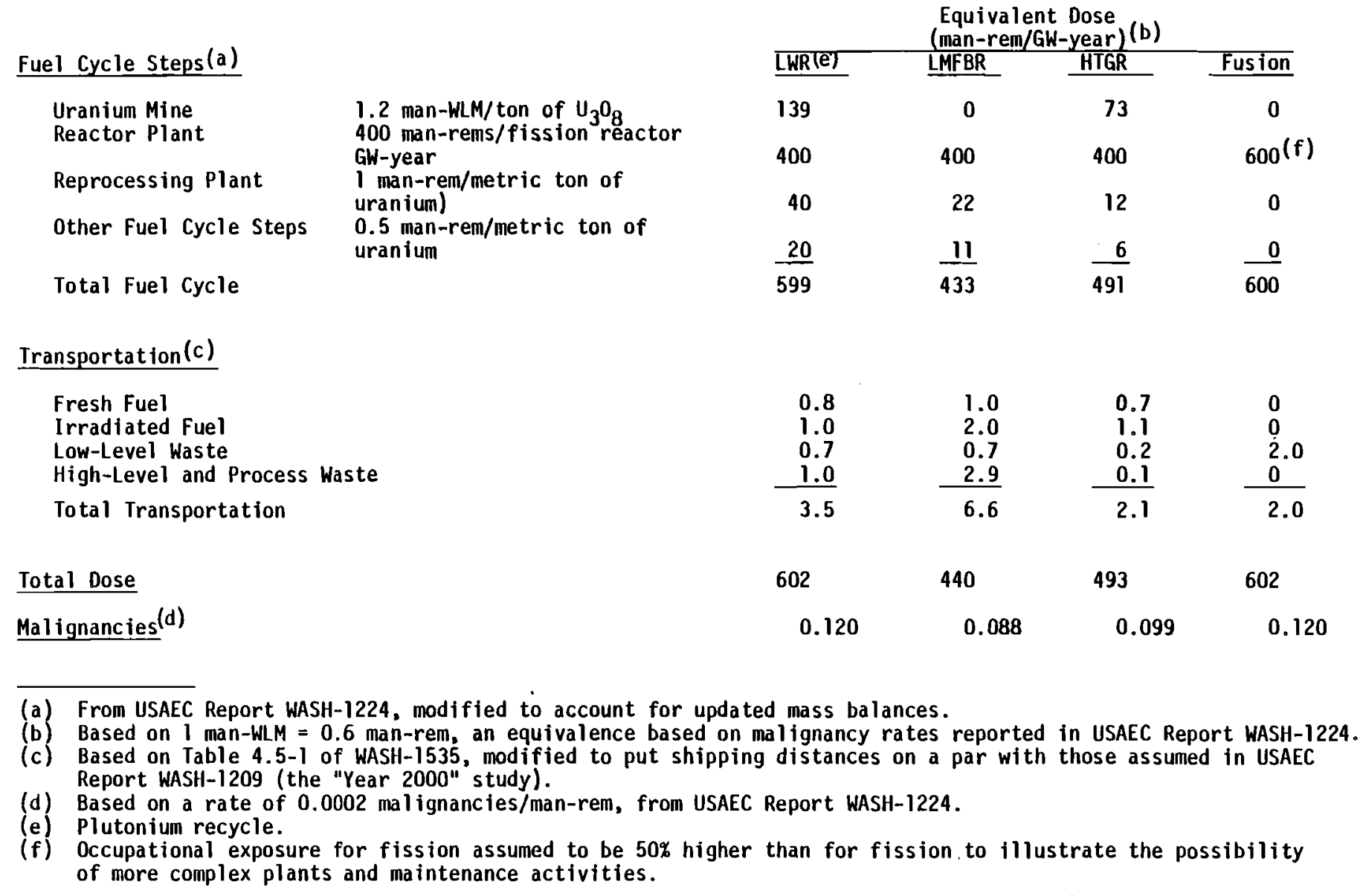


At each step in the nuclear fuel cycle, considerable precautions are taken to limit the exposure of industrial workers. For example, uranium miners are limited to 4 WLM (Working Level Months--170 hr exposure to air containing enough ${ }^{222} \mathrm{Rm}$ and daughter products to yield $1.3 \times 10^{5}$ $\mathrm{MeV} / \ell$ of alpha particle energy upon total decay) per year. The assessment of impact in this section has assumed that each miner receives this limiting exposure--an assumption that overestimates the impact. The biological effects of exposure such as miners receive have been determined by the U.S. Public Health Service in an extensive study of lung cancer in American uranium miners. In the other fuel cycle steps, exposure is limited to 5 rem per worker per year. The biological effect of the exposure that these workers receive is of the same order of magnitude as for the miners. These estimates of biological effect must be considered as only order of magnitude estimates rather than as statistically precise estimates because certain assumptions concerning the effects of long-term exposure to low-levels of radiation are involved. In very general terms, the assumptions lead to the same total radiation effect (number of cases of cancer, for example) being predicted for a group of $1 \mathrm{M}$ people each receiving $0.1 \mathrm{rem} / \mathrm{year}(100,000 \mathrm{man}-\mathrm{rems})$ as for a group of one hundred million people receiving 0.001 rem/year per person (again 100,000 man-rems). These assumptions of linearity of effect are involved for both occupational exposure and for dose to the general population.

WASH-1224 also indicates that one may expect an impact of 6000 man-days lost per malignancy and a malignancy rate of 0.0002 malignancies/man-rem. Data from Tables 3 and 14 are used later to assess the occupational and public health impacts.

Table 14 shows that the primary cause of radiation dose to the workers for fusion reactors would be that due to operation and maintenance of the power plant. Until the plant designs are known, and in particular, until the need to periodically replace the reactor inner wall is known, it is not possible to estimate the radiation dose. To illustrate the possible increase in dose, the total dose for a fusion reactor is assumed to be about $50 \%$ higher than for fission devices because of the larger worker force and the larger quantity of mobile radioisotopes. This very conservative assumption may well be excessive if tritium technology develops as expected or if the maintenance activities are reduced by improvements in remote handling technology or by simplification of fusion power plant designs.

\section{Plutonium Considerations}

Plutonium production and use data are derived from the cost/benefit calculations reported in the LMFBR Proposed Final Environmental Statement (WASH-1535). During most of the period before 2000, plutonium would be produced mainly in LWRs, and its production rate could limit growth of the LMFBR cycle. However, plutonium would probably be recycled and used in LWRs as well as in LMFBRs before the end of the century.

Plutonium is considered by many to present a special hazard because of $i$ ts high toxicity. There is no plutonium created or used in fusion reactions.

\section{Effects on Local Ecosystems and Land Use}

This compilation of environmental impacts does not detail the impacts to local ecosystems because so many aspects are site-specific in nature. In some sense, a measure of local impact is obtained from the land area disturbed. This section deals largely with land use. 
During construction of a plant, a certain amount of environmental damage is caused by construction of roads, by establishment of a lay-down area, and by construction activities in general. Frequently, the roads later become the normal access routes to the site, and the lay-down area is either included in the fenced-off portion of the site or restored, insofar as possible, to its original condition. For purposes of this tabulation, construction effects are not included separately but are included in the land use figures for the facility in question.

Three types of land usage are considered in this section. First, there is a base facility usage that represents the acreage required to site the facility in question. If it is a large facility serving several generating stations, the land usage is allocated to each station served. The second concept is that of annual usage, in which a given amount of land is used or disturbed for each unit of electrical energy produced. The land disturbed by strip mining is an example of this type of land usage. Finally, there is the concept of committed land, which represents land that has been disturbed and will not be returned to a natural state. For the nuclear fuel cycles, this concept represents the area required for the permanent storage of high-level waste, bottled noble gases, and transuranic waste (estimated to be $45 \mathrm{mile}^{2}$ in the year 2000, including surrounding exclusion zones); the area to be occupied by the reactor plants after decommissioning (assuming they are not all dismantled, as was successfully accomplished at Elk River); the area disturbed by uranium mining and storage of mining and milling waste; and land required for burial of low-level radioactive waste. For the fossil-fuel cycles, committed land is the land disturbed by subsidence only, because all other areas are assumed to be returned to a near-natural state, if necessary. This process includes complete reclamation of all lands strip mined for coal. Table 15 lists the land usage impacts per gigawatt for the various fuel-cycle steps in the major electrical energy generation process.

The land usage effects of decommissioning must also be considered. Plant sites are assumed to continue to be active through several generations of central station activities, and decommissioned plants may simply be absorbed in the land usage at such sites. Consequently, although entries are included in Table 15 for decommissioning, this commitment of land may not actually be required.

Water usage is a second way whereby the impact on ecosystems may be measured, but in quantities that are not site-specific. Unfortunately, much of the water usage impact is related to the site. For example, evaporation of water would be strongly dependent upon the cooling schemes used--once-through, cooling pond, or cooling tower. Also, water usage figures, particularly for process industries, do not generally convey the environmental impact, because the water may be reused many times. In general, process water use is only a small portion of the total water usage in the cycle and so is not considered in detail herein. Other water impacts include oil spills, acid mine drainage, and waste water from coal cleaning plants. 
TABLE 15. Land Use by Vartous Energy Conversion Schemes

\begin{tabular}{|c|c|c|c|c|c|c|c|}
\hline Base Facility (acres/GWe) & Coal & LWR & LMFBR & HTGR & Geothermal & Fusion & Solar \\
\hline $\begin{array}{l}\text { Mining } \\
\text { Milling--Processing } \\
\text { Converston, Enrichment } \\
\text { Fuel Manufacture } \\
\text { Power Plant } \\
\text { Reprocessing } \\
\text { Cooling Tower }\end{array}$ & $\begin{array}{c}0 \\
79(a) \\
0 \\
0 \\
800 \\
0 \\
70 \\
\end{array}$ & $\begin{array}{r}250 \\
50 \\
60 \\
12 \\
333 \\
12 \\
100 \\
\end{array}$ & $\begin{array}{r}0 \\
0 \\
0 \\
12 \\
333 \\
12 \\
67 \\
\end{array}$ & $\begin{array}{r}130 \\
25 \\
40 \\
12 \\
333 \\
12 \\
77 \\
\end{array}$ & $\begin{array}{r}0 \\
0 \\
0 \\
0 \\
6600 \\
0 \\
250 \\
\end{array}$ & $\begin{array}{r}0 \\
0 \\
0 \\
0 \\
333 \\
0 \\
0 \\
67 \\
\end{array}$ & $\begin{array}{r}0 \\
0 \\
0 \\
0 \\
6333 \\
0 \\
67 \\
\end{array}$ \\
\hline TOTAL & 949 & 817 & 424 & 629 & 6850 & 400 & 6400 \\
\hline
\end{tabular}

Land Usage (acres/GH-year)

Mining - Surface Mines

Milling--Processing

Conversion, Enrichment

Fuel Manufacture

Power Plant

Reprocessing

Was te Storage

Low Level Waste Storage

TOTAL

\begin{tabular}{|c|c|c|c|}
\hline $\begin{array}{r}960 \\
9 \\
0 \\
0 \\
8 \\
0 \\
0 \\
0 \\
\end{array}$ & $\begin{array}{l}12 \\
3 \\
0 \\
0 \\
0 \\
0 \\
0.006 \\
1.72 \\
\end{array}$ & $\begin{array}{l}0 \\
0 \\
0 \\
0 \\
0 \\
0 \\
0.006 \\
2.50 \\
\end{array}$ & $\begin{array}{l}6 \\
2 \\
0 \\
0 \\
0 \\
0 \\
0.006 \\
0.78 \\
\end{array}$ \\
\hline 977 & 17 & 2.5 & 8.8 \\
\hline
\end{tabular}

\begin{tabular}{ll}
0 & 0 \\
0 & 0 \\
0 & 0 \\
0 & 0 \\
0 & 0 \\
0 & 0 \\
0 & 0 \\
1.4 & 0 \\
\hline 1.4 & 0
\end{tabular}

(a) Includes base facilities for underground mining. 
For this analysis, water usage is computed as follows:

- The total condenser heat load is determined from data in Table 10.

- Additional once-through cooling is expected not to be used after 2000 . The water evaporation for supplemental cooling systems are $0.35 \mathrm{cfs}^{(a)}$ per trillion Btu for cooling ponds and $0.64 \mathrm{cfs}$ for cooling towers. The assumption is that about $20 \%$ of the plants would use cooling ponds and the rest would use wet towers (FPC, 1971).

The estimates of water evaporated by condenser cooling are probably larger than the consumptive water use that would actually occur. Some areas of the country would require the useof dry cooling towers because too little water is available for cooling tower or pond makeup requirements. A1so, these estimates cannot be used to determine total consumptive use of fresh water from precipitation run-off because some current and potential sites permit use of saline water.

\section{Nonradioactive Waste}

Nonradioactive waste occurs largely in the generation of electrical power by nonnuclear techniques. Emissions of sulfur dioxide, nitrogen oxides, carbon dioxide, and particulate matter ( $f l y$ ash) have all received considerable attention in recent years. A brief review of these and other emissions is given in Table 16. The emissions are not strictly cumulative, because they enter the environment and are removed from the air by precipitation. Consequently, only annual values will be cited for these airborne pollutants. Those potential pollutants that have been removed from the effluent stream and retained at the plant site do not actually contribute to the pollutant burden but occupy, at least temporarily, land at the site. Thus their impact is measured in terms of land use.

A11 power plants release some of these pollutants from heating boilers and emergency diesels. A wellknown fact is that some airborme pollutants (such as $\mathrm{SO}_{2}$ and $\mathrm{NO}_{x}$ ) can have somatic effects on man. Unfortunately, our knowledge of these effects is imprecise. Hence this assessment does not include further "tracting" of these pollutants into the biosphere. This generally causes underestimating, perhaps substantially, the environmental effects of fossil-fuel power generation.

\section{Transmission Lines and Corridors}

In very general terms, the environmental impact of transmission is independent of plant type. Nuclear plants will possibly be clustered into nuclear energy centers with an attendant increase in transmission requirements at any particular site. However, the increased acreage

(a) If a cooling pond is constructed specifically for power plant waste heat rejection, then the consumptive loss should be adjusted for normal losses and additions due to precipitation. 
TABLE 16. Selected Nonradioactive Waste Data

\begin{tabular}{|c|c|c|c|c|c|c|c|c|c|c|}
\hline & $\begin{array}{c}\text { Bituminous } \\
\text { Coal }\end{array}$ & $\begin{array}{c}\text { Subbituninous } \\
\text { Coal }\end{array}$ & Lignite & 011 & Gas & $\underline{\text { LWR }}$ & LMFBR & $\underline{\text { HTGR }}$ & Geothermal & Fusion \\
\hline 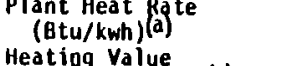 & 9,768 & IU,091 & 11.909 & 10,147 & 9,644 & 10,667 & 8,524 & 9,075 & $22,000^{(b)}$ & 8.524 \\
\hline$\left(10^{5} 8 \text { tus/unit }\right)^{(c)}$ & 26 & 19 & 13.4 & 6.3 & 1,045 & 69 & 69 & 69 & 1,014 & 202 \\
\hline $\begin{array}{l}\text { Consumption } \\
\quad \text { (units/GH-year) })^{(c)} \\
\text { Percentage Ash }\end{array}$ & $\begin{array}{r}3,300,000 \\
12.58\end{array}$ & $\begin{array}{r}5,030,000 \\
11.48\end{array}$ & $\begin{array}{r}7.785,000 \\
8.44\end{array}$ & $14,110,000$ & 80,800 & $1,350,000$ & $1,100,000$ & $1,150,000$ & 160,000 & $11,400,000$ \\
\hline $\begin{array}{l}\text { Bottom Ash } \\
\text { (tons/GW-year) } \\
\text { Fly Ash Renoved }\end{array}$ & 72.750 & 72,750 & 72,750 & - & - & - & - & - & - & - \\
\hline $\begin{array}{l}\text { (tons/GW-year) } \\
\text { Fly Ash Emitted }\end{array}$ & 410,200 & 571,200 & 650,500 & 1,867 & 570 & - & - & - & - & - \\
\hline $\begin{array}{l}\text { (tons/GN-year) } \\
\text { Percentage Sulfur }\end{array}$ & $\begin{array}{r}4.160 \\
2.59\end{array}$ & $\begin{array}{r}5.780 \\
0.56\end{array}$ & $\begin{array}{l}6.570 \\
0.76\end{array}$ & ${ }^{280} 1.69$ & - & 5.7 & 5.7 & 5.7 & $0.25^{(\mathrm{e}}$ & -5.7 \\
\hline $\begin{array}{l}\text { (tons/GN-year) } \\
\text { so? Emitted }\end{array}$ & 68,500 & 22.513 & 47,300 & 37,500 & - & - & - & - & 20,000 & - \\
\hline $\begin{array}{l}\text { (tons/GW-year) } \\
\text { other fmissions } \\
\text { (tons/GW-year) } \\
\text { Airborne }\end{array}$ & 17,100 & 5,600 & 11,800 & 9,370 & 24 & 34 & 34 & 34 & - & 34 \\
\hline 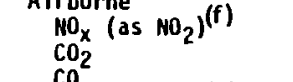 & $\begin{array}{r}36,000 \\
8,000,000\end{array}$ & $\begin{array}{r}36,000 \\
8,000,000\end{array}$ & $\begin{array}{r}36,000 \\
8,000,000\end{array}$ & $\begin{array}{r}27,200 \\
6,000,000\end{array}$ & $\begin{array}{r}15,800 \\
6.000,000\end{array}$ & $\begin{array}{r}76 \\
700\end{array}$ & $\begin{array}{r}76 \\
700\end{array}$ & $\begin{array}{r}76 \\
700\end{array}$ & 803,000 & $\begin{array}{r}76 \\
700 \\
-\end{array}$ \\
\hline rocarbons $(\mathbf{G})$ & 1 & $\begin{array}{l}1.330 \\
-\end{array}$ & $\begin{array}{l}1,330 \\
-\end{array}$ & $\begin{array}{r}10,000 \\
1,730 \\
250\end{array}$ & $\begin{array}{r}16 \\
1.467 \\
110\end{array}$ & $\begin{array}{l}1.3 \\
0.7\end{array}$ & $\begin{array}{l}1.3 \\
0.7\end{array}$ & $\begin{array}{l}1.3 \\
0.7\end{array}$ & $\overline{-}$ & $0 . i^{1.3}$ \\
\hline & - & - & - & - & 1 & - & - & - & - & - \\
\hline etals $(9)$ & 41,600 & - & - & - & - & - & 0.028 & - & 16,000 & - \\
\hline $\begin{array}{l}\text { Hydrogen Fluoride } \\
\text { Waterborne }\end{array}$ & - & - & - & - & - & 1.04 & 0.014 & 0.52 & - & - \\
\hline $\begin{array}{l}\text { Wateroorne } \\
\text { Chloride } \\
\text { Antmonium Hydroxide } \\
\text { Calcium Hydroxide } \\
\text { Iron (h) } \\
\text { Sulfuric Acid }(\mathrm{h})\end{array}$ & $\begin{array}{l}25.4 \\
-\quad \\
107\end{array}$ & -30.4 & -36.1 & $\begin{array}{l}26.5 \\
- \\
- \\
-\end{array}$ & $\begin{array}{l}-^{23} \\
- \\
-\end{array}$ & $\begin{array}{l}47.1 \\
27.5 \\
10.4 \\
.55\end{array}$ & $\begin{array}{r}23.4 \\
39.9\end{array}$ & $\begin{array}{l}32.9 \\
13.9 \\
10.2 \\
.28\end{array}$ & $\begin{array}{l}- \\
- \\
-\end{array}$ & $\begin{array}{l}20 \\
-\end{array}$ \\
\hline
\end{tabular}

a) Includes cooling tower and desulfurization penalties.

(c) Ubserved at The Geysers. of cubic feet of gas, millions of pounds of steam for geothermal, and grams of fuel material for nuclear.

(f) USAEC Report WASH-1224 used for coal values; FPC report in footnote $c$ for ofl and gas: JSAEC Report WASH-1224 data for coal correspond roughiy

Source: Federal Power Commission, "Steam-Electric Plant Air and Water Quality Control Data--Sunmary Report, "February 1973; Ifgnites assumed from North Dakota, subbituminous coal from
the mountain states. Computations follow USAEC Report HASH-1224. bottom firing.

(g) From USAEC Report WASH-1224

h) Fossil fuel contribution is primarily acid mine

(e) As $\mathrm{H}_{2} \mathrm{~S}$. 
will usually be small because under such circumstances, higher voltage lines can be used. The total land use for the power system would decrease with the use of nuclear energy centers. The FPC has estimated (FPC, 1971) that the 65,000 miles of transmission lines anticipated in 1970 would grow to 118,000 miles by 1980 and 159,000 miles by 1990 . These estimates remain unchanged for various mixes of central station fuel sources. Extrapolation of these data indicates that some 205,000 miles of transmission lines could be required by the year 2000 and 280,000 miles by the year 2020. Although less miles of transmission line may be needed for fusion power plants than for fission plants because fusion may be sited closer to load centers, it was conservatively assumed here that the length of transmission lines per unit of generating capacity would be the same regardless of the types of power plants built.

\section{Transportation Aspects}

Transportation of nuclear fuels and waste is expected to grow significantly as the nuclear industry expands. Even so, this growth will comprise only a very small part of all freight shipments. Table 17 shows the relative transportation requirements for coal and the nuclear fuel cycles. The transportation requirements of a coal-fired plant are large. Coal is frequently transported in unit trains consisting of perhaps 100 cars loaded with coal. A single 1000-MWe coal plant would require a train load of coal for each day's operation. The LMFBR, on the other hand, requires much less than a single such train load of fuel in an entire year. The total annual fuel for a fusion reactor can be transported on a single truck. Several rail cars might be needed for shipments of new inner liners.

\section{Health and Safety Considerations}

Occupational Safety. Occupational safety data are shown in Table 18 and summarized in Table 19. A fatality was assumed to be the equivalent of 6000 man-days lost. This estimate in no way measures the priceless value of human life but represents an average cost to the industrial community of the loss of that person's productivity. Clearly, this cost is less than the value of this life to society. In fact, the estimate cannot even include contributions made outside of working hours. The approach is, nevertheless, consistent and usefut in comparing various alternatives.

By far the largest risk is in the fuel mining step, and at least to the first order, the occupational injury and fatality rates are proportional to the amount of mining involved. For the fusion reactor and LMFBR essentially no mining is anticipated for the period this study covers. Current stockpiles of uranium hexafluoride tails from operation of the gaseous diffusion plants can provide the uranium feedstock for LMFBR fuel for many years to come. These stockpiles are the result of processing natural uranium to produce the slightly enriched (in $235_{U}$ ) uranium needed for LWRs. As use of enriched uranium continues, the stockpile of depleted uranium for use in the LMFBRs will grow. The primary fusion reactor fuel, deuterium, does not require mining.

Public Safety. A major interface between the electricity generation industry and the public is in the transportation of fuel materials to the generating station. This portion considers 
TABLE 17. Transportation Requirements for Various Fuel Cycles

Truck Shipments

Fuel Materials

$$
\begin{aligned}
& \mathrm{U}_{3} \mathrm{O}_{8} \\
& \mathrm{UF}_{6} \\
& \mathrm{UO}_{2} \\
& \mathrm{PuO}_{2}
\end{aligned}
$$

Fabricated Fuel

Total Fuel Materials

\begin{tabular}{|c|c|c|c|c|c|c|c|c|c|}
\hline Ship & ments & - Gigaw & $t$-year & & Ton & $\begin{array}{l}\text { Millio } \\
\text { iles p }\end{array}$ & Gigaw & t-year & \\
\hline Coal & LWR & LMFBR & HTGR & Fusion & Coal & LWR & LMFBR & HTGR & Fusion \\
\hline & 9.5 & 0 & 7.9 & 0 & & 0.144 & 0 & 0.120 & 0 \\
\hline & 39.4 & 2.51 & 19.5 & 0 & & 0.354 & 0.022 & 0.176 & 0 \\
\hline & 7.9 & 3.22 & 3.95 & 0 & & 0.025 & 0.010 & 0.012 & 0 \\
\hline & 1.1 & 3.64 & 0 . & 0 & & 0.001 & 0.005 & 0. & 0 \\
\hline & 52.2 & 25.1 & 13.8 & 1 & & $\underline{0.076}$ & 0.035 & $\underline{0.020}$ & $\underline{0.006}$ \\
\hline & 110.1 & 34.5 & 45.1 & 1 & & 0.600 & 0.073 & 0.328 & 0.006 \\
\hline & 81.2 & 76.1 & 17.0 & 55 & & 0.200 & 0.191 & 0.042 & 0.14 \\
\hline
\end{tabular}

Low-Level Waste and Bottled Gases

Rail Shipments

$\begin{array}{rlrllrllll}33,750 & 0 & 0 & 0 & 0 & 1,025 & 0 & 0 & 0 & 0 \\ 0 & 16.35 & 33.44 & 18.28 & 0 & 0 & 0.372 & 0.762 & 0.418 & 0 \\ & & & & & & & & & \\ 0 & 12.45 & 41.16 & 8 & 0 & 0 & 1.001 & 2.981 & 0.151 & 0 \\ 0 & 0.94 & 0.94 & 0.86 & 0 & 0 & 0.158 & 0.158 & 0.144 & 0 \\ 0 & 0 & 0 & 0 & 5 & 0 & 0 & 0 & 0 & 0.15\end{array}$

(a) A shipment consists of one truck or rall car which is equivalent to 100 tons of coal, 3 tons of irradiated LWR fuel and (111 tons of cask), or 0.7 tons of irradiated LMFBR or HTGR fuel.

(b) Average shipment distance for coal is 300 miles (WASH-1535, Bituminous Coal Facts--1970, National Coal Association, Washington, $D C, 1971)$. For nuclear fuel, the average shipment distance is dependent upon the growth patterns of the industry and is projected to be $200 \mathrm{miles}$ for irradiated fuel in the year 2000 and beyond. Construction of large reprocessing plants could increase the $200 \mathrm{miles}$ to perhaps as much as 500 miles. UF 6 is assumed to be shipped $600 \mathrm{miles}$, and the other fuel materials only 200 miles. Shipping distances for waste materials are as specified in Table 4.5-1 of WASH-1535. U $\mathrm{U}_{8}$ shipping distance is assumed to be $1000 \mathrm{miles}$ (WASH-1248). CTR fuel is assumed to be shipped 1000 miles; CTR inner walls are assumed to be shipped 500 miles. 
TABLE 18. Occupational Safety Aspects of Energy Conversion (a)

\begin{tabular}{|c|c|c|c|c|c|}
\hline Occupational Fatalities per GW-year & Coal & LWR & LMFBR & HTGR & Fuston \\
\hline $\begin{array}{l}\text { Mining and Milling } \\
\text { Enrichment } \\
\text { Fabrication } \\
\text { Reprocessing } \\
\text { Transportation } \\
\text { Plant Operation }\end{array}$ & $\begin{array}{l}1.31 \\
0 \\
0 \\
0 \\
0.073 \\
0.04\end{array}$ & $\begin{array}{l}0.124 \\
0.001 \\
0.0006 \\
0.0001 \\
0.003 \\
0.013(b)\end{array}$ & $\begin{array}{l}0 \\
0 \\
0.0003 \\
0.0001 \\
0.003 \\
0.013(b)\end{array}$ & $\begin{array}{l}0.0648 \\
0.0007 \\
0.0002 \\
0.0001 \\
0.0003 \\
0.013(\mathrm{~b})\end{array}$ & $\begin{array}{l}0 \\
0 \\
0 \\
0 \\
0.0005 \\
0.0195(b)\end{array}$ \\
\hline TOTAL & $\overline{1.42}$ & 0.1417 & 0.0164 & 0.0791 & 0.020 \\
\hline
\end{tabular}

Occupational Non-Fatal Injuries per GW-year

Mining and Milling
Enrichment
Fabrication
Reprocessing
Transportation
Plant Operation
$\quad$ TOTAL

TOTAL

Occupational Man-Days Lost per GW-year
Mining and Milling

Enrichment

Fabrication

Reprocessing

Transportation

Plant Operation

TOTAL

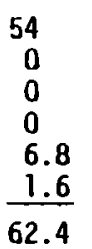

0

0

$\frac{1.6}{62.4}$

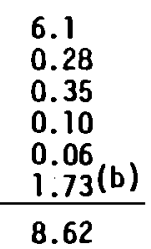

0.28

0.10

$1.73(\mathrm{~b})$

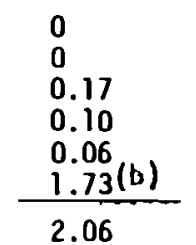

\begin{tabular}{l}
3.2 \\
0.18 \\
0.11 \\
0.06 \\
0.06 \\
$1.73(b)$ \\
\hline 5.34
\end{tabular}

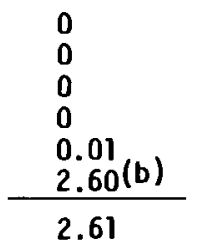

$\begin{array}{r}11,107 \\ 0 \\ 0 \\ 0 \\ 760 \\ 467 \\ \hline 12,334\end{array}$
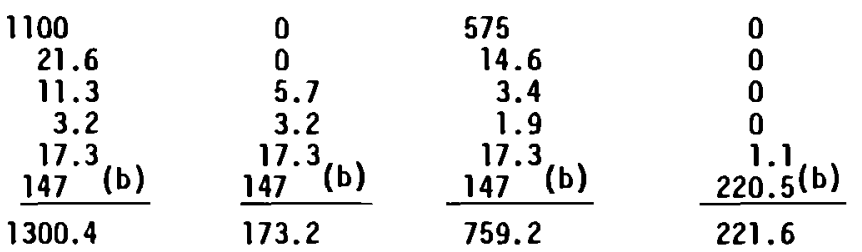

a) Data based on USAEC Report WASH-1224 madified to account for different mass balances.

(b) Higher effects for fusion result from arbitrary assumption at a $50 \%$ higher operating force and radiation doses than for fission to illustrate the possible effects of more complex power plant designs and maintenance activities. 
only that part of this interface associated with nonradiological accidents (radiological effects are discussed above in the section on radiological implications). Table 19 gives a measure of the public safety impact of fuel transportation for the various energy conversion techniques. Coal, with its very large transportation requirement, poses a significantly greater nonradiological hazard to the public with regard to transportation than do the nuclear fuel cycles. Addition of impacts due to fuel transportation in the nuclear fuel cycle do not appreciably change the results. For example, the fusion reactor requires less than one-tenth of one percent the accident exposure (number of ton-miles) the coal-fired plant does. On this basis, fusion reactor fuel transportation also involves about one-thousandth the (nonradiological) public safety impact of coal transportation for a similar plant.

Occupational Health. Radiological aspects of occupational health are included above in the discussion in the section on radiological implications. The numerical data are summarized in Table 19. Data relating to coal workers' pneumoconiosis (CWP or "black lung") have been extracted from WASH-1224.

Public Health. Public health effects of radiological emissions were discussed in the section on radiological implications and are summarized in Table 19. Somatic effects of nonradioactive (fossil fuel) pollutants have not been included for two major reasons. First of all, the effects are not well known quantitatively, al though qualitative evidence of these effects is found in the many situations where atmospheric temperature inversions have trapped such pollutants in confined valleys for extended periods of time. Secondly, the assumption made in this section is that all nonradiological emission produce no effect if they are within state or Federal standards, even though data may exist to refute this position. This assumption has the general effect of understating the environmental impact of fossil-fueled power plants. 
TABLE 19. Health and Safety Aspects of Electrical Energy Generation, per GW/year in Year 2040

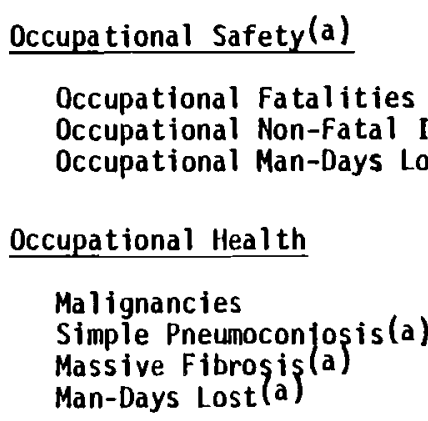

Public Safety $($ a)

Transportation Fatalities Non-Fatal Injuries

Man-Days Lost

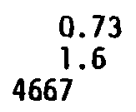

NA
NA

Public Health

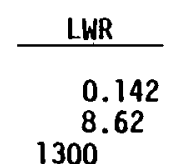

1300

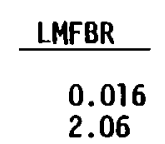

173
Fusion

0.024

2.7

260

$\begin{array}{llccc}\text { NA }(c) & 0.120 & 0.088 & 0.099 & 0.120 \\ 0.8 & \text { NA } & \text { NA } & \text { NA } & \text { NA } \\ 0.008 & \text { NA } & \text { NA } & \text { NA } & \text { NA } \\ 848 & 720 & 528 & 594 & 720\end{array}$

$\begin{array}{cccccc}\text { Malignancies }(b) & \text { NA } & 0.00568 & 0.00024 & 0.00618 & 0.000048 \\ \text { Man-Days Lost } & \text { NA } & 0.03408 & 0.00144 & 0.03708 & 0.000288\end{array}$

(a) From USAEC Report WASH-1224 for fission plants, modified to reflect updaied mass balances.

(b) Based on regional studies of the Tennessee Valiey Region and the Upper Mississippi River Basin. to be published.

(c) Not Applicable. 


\section{Demographic Effects}

The current approach in siting nuclear power plants is to locate them some distance from population centers. A number of incentives exist for siting several nuclear plants and associated facilities together at one site. Such an arrangement could reduce fuel shipping and nuclear safeguards requirements while minimizing overall land use. A reasonable expectation is that such clustering could cause some population shifts away from urban areas as communities nearer the cluster site grow to accomodate the influx of workers seeking housing near their work location. Overall, such demographic shifts are expected to be small because of the relatively small number of workers at an operating power plant.

Overall Impact of the Year 2040

The overall cumulative environmental impact to the year 2040 can be represented by the aggregate of parameters discussed above. Table 20 gives a summary tabulation of this information for the fossil economy. Tables 21 and 22 provide similar tabulations for the cases with fission plants and fusion reactors. The impact of the fusion Program in this time span is determined by the difference in impacts between the anticipated case where the fusion reactor enters the market and competes effectively with the other generation techniques and the cases where the fusion reactor is excluded. Table 23 shows the difference that was obtained by subtracting the entries in Tables 21 and 22 . These results support several of the arguments favoring the introduction of fusion reactors and the continuation of the program for their development. 
TABLE 20. Summary of Environmental Impact Without Nuclear Plants (The Fossil Economy) (Cumulative 2010 to 2039 Except Where Indicated)

\begin{tabular}{|c|c|c|c|c|c|}
\hline & Fossil & Hydroelectric & Solar & Geotherma l & Total \\
\hline $\begin{array}{l}\text { Energy Production, Year } 2040 \\
\text { Capacity Operating (GW) } \\
\text { Annual Generation (GW-year) } \\
\text { Cumulative Generation (GW-year) }\end{array}$ & $\begin{array}{r}4714 \\
2471 \\
47,780\end{array}$ & $\begin{array}{r}165 \\
55 \\
1650\end{array}$ & $\begin{array}{r}507 \\
152 \\
2940\end{array}$ & $\begin{array}{r}507 \\
482 \\
9320\end{array}$ & $\begin{array}{r}5893 \\
3160 \\
61,690\end{array}$ \\
\hline $\begin{array}{l}\text { Heat Rejection in the Year } 2040 \\
\text { To Air (1015 BTU) } \\
\text { To Hater (1015 BTU) }\end{array}$ & $\begin{array}{r}108.0 \\
36.0\end{array}$ & $\begin{array}{l}0 \\
0\end{array}$ & $\begin{array}{l}5.0 \\
1.7\end{array}$ & $\begin{array}{r}58.9 \\
9.6\end{array}$ & $\begin{array}{r}172 \\
57\end{array}$ \\
\hline $\begin{array}{l}\text { Radionuclides Released in the Year } 2040 \\
\text { To Air } \\
\text { Tritium (megacuries) } \\
\text { Krypton (megacuries) } \\
\text { Xenon (megacuries) } \\
\text { Iodine (curies) } \\
\text { Strontium (curies) } \\
\text { Cesium (curies) } \\
\text { Plutonium (millicuries) } \\
\text { Transuranics (millicuries) }\end{array}$ & 0 & 0 & 0 & 0 & 0 \\
\hline $\begin{array}{l}\text { To Water } \\
\text { Tritium (megacuries) } \\
\text { Iodine (curies) } \\
\text { Strontium (curies) } \\
\text { Cesium (curies) } \\
\text { Plutonium (millicuries) } \\
\text { Transuranics (millicuries) }\end{array}$ & 0 & 0 & 0 & 0 & 0 \\
\hline $\begin{array}{l}\text { Other Radioactive Waste } \\
\left.\text { Cladding Hulls (Million } \mathrm{ft}^{3}\right) \\
\text { Pu-Contaminated (Million } \mathrm{ft}^{3} \text { ) } \\
\text { Low-Level Solid (Million } \mathrm{ft}^{3} \text { ) } \\
\text { High-Level Solid (Million } \mathrm{ft}^{3} \text { ) }\end{array}$ & 0 & 0 & 0 & 0 & 0 \\
\hline
\end{tabular}




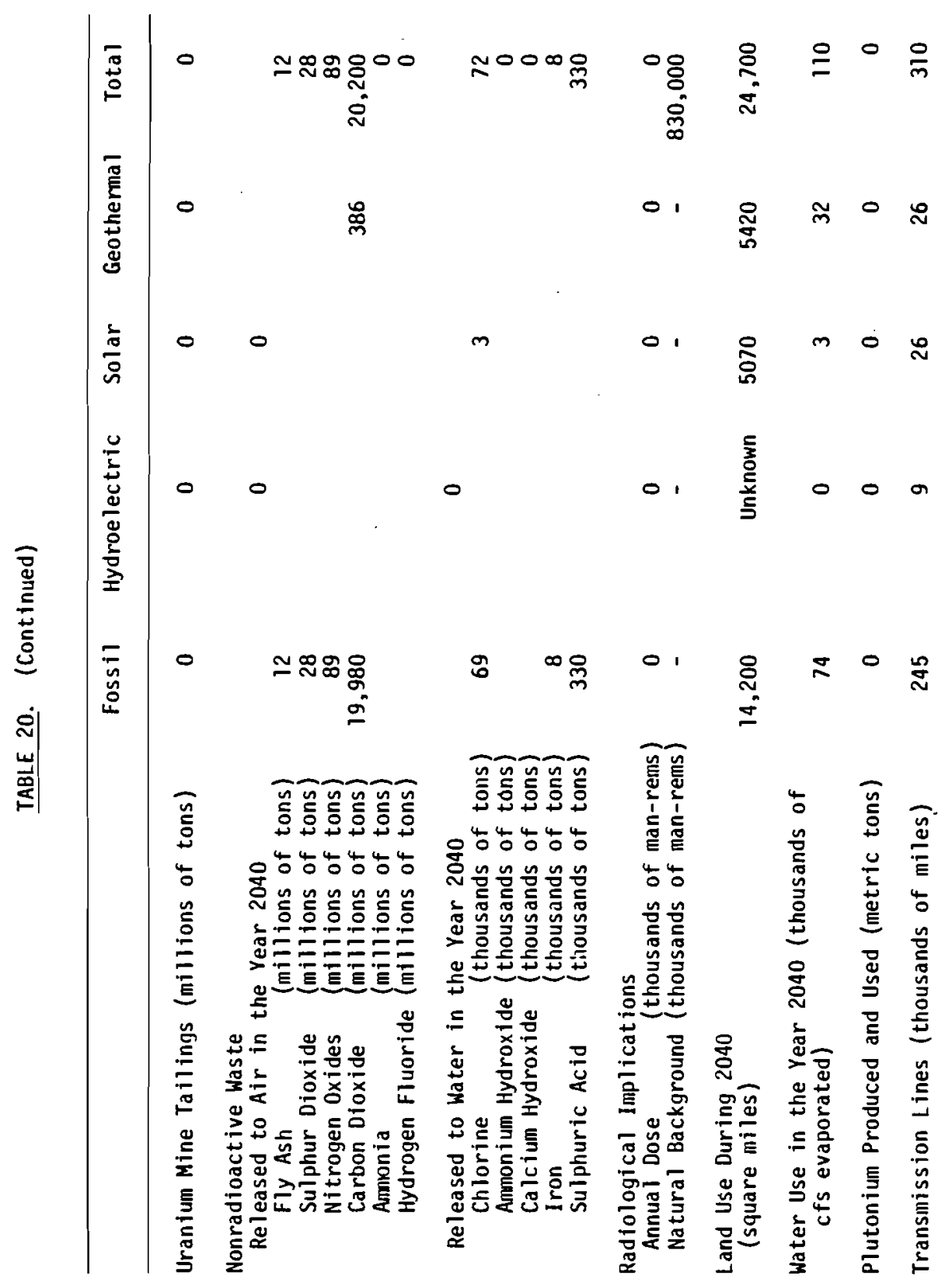


TABLE 20. (Continued)

\begin{tabular}{|c|c|c|c|c|c|}
\hline & Fossil & Hydroelectric & Solar & Geothermal & Total \\
\hline $\begin{array}{l}\text { Transportation } \\
\text { Truck Shipments in the Year } 2040 \\
\text { Fuel Materials (thousands) } \\
\text { Low-Level Waste (thousands) } \\
\text { Ton-Miles (billions) }\end{array}$ & 0 & $\mathbf{0}$ & $\mathbf{0}$ & 0 & 0 \\
\hline $\begin{array}{l}\text { Rail Shipments in the Year } 2040 \\
\text { Fossil Fuel (thousands) } \\
\text { Spent Fuel (thousands) } \\
\text { Process Waste (thousands) } \\
\text { High-Level Waste (thousands) } \\
\text { Ton-Miles (billions) }\end{array}$ & $\begin{array}{r}84,300 \\
2,500\end{array}$ & $\mathbf{0}$ & $\mathbf{0}$ & 0 & $\begin{array}{r}84,300 \\
0 \\
0 \\
0 \\
2,500\end{array}$ \\
\hline $\begin{array}{ll}\text { Occupational Health } & \\
\text { Malignancies } & \text { (thousands) } \\
\text { Simple Pneumoconiosis } & \text { (thousands) } \\
\text { Massive Fibrosis } & \text { (thousands) } \\
\text { Man-Days Lost } & \text { (millions) }\end{array}$ & $\begin{array}{l}0 \\
38 \\
0.4 \\
40\end{array}$ & $\mathbf{0}$ & 0 & 0 & $\begin{array}{c}0 \\
38 \\
0.4 \\
40\end{array}$ \\
\hline $\begin{array}{ll}\text { Occupational Safety } & \\
\text { Fatalities } & \text { (thousands) } \\
\text { Non-Fatal Injuries } & \text { (thousands) } \\
\text { Man-Days Lost } & \text { (millions) }\end{array}$ & $\begin{array}{r}68 \\
2980 \\
589\end{array}$ & $\begin{array}{l}0.04 \\
5.0 \\
0.4\end{array}$ & $\begin{array}{l}0.07 \\
8.8 \\
0.8\end{array}$ & $\begin{array}{c}0.22 \\
28 \\
2.4\end{array}$ & $\begin{array}{r}68 \\
3020 \\
59\end{array}$ \\
\hline $\begin{array}{l}\text { Public Health } \\
\text { Mal Ignancies } \\
\text { Man-Days Lost (thousands) }\end{array}$ & & & & & $\begin{array}{l}0 \\
0\end{array}$ \\
\hline $\begin{array}{ll}\text { Public Safety } & \\
\text { Fatalities } & \text { (thousands) } \\
\text { Non-Fatal Injuries } & \text { (thousands) } \\
\text { Man-Days Lost } & \text { (millions) }\end{array}$ & $\begin{array}{r}35 \\
76 \\
223\end{array}$ & & & & $\begin{array}{r}35 \\
76 \\
223\end{array}$ \\
\hline $\begin{array}{l}\text { Resources Used } \\
\mathrm{U}_{3} \mathrm{O}_{8}(\mathrm{millions} \text { of tons) } \\
\mathrm{Th} 0_{2} \text { (millions of tons) } \\
\text { Coal (billions of tons) } \\
\mathrm{D}_{2}\end{array}$ & 190 & & & & $\begin{array}{r}0 \\
0 \\
190 \\
0\end{array}$ \\
\hline
\end{tabular}


TABLE 21. Summary of Environmental Impact With Fusion Reactor Not Present (The Fission Economy) (Cumulative 2010 to 2040 except where indicated)

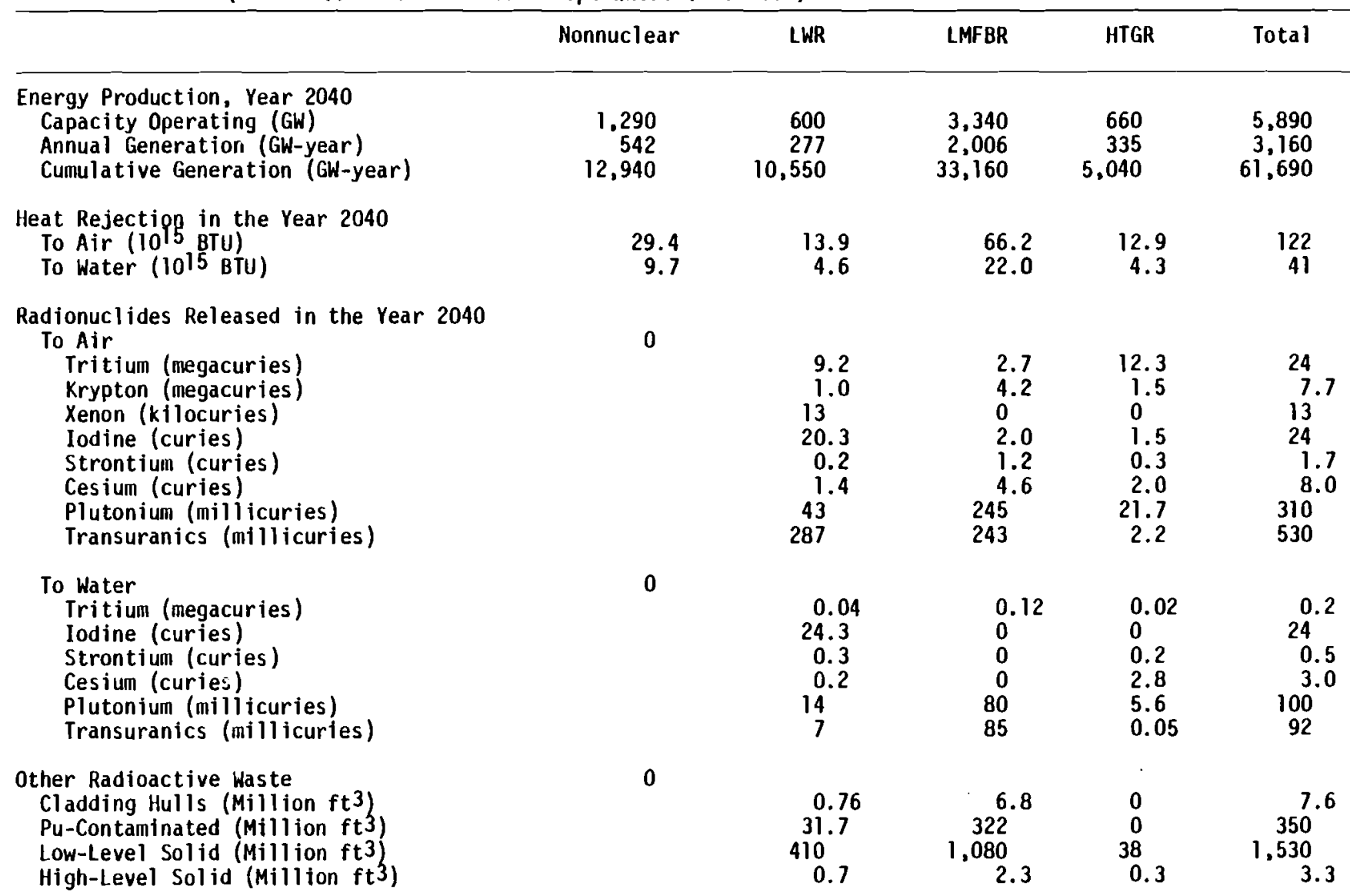


TABLE 21 (continued)

\begin{tabular}{|c|c|c|c|c|c|}
\hline & Nonnuclear & LWR & LMFBR & HTGR & Total \\
\hline Uranium Mine Tailings (millions of tons) & $\mathbf{0}$ & 1,110 & 0 & 274 & 1,380 \\
\hline $\begin{array}{l}\text { Monradioactive Waste } \\
\text { Released to Air in the Year } 2040 \\
\text { Fly Ash } \\
\text { Sulphur Dioxide (millions of tons) } \\
\text { Nitrogen Oxides (millions of tons) } \\
\text { Carbon Dioxide } \quad \text { (millions of tons) } \\
\text { Ammonia } \\
\text { Hydrogen Fluoride (thousands of tons) }\end{array}$ & $\begin{array}{r}2.0 \\
4.8 \\
15.0 \\
3,400 \\
0 \\
0\end{array}$ & $\begin{array}{l}0 \\
0.01 \\
0.02 \\
0.2 \\
0 \\
0.3\end{array}$ & $\begin{array}{l}0 \\
0.07 \\
0.15 \\
1.4 \\
0.06 \\
0.03\end{array}$ & $\begin{array}{l}0 \\
0.01 \\
0.03 \\
0.2 \\
0 \\
0.2\end{array}$ & $\begin{array}{r}2.0 \\
4.9 \\
15 \\
3,400 \\
0.06 \\
0.53\end{array}$ \\
\hline $\begin{array}{l}\text { Released to Water in the Year } 2040 \\
\text { Chlorine Hydroxide (thousands of tons) } \\
\text { Ammonium Hyands of tons) } \\
\text { Calcium Hydroxide (thousands of tons) } \\
\text { Iron } \\
\text { Sulphuric Acid (thousands of tons) }\end{array}$ & $\begin{array}{l}11.8 \\
0 \\
0 \\
1.4 \\
56.8\end{array}$ & $\begin{array}{l}13.0 \\
7.6 \\
2.9 \\
0.2 \\
0.8\end{array}$ & $\begin{array}{l}46.9 \\
80 \\
48.1 \\
0 \\
0.16\end{array}$ & $\begin{array}{l}11.0 \\
4.6 \\
3.4 \\
0.09 \\
1.3\end{array}$ & $\begin{array}{l}83 \\
92 \\
54 \\
1.7 \\
60\end{array}$ \\
\hline $\begin{array}{l}\text { Radiological Implications (General Public in } \\
\text { Annual Dose (thousands of man-rems) } \\
\text { Natural Background(thousands of man-rems) }\end{array}$ & 2040) 0 & $\begin{array}{l}9.0 \\
-\end{array}$ & $\begin{array}{c}10.4 \\
-\end{array}$ & $\begin{array}{c}10.7 \\
-\end{array}$ & 830,000 \\
\hline Land Use during 2040 (square miles) & 3,890 & 788 & 2,226 & 660 & 7,590 \\
\hline $\begin{array}{l}\text { Water Use in the Year } 2040 \text { (thousands of } \\
\text { cfs evaporated) }\end{array}$ & 19 & 8 & 45 & 8 & 80 \\
\hline Plutonium Discharged (metric tons) & 0 & 5,580 & 79,580 & 0.2 & 85,200 \\
\hline Transmission Lines (thousands of miles) & 66 & 32 & 174 & 34 & 310 \\
\hline
\end{tabular}




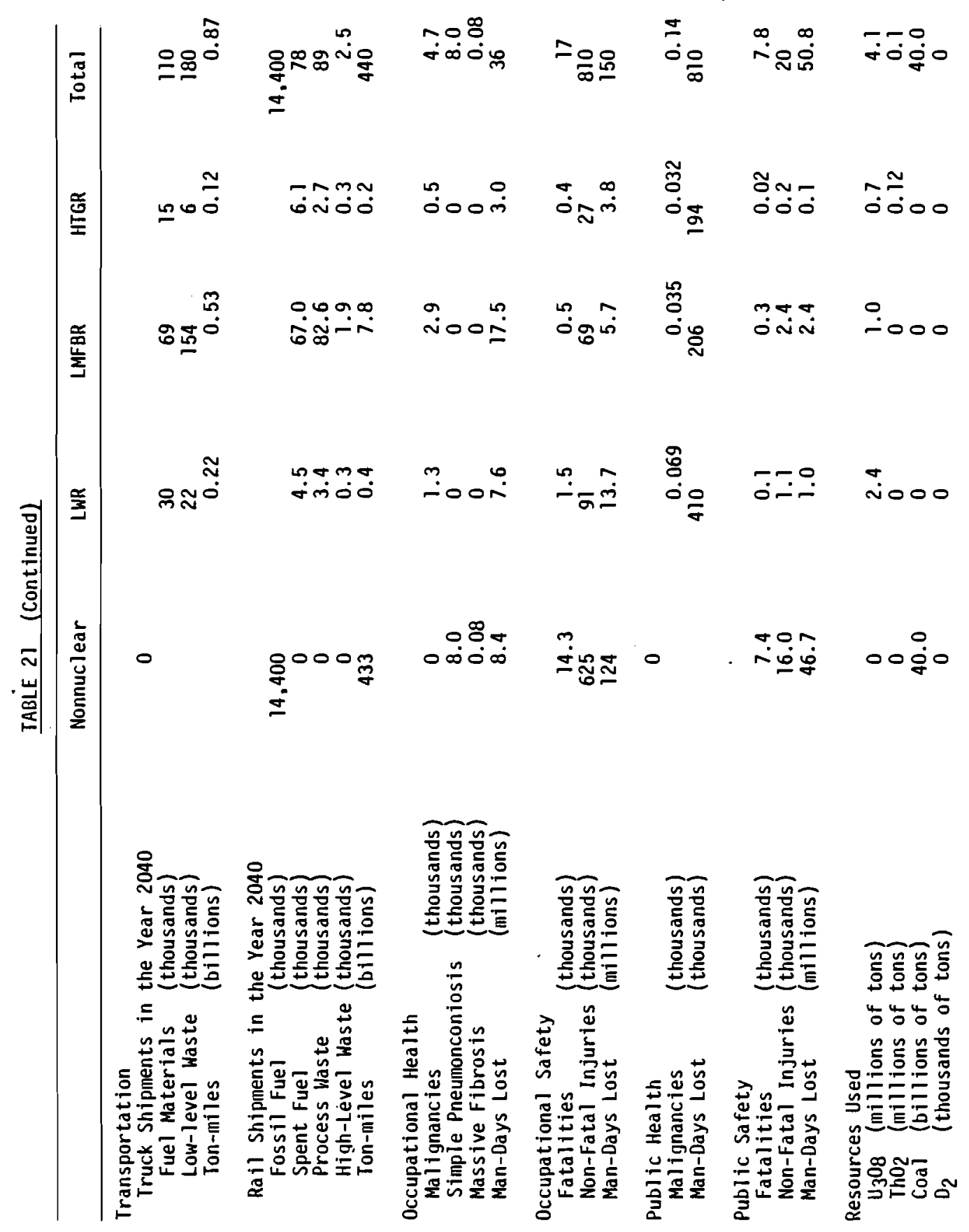




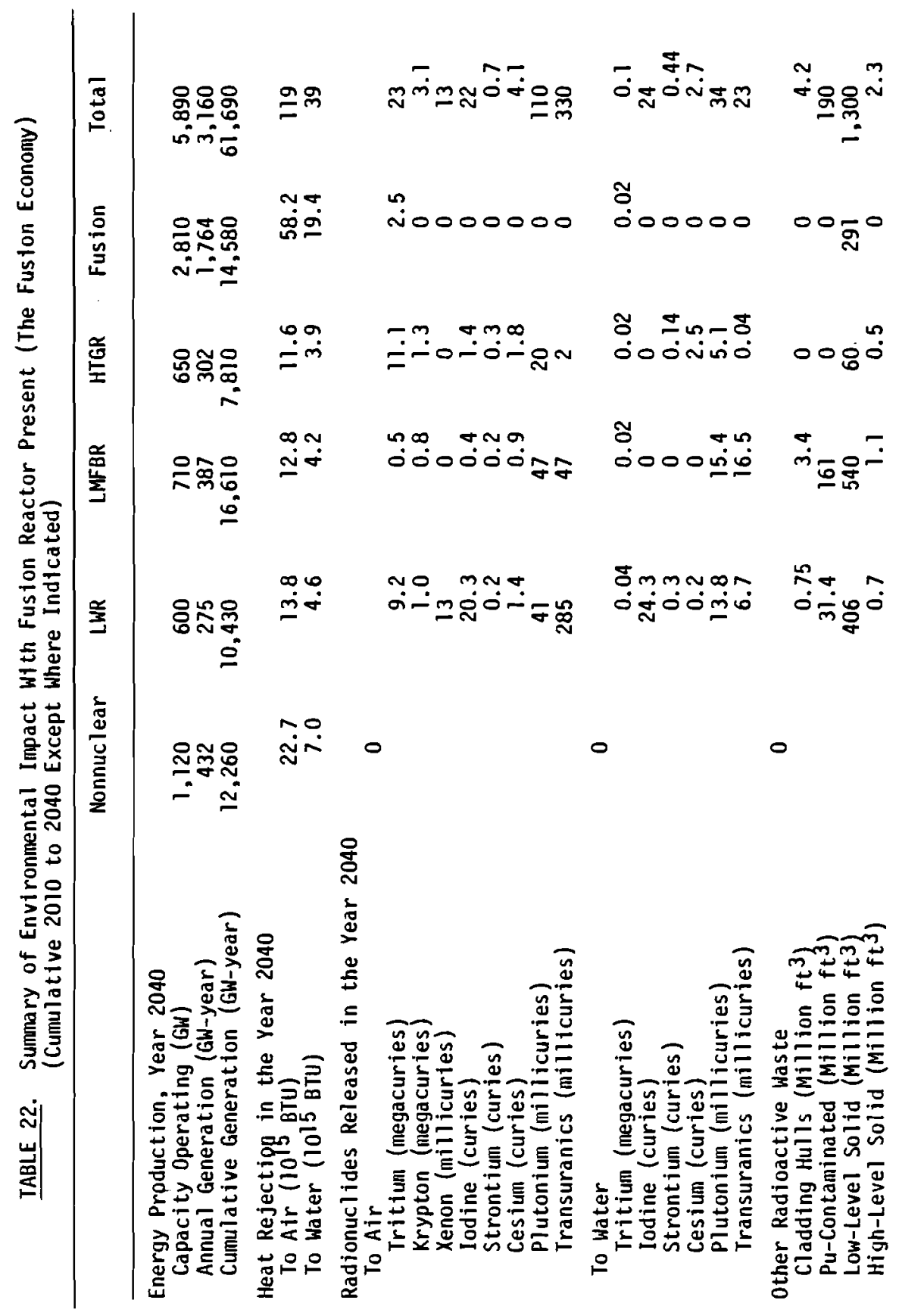




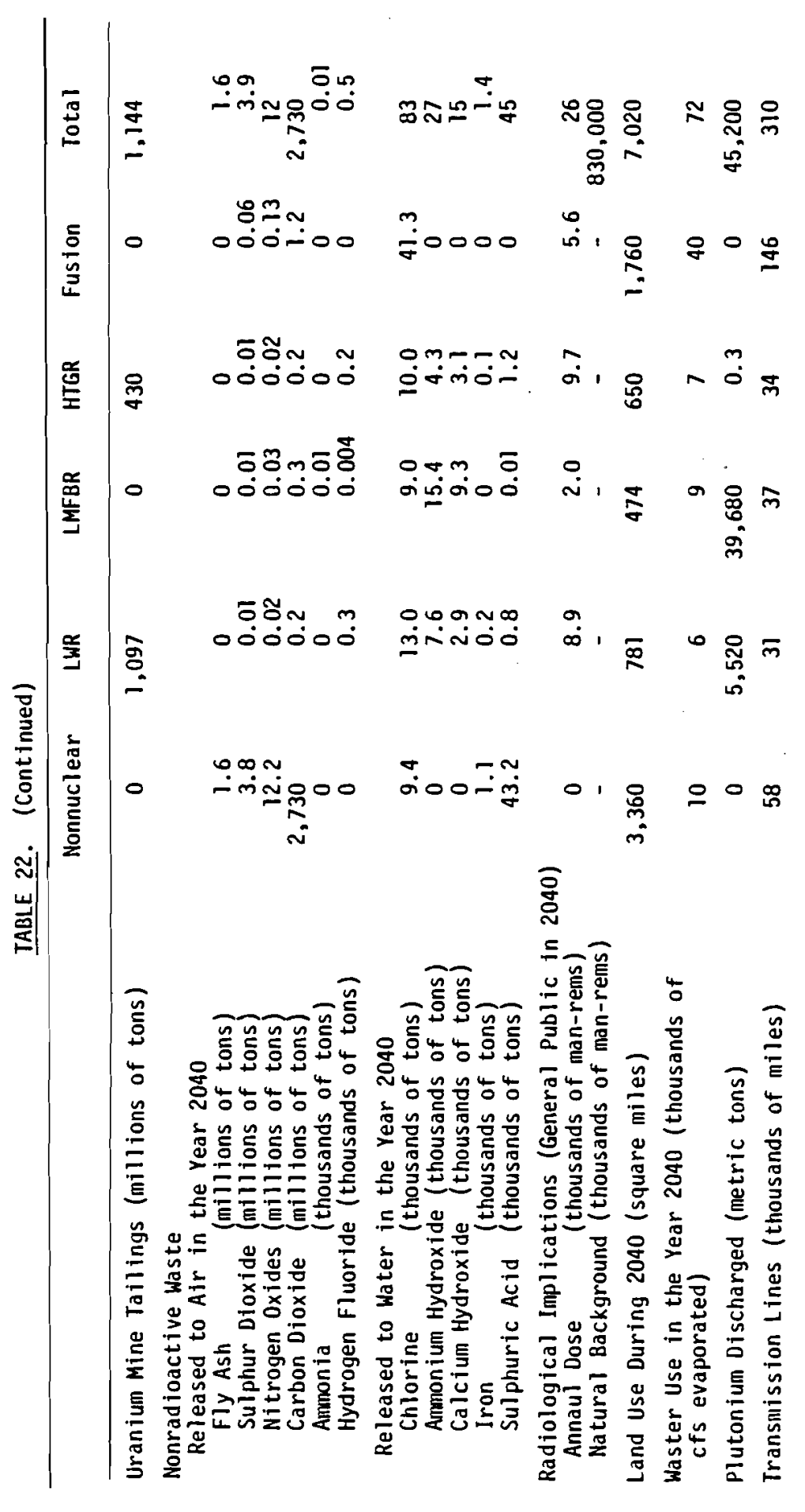




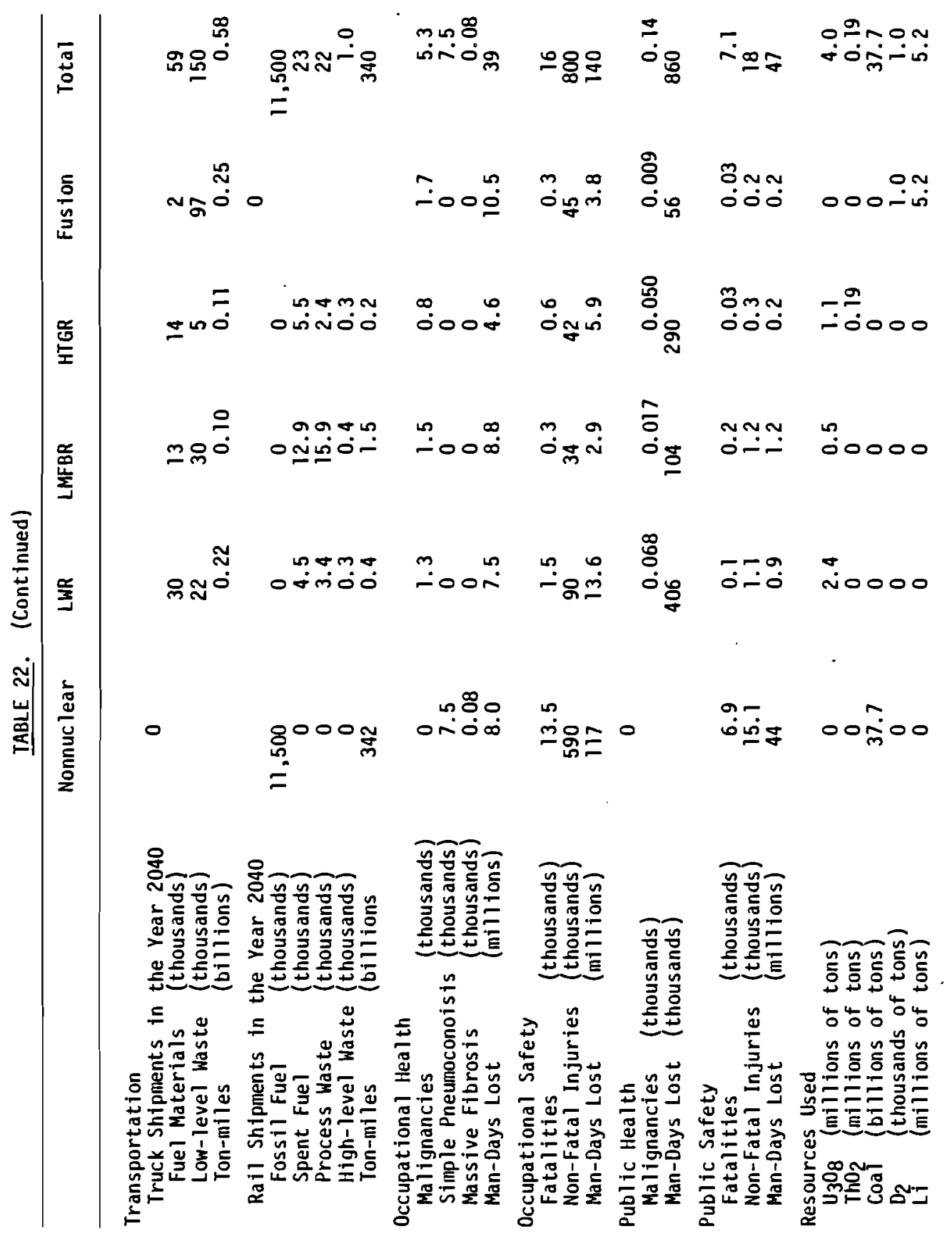


TABLE 23. Summary of Environmental Impact of Fusion Reactor Prograin through the Year 2040

\begin{tabular}{|c|c|c|c|c|c|}
\hline & $\begin{array}{l}\text { Fossil } \\
\text { Economy }\end{array}$ & $\begin{array}{l}\text { Fission } \\
\text { Economy }\end{array}$ & $\begin{array}{l}\text { Fusion } \\
\text { Economy }\end{array}$ & $\frac{\text { Fusion vs. }}{\text { Increase }}$ & $\frac{\text { Fission }}{\text { Decrease }}$ \\
\hline $\begin{array}{l}\text { Energy Production, Year } 2040 \\
\text { Capacity Operating (GW) } \\
\text { Annual Generation (GW-year) } \\
\text { Cumulative Generation (GW-year) }\end{array}$ & $\begin{array}{r}5,890 \\
3,160 \\
61,690\end{array}$ & $\begin{array}{r}5,890 \\
3,160 \\
61,690\end{array}$ & $\begin{array}{r}5,890 \\
3,160 \\
61,690\end{array}$ & & \\
\hline $\begin{array}{l}\text { Heat Rejection in theYear } 2040 \\
\text { To Air (1015 BTU) } \\
\text { To Water (1015 BTU) }\end{array}$ & $\begin{array}{r}172 \\
57\end{array}$ & $\begin{array}{r}122 \\
41\end{array}$ & $\begin{array}{r}119 \\
39\end{array}$ & & $\begin{array}{l}3 \\
2\end{array}$ \\
\hline $\begin{array}{l}\text { Radionuclides Released in the Year } 2040 \\
\text { To Air } \\
\text { Tritium (megacuries) } \\
\text { Krypton (megacuries) } \\
\text { Xenon (kilocuries) } \\
\text { lodine (curies) } \\
\text { Strontium (curies) } \\
\text { Cesium (curies) } \\
\text { Plutonium (milicuries) } \\
\text { Transuranics (millicuries) }\end{array}$ & 0 & $\begin{array}{r}24 \\
8 \\
13 \\
24 \\
1.7 \\
8.0 \\
310 \\
530\end{array}$ & $\begin{array}{c}23 \\
3 \\
13 \\
22 \\
0.7 \\
4.1 \\
110 \\
330\end{array}$ & & $\begin{array}{l}1 \\
5 \\
2 \\
1.0 \\
3.9 \\
200 \\
200\end{array}$ \\
\hline $\begin{array}{l}\text { To Water } \\
\text { Tritium (megacuries) } \\
\text { Iodine (curies) } \\
\text { Strontium (curies) } \\
\text { Cesium (curies) } \\
\text { Plutonium (millicuries) } \\
\text { Transurancis (millicuries) }\end{array}$ & 0 & $\begin{array}{c}0.2 \\
24 \\
0.5 \\
3.0 \\
100 \\
92\end{array}$ & $\begin{array}{c}0.1 \\
24 \\
0.4 \\
2.7 \\
34 \\
23\end{array}$ & & $\begin{array}{c}0.1 \\
\\
0.1 \\
0.3 \\
66 \\
69\end{array}$ \\
\hline $\begin{array}{l}\text { Other Radioactive Waste } \\
\text { Cladding Hulls (Million } \mathrm{ft}^{3} \text { ) } \\
\text { Pu-Contaminated (Million } \mathrm{ft}^{3} \text { ) } \\
\left.\text { Low-Level Solid (Million } \mathrm{ft}^{3}\right) \\
\text { High-Level Sol id (Million } \mathrm{ft}^{3} \text { ) }\end{array}$ & 0 & $\begin{array}{r}8 \\
350 \\
1,530 \\
3.3\end{array}$ & $\begin{array}{r}4 \\
190 \\
1,300 \\
2.3\end{array}$ & & $\begin{array}{r}4 \\
160 \\
230 \\
1.0\end{array}$ \\
\hline
\end{tabular}


TABLE 23. (Continued)

\begin{tabular}{|c|c|c|c|c|}
\hline & $\begin{array}{l}\text { Fossil } \\
\text { Economy }\end{array}$ & $\begin{array}{l}\text { Fission } \\
\text { Economy }\end{array}$ & $\begin{array}{l}\text { Fusion } \\
\text { Economy }\end{array}$ & $\frac{\text { Fuston vs. Fission }}{\text { Increase Decrease }}$ \\
\hline Uranium Mine Tailings (millions of tons) & 0 & 1,380 & 1,140 & 240 \\
\hline 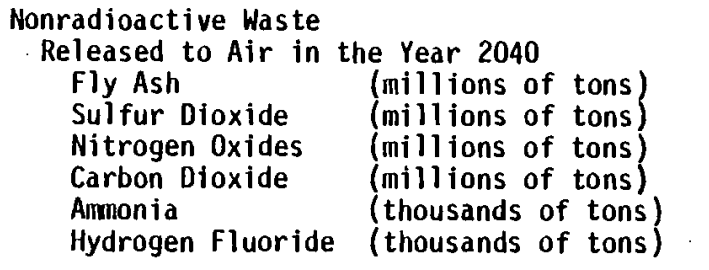 & $\begin{array}{r}12 \\
28 \\
89 \\
20,200 \\
0 \\
0\end{array}$ & $\begin{array}{l}2 \\
4.9 \\
15 \\
3,400 \\
0.06 \\
0.5\end{array}$ & $\begin{array}{c}1.6 \\
3.9 \\
12 \\
2.730 \\
0.01 \\
0.5\end{array}$ & $\begin{array}{c}0.4 \\
1 \\
3 \\
670 \\
0.05\end{array}$ \\
\hline $\begin{array}{ll}\begin{array}{c}\text { Released to Water in the Year } 2040 \\
\text { Chlorine }\end{array} \\
\begin{array}{l}\text { (thousands of tons) } \\
\text { Ammonium Hydroxide }\end{array} \\
\text { Calcium Hydroxide } & \begin{array}{l}\text { (thousands of tons) } \\
\text { (thousands of tons) } \\
\text { Iron }\end{array} \\
\text { Sulfuric Acid } & \begin{array}{l}\text { (thousands of tons) } \\
\text { (thousands }\end{array}\end{array}$ & $\begin{array}{r}72 \\
0 \\
0 \\
8 \\
330\end{array}$ & $\begin{array}{c}83 \\
92 \\
54 \\
1.7 \\
60\end{array}$ & $\begin{array}{l}83 \\
27 \\
15 \\
1.4 \\
45\end{array}$ & $\begin{array}{c}65 \\
39 \\
0.3 \\
15\end{array}$ \\
\hline $\begin{array}{l}\text { Radiological Implications in the Year } 2040 \\
\text { Annual Dose } \\
\text { Natural Background (thousands of man-rems) } \\
\text { (thousands of man-rems) }\end{array}$ & $\left\{\begin{array}{r}0 \\
830,000\end{array}\right.$ & 830,000 & 830,000 & 4 \\
\hline Land Use during 2040 (square miles) & 24,700 & 7,590 & 7,020 & 570 \\
\hline $\begin{array}{l}\text { Water Use in the Year } 2040 \text { (thousands of } \\
\text { cfs evaporated) }\end{array}$ & 110 & 80 & 72 & 8 \\
\hline Plutonium Produced and Used (metric tons) & 0 & 85,200 & 45,200 & 40,000 \\
\hline Transmission Lines (thousands of miles) & 310 & 310 & 310 & \\
\hline
\end{tabular}


TABLE 23. (Continued)

\begin{tabular}{|c|c|c|c|c|c|}
\hline & $\begin{array}{l}\text { Fossil } \\
\text { Economy }\end{array}$ & $\begin{array}{l}\text { Fission } \\
\text { Economy }\end{array}$ & $\begin{array}{l}\text { Fusion } \\
\text { Economy }\end{array}$ & $\frac{\text { Fusion vs. }}{\text { Increase }}$ & . Fission \\
\hline $\begin{array}{l}\text { Transportation } \\
\text { Truck Shipments in the year } 2040 \\
\text { Fuel Materials (thousands) } \\
\text { Low-level Waste (thousands) } \\
\text { Ton-miles }\end{array}$ & 0 & $\begin{array}{c}110 \\
180 \\
0.9\end{array}$ & $\begin{array}{c}60 \\
150 \\
0.6\end{array}$ & & $\begin{array}{c}50 \\
30 \\
0.3\end{array}$ \\
\hline $\begin{array}{ll}\text { Rail Shipments in the Year } 2040 \\
\text { Fossil Fuel } & \text { (thousands) } \\
\text { Spent Fuel } & \text { (thousands) } \\
\text { Process Waste } & \text { (thousands) } \\
\text { High-level Waste } & \text { (thousands) } \\
\text { Ton-miles } & \text { (billions) }\end{array}$ & $\begin{array}{r}84,300 \\
0 \\
0 \\
0 \\
2,500\end{array}$ & $\begin{array}{r}14,400 \\
78 \\
89 \\
2.5 \\
440\end{array}$ & $\begin{array}{r}11,500 \\
23 \\
22 \\
1 \\
340\end{array}$ & & $\begin{array}{r}2,900 \\
55 \\
67 \\
1.5 \\
100\end{array}$ \\
\hline $\begin{array}{ll}\text { Occupational Health } & \\
\text { Malignancies } & \text { (thousands) } \\
\text { Simple Pneumoconiosis } & \text { (thousands) } \\
\text { Massive Fibrosis } & \text { (thousands) } \\
\text { Man-Days Lost } & \text { (millions) }\end{array}$ & $\begin{array}{c}0 \\
38 \\
0.4 \\
40\end{array}$ & $\begin{array}{c}4.7 \\
38 \\
0.08 \\
36\end{array}$ & $\begin{array}{l}5.3 \\
7 \\
0.08 \\
39\end{array}$ & $\begin{array}{l}0.6(a) \\
3(a)\end{array}$ & 1 \\
\hline $\begin{array}{l}\text { Occupational Safety } \\
\text { Fatalities (thousands) } \\
\text { Non-Fatal Injuries (thousands) } \\
\text { Man-Days Lost (millions) }\end{array}$ & $\begin{array}{r}68 \\
3,020 \\
590\end{array}$ & $\begin{array}{r}17 \\
810 \\
150\end{array}$ & $\begin{array}{r}16 \\
800 \\
140\end{array}$ & & $\begin{array}{l}1 \\
10 \\
10\end{array}$ \\
\hline $\begin{array}{l}\text { Public Health } \\
\text { Malignancies (thousands) } \\
\text { Man-Days Lost (millions) }\end{array}$ & 0 & $\begin{array}{l}0.14 \\
0.8\end{array}$ & $\begin{array}{l}0.14 \\
0.8\end{array}$ & & \\
\hline $\begin{array}{ll}\text { Public Safety } & \\
\text { Fatalities } & \text { (thousands) } \\
\text { Non-Fatal Injuries } & \text { (thousands) } \\
\text { Man-Days Lost } & \text { (millions) }\end{array}$ & $\begin{array}{r}35 \\
76 \\
220\end{array}$ & $\begin{array}{r}8 \\
20 \\
50\end{array}$ & $\begin{array}{r}7 \\
18 \\
47\end{array}$ & & $\begin{array}{l}1 \\
2 \\
3\end{array}$ \\
\hline $\begin{array}{ll}\text { Resources Used } \\
\mathrm{U}_{3} \mathrm{O}_{8} & \text { (millions of tons) } \\
\mathrm{ThO}_{2} & \text { (millions of tons) } \\
\mathrm{Coal} & \text { (billions of tons) } \\
\mathrm{D}_{2} & \text { (thousands of tons) } \\
\mathrm{Li} & \text { (millions of tons) }\end{array}$ & $\begin{array}{r}0 \\
0 \\
190 \\
0 \\
0\end{array}$ & $\begin{array}{c}4.1 \\
0.1 \\
40 \\
0 \\
0\end{array}$ & $\begin{array}{l}4.0 \\
0.1 \\
38 \\
1.0 \\
5.2(b)\end{array}$ & $\begin{array}{l}1.0 \\
5.2(b)\end{array}$ & $\begin{array}{l}0.1 \\
2\end{array}$ \\
\hline
\end{tabular}

(a) Increase due to arbitrary assumption of a $50 \%$ higher total number of employees receiving radiation doses to lilustrate the possible higher complexity of fusion power plant designs and maintenance activities.

(b) Upper limit based on use of liquid lithium coolants in all fusion power plants. Actual use could be as low as 1.0 if lithium is used only as a target material to form tritium. 
At present the economic benefits of the fusion reactor cannot be estimated because neither the designs nor the electricity production costs are known. Many years of development must be completed before satisfactory estimates can be made.

However, an indication of the economic benefits can be obtained by assuming for illustration purposes that the fusion reactor would produce electricity at a $10 \%$ lower cost than for the most probable competitor--the LMFBR. In that case the total cost reduction for the period of 2010 to 2040 would be about $\$ 120$ billion or $2 \%$ of the total electricity cost. At least a $10 \%$ lower electricity cost probably is required to provide an incentive for construction of fusion power plants if the decision is based solely on economics.

No restrictions on the electricity cost reduction achievable with fusion reactors are apparent. Because numerous different designs appear available for fusion reactors (tokamak, laserfusion, etc.), numerous methods for reducing costs appear available. Also, because there seem to be no inherent limitations on reactor capacity, substantial unit cost reductions may be possible by use of economies-of-scale. Thus the actual cost reductions may be much larger than estimated. Whether or not cost reductions will be realized will depend on the results of the fusion reactor development efforts.

\section{SUMMARIZED COST/BENEFIT ANALYSIS}

The advantages and disadvantages that would result from adoption of fusion reactors will depend on the final design of both the fusion reactor and the competitive power systems and on the date of commercial introduction of the fusion reactor. Although specific numerical values cannot be placed on the effects of adoption of fusion reactors, the general nature of the effects can be discussed on the basis of the inherent characteristics of the fusion reactor.

In addition to significant changes in environmental effects when fusion reactors are adopted, it is also useful to know 1) the effects that probably will not change and 2) the effects which would be the same if only current technology were available, but would be beneficial if improved technology is developed in the next 40 years.

The following summarized cost/benefit analysis is presented in five sections. The first presents the environmental effects of power plants which probably will be the same whether or not fusion reactors are adopted. The second section presents the environmental benefits inherent from adoption of fusion reactors. The third section presents the potential adverse environmental effects from adoption of fusion reactors. The fourth section describes one unknown effect. The final section describes potential environmental benefits in comparison to use of current technology that may result from continuing research and development efforts.

This entire cost/benefit analysis is based on the expected characteristics of the first commercial fusion reactors and on comparison of a power system of mainly fossil, fission, and fusion plants to one comprising chiefly fossil and fission plants. Although previous sections contain information on a power system that does not include fission or fusion plants, that system is not compared to the other two here in order to simplify the cost/benefit analysis and 
because such a system does not appear representative of future conditions. The characteristics of the LMFBR are used as representative of the competitive fission plants.

Unchanged Environmental Effects

Assured Long-Term Fuel Supply

The fuel available for either the fusion reactors or the LMFBR is ample for over 500 years at the consumption rate forecast for 2020 . This precludes concern about an impending shortage of fuel for the primary types of electricity generation plants. Both types of reactors use domestic fuels so that dependence on foreign supplies is not necessary.

\section{Waste Heat Releases}

The amount of waste heat released per unit of electricity production probably will be about the same for fusion reactors, fission, and fossil plants. The resultant environmental effects due to use of water in the power plant cooling system and releases of heat and chemicals to both the air and water also should be much the same.

\section{Noise and Odor Effects}

Operation of both fusion reactors or fission power plants is expected to result in insignificant noise and odor releases and impacts.

\section{Potential Environmental Benefits}

\section{Improved Nuclear Power Plant Safety}

Fusion reactors inherently should have a low probability of accidents resulting in dispersion of radioisotopes outside the plant exclusion area. Uncontrolled power excursions are not expected to occur, and 10s5-of-coolant accidents are not expected to have offsite effects. The accidents of most concern probably will be liquid metal fires and fuel handling accidents which would release large quantities of tritium.

The biological effects of radioisotope releases as a result of an accident at a fusion reactor probably would be much lower than for the fission plants. This is because the radioisotopes released (mainly tritium) do not concentrate biologically in the same manner as plutonium and fission products.

\section{Elimination of Safeguard Concerns}

Fusion power plants do not contain plutonium, ${ }^{233} U$ or ${ }^{235} U$, materials which must be safeguarded to prevent diversion for making clandestine nuclear weapons. Although tritium can be used in nuclear weapons, it must be triggered by one of these other materials and consequently is not of value by itself for such a weapon. The small and infrequent shipments of tritium can easily be safeguarded.

\section{Lower Routine Chemical Releases}

The fusion power plant system does not contain the extensive fuel mining, miling, enrichment, fabrication, and reprocessing systems required for fission and fossil power plants. As a 
result, the fusion system should have much lower release rates for chemicals. The major chemical release for the fusion fuel cycle probably will be small amounts of $\mathrm{H}_{2} \mathrm{~S}$ at heavy water production plants.

\section{Reduced Aesthetfc Impacts}

Operation of a fusion power system requires only construction of the power plants and transmission lines. A lower aesthetic impact would result because separate industrial plants are not needed for mining, milling, enrichment, fabrication, and reprocessing plants.

Elimination of High-Level Waste Storage

Because fusion reactors neither contain nor create fission products or transuranic radioisotopes such as plutonium, there is no high-level waste storage requirement. All radioactive waste is expected to be handled as low-level waste.

\section{Reduction of Low-Level Radioactive Waste}

The fusion power system probably will have less low-level radioactive waste than other nuclear power plants because no radioactive waste is generated in fuel cycle facilities external to the electric power plants.

\section{Reduced Land Use}

Land use for fusion requirements should be lower than for other power plants. This is because they have no separate fuel cycle facilities and because procuring deuterium fuel does not significantly alter much land.

\section{Decreased General Population Radiation Dose}

The reduced release of radionuclides and transportation of radioactive wastes should result in a decrease in the current trivial radiation dose to the general public in comparison to competitive fission power plants.

Potential Adverse Environmental Effects

Increased Material Use

Many of the current fusion reactor design concepts include massive reactor systems containing tens of thousands of tons of metallic structural materials. Construction of these systems could increase the total quantity of materials used per unit of electrical capacity built. Some of these materials also may be scarce, resulting in a rapid depletion of available resources.

\section{Increased Employee Radiation Dose}

The large size and complexity of the fusion reactor, heat transfer, and fueling systems could result in a larger operations and maintenance crew and a larger employee radiation dose. A substantial increase in dose may result from periodic replacement and reconstruction of the reactor's inner walls. The amount of dose increase would depend on the degree of automation of the wall replacement activities.

An increase in facility size could reduce most adverse environmental impacts by decreasing the number of power plants, the quantities of materials used per unit of capacity, and the amounts of waste releases per unit of capacity. 
Unknown Environmental Effects

\section{Biological Effects of Magnetic Fields}

Magnetic confinement fusion reactors may have both static and changing magnetic field strengths up to several hundred gauss in the locations occupied by plant employees. At present the biological effects of chronic exposures to such magnetic fields are not known. Research must be conducted to determine whether these magnetic fields are beneficial or damaging or neither.

Potential for Improved Environmental Effects

\section{Reduced Radionuclide Releases}

The primary radionuclides released at the first generation fusion power plants appear to be tritium and possibly carbon-14. The carbon-14 releases probably can be eliminated by using reactor designs that allow no air leakage into the reactor system. Tritium releases may be reduced or essentially prevented with a better understanding of tritium permeation mechanisms or of better tritium barriers.

All radionuclide releases may be eliminated by developing advanced fusion power plants that do not use radioactive fuels or create neutrons.

\section{Reduced Heat Releases}

Development of better materials, direct conversion systems for electricity generation, or topping systems may result in higher thermal efficiencies, lower heat releases, and lower plant sizes per unit of electricity capacity.

\section{Economies-of-Scale}

Some fusion reactor design concepts do not appear to have inherent 1 imitations on plant thermal capacity as the size of the reactor is increased. Thus lower electricity production costs may possibly be obtained by increasing the thermal capacity to much higher values than for current power plants (e.g., to as much as 20,000 MWt versus 4,000 MWt at present). Much additional information concerning plasma physics and the reactor physical designs must be acquired before the reactor thermal capacity resulting in minimum electricity unit cost is known.

\section{REFERENCES}

U.S. Atomic Energy Commission, Nuclear Power 1973-2000. WASH-1139(72), December 1972.

U.S. Atomic Energy Commission, The Potential Radiological Implications of Nuclear Facilities in the Upper Mississippi River Basin in the Year 2000--The Year 2000 Study. WASH-1209, January 1973.

U.S. Atomic Energy Commission, Comparative Risk-Cost-Benefit Study of Alternate Sources of Electrical Energy. WASH-1224, December 1974.

Federal Power Comission, The 1970 National Power Survey. Washington, D.C., 1971.

U.S. Atomic Energy Comnission, Updated (1970) Cost Benefit Analysis of the U.S. Breeder Reactor Program. WASH-1184, January 1972. 
National Economic Research Associates, Inc., Fuels for the Electric Ut1lity Industry 1971-1985. Edison Electric Institute, Publication No. 72-27, New York, August 1972.

National Coal Association, Steam Electric Plant Factors 1972. 22nd ed., Washington, D.C., 1972. (See also editions for previous years, particularly 1969 and 1965.)

Federal Power Commission, Steam-Electric Plant Construction Cost and Annual Production Expenses-Twenty-third Annual Supplement--1970, Washington, D.C., June 1972.

D. T. Clark, "A History and Preliminary Report on the Kentucky Radioactive Waste Oisposal Site," Radiation Data and Reports 14(10) 573-585, October 1973.

D. E. Peterson et al. Thermal Effects of Projected Power Growth: The National Outlook. HEDL-TME 73-45, July ig73. 
A. A. Churm ERDA Chicago Patent Group

9800 S. Cass Avenue

Argonne, IL 60439

J. W. Beal

ERDA Div. of Magnetic

Fusion Energy

Washington, DC 20545

S. 0. Dean

ERDA Div. of Magnetic

Fusion Energy

Washington, DC 20545

E. E. Kintner

ERDA Div. of Magnetic

Fusion Energy

Washington, DC 20545

J. M. Williams

ERDA Div. of Magnetic

Fusion Energy

Washington, DC 20545

J. N. Grace

ERDA Div. of Magnetic Fusion Energy

Washington, DC 20545

J. Baublitz

ERDA Div. of Magnetic

Fusion Energy

Washington, DC 20545

3 F. E. Coffman

ERDA Div. of Magnetic Fusion Energy Washington, DC 20545

J. F. Decker

ERDA Div. of Magnetic

Fusion Energy

Washington, DC 20545

3 K. M. Zwilsky

ERDA Div. of Magnetic Fusion Energy Washington, DC 20545

Or. Philip M. Stone ERDA Applied Plasma Physics Program

Washington, DC 20545

G. W. Kuswa

ERDA Div. of Laser Fusion

Washington, DC 20545
OFFSITE

R. Blaunstein

ERDA Div. of Biomedical

and Environmental Research

Washington, DC 20545

H. M. Busey

ERDA Div. of Military

Application

Washington, DC 20545

M. A. Bell

ERDA Div. of Safety

Standards and Compliance

Washington, DC 20545

27 ERDA Technical Information Center

M. S. Kaminsky

Argonne National Laboratory

$9700 \mathrm{~S}$. Cass Avenue

Argonne, IL 60439

V. A. Maroni

Argonne National Laboratory

$9700 \mathrm{~S}$. Cass Avenue

Argonne, IL 60439

P. M. Persiani

Argonne National Laboratory

9700 S. Cass Avenue

Argonne, IL 60439

M. Petrick

Engineering and Technology

Division

Argonne National Laboratory

9700 S. Cass Avenue

Argonne, IL 60439

W. E. Parkins, Manager

Atomics International

Component Engineering and

Technology Division

North American Rockwell

P.0. Box 309

Canoga Park, CA 91304

D. Gurinsky

Brookhaven National Laboratory ERDA Brookhaven Area Office

Upton, NY 11973

H. J. Kouts

Brookhaven National Laboratory

ERDA Brookhaven Area Office

Upton, NY 11973

5. Pearlstein

Brookhaven National Laboratory ERDA Brookhaven Area Office

Upton, NY 11973
OFFSITE

J. R. Powell

Brookhaven National Laboratory ERDA Brookhaven Area Office

Upton, NY 11973

A. J. Impink, Jr.

Carnegie Melion University

Pittsburgh, PA 15213

R. A. Gross

Plasma Research Laboratory

236 SW Mudd Bldg.

Columbia University

New York, NY 10027

W. C. Gough

Electric Power Research Inst.

3412 Hillview Ave.

Palo Alto, CA 94304

G. R. Hopkins

Gulf General Atomic

P.0. Box 1111

San Diego, CA 92112

Zeinab Sabri

Iowa State University

261 Sweeney Hall

Nuclear Engineering Department

Ames, IA 50010

R. Borg

Lawrence Livermore Laboratory

P.O. Box 808

Livermore, CA 94550

T. K. Fowler

Lawrence Livermore Laboratory

P.0. Box 808

Livermore, CA 94550

R. Moir

Lawrence Livermore Laboratory

P.0. Box 808

Livermore, CA 94550

A. Carl Haussmann

Lawrence Livermore Laboratory P.0. Box 808

Livermore, CA 94550

J. Hovingh

Lawrence Livermore Laboratory

P.0. Box 808

Livermore, CA 94550

R. F. Post

Lawrence Livermore Laboratory P.0. Box 808

Livermore, CA 94550

C. J. Taylor

Lawrence Livermore Laboratory

P.0. Box 808

Livermore, CA 94550 
R. Werner Lawrence Livermore Laboratory

P.0. Box 808

Livermore, CA 94550

L. L. Wood Lawrence Livermore Laboratory

P.0. Box 808

Livermore, CA 94550

W. Bauer

Division Supervisor of Physical Research

Sandia Labs Livermore Livermore, CA 94550

L. Booth

Los Alamos Scientific Laboratory

CTN Research

P.0. Box 1663

Los Alamos, NM 87544

D. J. Dudziak

Los Alamos Scientific

Laboratory

CTN Research

P.0. Box 1663

Los Alamos, NM 87544

D. B. Henderson

Los Alamos Scientific Laboratory

CTN Research

P.0. Box 1663

Los Alamos, NM 87544

E. L. Kemp

Los Alamos Scientific

Laboratory

CTN Research

P.0. Box 1663

Los Alamos, NM 87544

F. L. Ribe

Los Alamos Scientific

Laboratory

CTN Research

P.0. Box 1663

Los Alamos, NM 87544

L. Stewart

Lus Alamos Scientific

Laboratory

CTN Research

P.0. Box 1663

Los Alamos, NM 87544

K. Thomassen

Los Alamos Scientific

Laboratory

CTN Research

P.O. Box 1663

Los Alamos, NM 87544
OFFS ITE

O. K. Harling

Massachusetts Institute of

Technology

Cambridge, MA 02139

Bruno Coppi

Department of Physics

Massachusetts Institute of

Technology

Cambridge, MA 02139

L. Lidsky

Dept. of Nuclear Engineering

Massachusetts Institute of

Technology

Cambridge, MA 02139

Norm Rasmussen

Dept. of Nuclear Engineering

Massachusetts institute of

Technology

Cambridge, MA 02139

David Rose

Massachusetts institute of

Technology

Cambridge, MA 02139

R. E. Stickney

Mechanical Engineering

Massachusetts Institute of

Technology

Cambridge, MA 02139

J. J. Reinmann

NASA - Lewis Research Center

2100 Bookpark Rd.

Cleveland, $\mathrm{OH} \quad 44135$

Vincent Arp

National Bureau of Standards

Cryogenics Division

Boulder, CO 80302

J. F. Clarke

Oak Ridge National

Laboratory

P.0. Box $Y$

Oak Ridge, TN 37830

A. P. Fraas

Oak Ridge National

Laboratory

P.O. Box $Y$

Oak Ridge, TN 37830

3. Rand McNaliy, Jr.

Oak Ridge National

Laboratory

P.0. Box Y

Oak Ridge, TN 37830

D. Steiner

Oak Ridge National

Laboratory

P.0. Box Y

Oak Ridge, TN 37830
OFFSITE

J. $5 \operatorname{cott}$

Oak Ridge National Laboratory

P. O. Box $X$

Oak Ridge, TN 37830

J. Banford

Physics International

2700 Merced St.

San Leandro, CA 94577

R. A. Huse

Public Service Electric

and Gas Co.

80 Park Place

Newark, NJ 07101

M. Gottlieb

Princeton University, PPPL

P.0. Box 451

Princeton, NJ 08540

R. G. Mills

Princeton University

P.O. Box 451

Princeton, NJ 08540

E. C. Tanner

Princeton University

P.0. Box 451

Princeton, NJ 08540

H. Perkins

Dept. of Chemistry

Princeton University

Princeton, NJ 06540

R. E. Gold

303 Sayre Hall

Forrestal Campus

P.0. Box 451

Princeton, NJ 06540

M. Kristiansen

Texas Tech. University

Lubbock, TX 79409

A. F. Haught

United Aircraft Research Lab. United Aircraft Corporation

East Hartford, CT 06108

L. Levine

U.S. Naval Research Laboratory

Washington, DC 20390

C. Z. Serpan, Jr

U.S. Naval Research Laboratory

Washington, DC 20390

Francis Chen

University of California

Electronics Research

Laboratory

College of Engineering

Berkeley, CA 94720 
A. J. Lichtenberg University of California

Electronics Research Laboratory

College of Engineering

Berkeley, CA 94720

Dave Okrent

U.C.L.A.

Los Angeles, CA 90024

C. D. Hendricks

University of Illinois

Nuclear Engineering

Laboratory

Urbana, IL 61801

G. H. Miley

University of Illinois

Nuclear Engineering

Laboratory

Urbana, IL 61801

Terry Kammash

University of Michigan

Nuclear Engineering

Department

Ann Arbor, MI 48105

Dean Abrahamson

University of Minnesota

School of Public

Affairs

Social Science

Building/309

Minneapolis, MN 55455

W. G. Davey

University of Texas

Department of Physics

Austin, TX 78712

E. Linn Oraper, Jr.

University of Texas

Department of Physics

Austin, TX 78712

W. E. Drummond

University of Texas

Department of Physics

Austin, TX 78712

Abraham Hertzberg

University of Washington

Aerospace Research

Laboratory

316 Guggenheim

Seattle, WA 98105

A. L. Babb

University of Washington

Nuclear Engineering

Department

Seattle, WA 98105
R. Conn

University of Wisconsin

Nuclear Engineering

Department

Madison, WI 53706

G. L. Kulcinski

University of Wisconsin

Nuclear Engineering

Department

Madison, WI 53706

C. W. Maynard

University of Wisconsin

Nuclear Engineering

Department

Madison, WI 53706

D. Lichtman

Department of Physics

University of Wisconsin

Milwaukee, WE 53201

E. E. Donaldson

Washington State University

Deparment of Physics

Pullman, WA 99163

D. D. Mahlum

Division of Biomedical

and Environmental Research

Washington, DC 20545

3. V. Vanston

Engineering Science

Building

University of Texas

Austin, TX 78712

Leslie S. Ramsey

450 North 5 th Street

Indiana, PA 15701 
ERDA Richland Operations Office

W. A. Burns

Atlantic Richfield Hanford Company

$$
\text { J. D. Kaser }
$$

Hanford Engineering Development Labs

D. G. Doran

H. H. Yoshikawa

\section{Battelle-Northwest}

D. T. Aase

G. S. Allison

$T$. W. Ambrose

D. G. Atteridge

D. A. Baker

j. L. Bates

M. A. Bayne

E. R. Bradley

J. L. Brimhall

R. L. Brodzinski

R. J. Brouns

L. R. Bunnell

L. L. Burger

S. H. Bush

N. E. Carter

T. D. Chikalla

R. G. Clark

T. L. Criswell

S. D. Dahlgren

M. T. Dana

D. E. Deonigi

R. L. Dillon

$D$. A. Dingee

P. J. Dionne

B. H. Duane

J. W. Finnigan

J. C. Fox

J. J. Fuquay

J. E. Garnier

R. D. Gastil

B. F. Gore

J. N. Hartley

A. J. Haverfield

$U$. P. Jenquin

A. B. Johnson, Jr.

R. H. Jones

T. J. Kabele

W. S. Kelly

H. E. Kissinger

D. A. Kottwitz

N. Laegried

B. R. Leonard, Jr

D. L. Lessor

H. B. Liemohn

R. C. Li ikala

M. A. Mckinnon

R. F. Maness

R. P. Marshall
Battelle-Northwest - Continued

E. S. Murphy

R. D. Nelson

D. F. Newman

R. E. Nightingale

D. E. Olesen

L. T. Pedersen

R. T. Perry

D. R. Pratt

L. A. Rancitelli

J. F. Remark

U. S. Renne

R. E. Rhoads

W. D. Richmond

W. F. Sandusky

L. C. Schmid

N. M. Sherer

E. P. Simonen

R. I. Smith

J. K. Soldat

C. W. Stewart

K. B. Stewart

R. W. Stewart

J. A. Strand

D. L. Styris

A. M. Sutey

V. L. Teofilo

G. L. Tingey

M. T. Thomas

R. C. Thompson

L. H. Toburen

T. J. Trapp

R. Wang

R. E. Westerman

L. D. Williams

20 J. R. Young

M. G. Zimmerman

Technical Publications (BH)

5 Technical Information 